UNIVERSIDADE DE SÃO PAULO

INSTITUTO DE FÍSICA

\title{
O modelo de Sznajd em redes complexas
}

\author{
Fabio Stucchi Vannucchi \\ Orientadora: Profa. Dra. Carmen Pimentel Cintra do Prado
}

Dissertação de mestrado apresentada ao Instituto de Física para obtenção do título de Mestre em Ciências.

Banca examinadora:

Profa. Dra. Carmen Pimentel Cintra do Prado (IF-USP)

Profa. Dra. Tânia Tomé Martins de Castro (IF-USP)

Prof. Dr. José Soares Andrade Júnior (Dep. Física - UFC)

São Paulo 


\section{AGRADECIMENTOS}

Agradeço à professora Carmen pela orientação respeitosa e, ao mesmo tempo, instigante.

Aos professores Américo T. Bernardes, Mário J. de Oliveira, Domingos Marchetti e Márcio A. F. de Menezes pelas sugestões e dúvidas esclarecidas.

Aos colegas Tiago Peixoto e Alexandre H. Abdo pelas dicas e discussões.

Aos colegas da fria sala de micros, Leo, Marcus, Carelli, Áttila, Henrique, Fabiano, Marco Aurélio, Carlos, Darielder, Evandro, Alexei, Camila, Cris, Evaldo, Christian, Adriane, Silas, André, Masayuki, Eduardo e Danilo, pela calorosa companhia.

Aos funcionários do IFUSP, em especial ao pessoal da secretaria do departamento, da secretaria da comissão de pós-graduação, do "time" de informática, da portaria, da biblioteca e da limpeza.

Ao Departamento de Física Geral, ao Instituto de Física e à Universidade de São Paulo pelas condições de trabalho possibilitadas.

Ao Conselho Nacional de Desenvolvimento Científico e Tecnológico - CNPq - Brasil, e à sociedade brasileira, pelo financiamento deste trabalho.

Aos meus pais, Ana e Gianfranco, e meu irmão Pedro, pelos mais diversos apoios.

Agradeço ainda à Isa, companheira de todas as horas, tanto pelo contínuo e fundamental estímulo, como pelos bons momentos vividos durante esses anos. 
"Nem sequer nos olhamos. Apertei o braço de Irene e a fiz correr comigo até a porta-persiana, sem olhar para trás. Os ruídos se ouviam mais fortes, mas sempre surdos, às nossas costas. Fechei de um golpe a porta-persiana e ficamos no saguão. Agora não se ouvia nada.

- Tomaram essa parte - Disse Irene."

trecho de "Casa Tomada"

Julio Cortázar 


\section{RESUMO}

Esta dissertação apresenta um estudo detalhado do comportamento do modelo de Sznajd, um modelo de interações microscópicas entre sítios empregado com freqüência para representar o processo de formação de opinião em uma comunidade. Neste modelo cada sítio tentará convencer seus vizinhos a assumir o mesmo estado em que está, com uma regra que privilegia a existência de pares de sítios já em um mesmo estado, ou seja, caso um par de vizinhos esteja no mesmo estado, a probabilidade dos outros vizinhos assumirem este estado será maior.

Analisamos o papel das condições iniciais do sistema (particularmente do grau dos eleitores iniciais) e tentamos, através de representações gráficas e outros métodos, enteder que caracteríticas determinam o resultado final do processo. Os resultados previstos pelo modelo na rede de Barabási-Albert são também comparados com dados obtidos no TRE para eleições para casas legislativas brasileiras, e, no apêndice A, generalizamos o método da estimação via máxima verossimilhança para o caso em que a distribuição apresenta efeitos de tamanho finito nos dois extremos.

Estudamos também os resultados de duas alterações da dinâmica do modelo, ainda na rede de Barabási-Albert. Na primeira, inserimos inomogeneidades na rede (que podem ser, por exemplo, cabos eleitorais) e vemos como a introdução destes defeitos na rede afetam o resultado final. Na segunda estudamos como a introdução de uma influência externa, não local, (que mimetizaria, por exemplo, a campanha publicitária) afeta a dinâmica, e encontramos uma transição de fase de primeira ordem no comportamento do sistema. As previsões da aproximação de campo médio para o modelo com ruído, por nós desenvolvida, descrevem qualitativamente bem a transição.

Por fim, investigamos a influência de alterações na rede em que se dá a dinâmica do modelo, utilizando reticulados, cadeias regulares e a rede de Watts-Strogatz. Comparamos o comportamento do modelo nessas redes com a dinâmica de Glauber a temperatura nula e com o modelo do votante. 


\begin{abstract}
This work studies in detail the Sznajd model, a dynamical model based on microscopic local interactions between sites, usually employed to simulate rumor spreading and opinion formation in a community. In the model each site tries to "convince" its neighbors to assume its own state (opinion) in such a way that the convincing strength of pairs of neighbouring sites in the same state is enhanced.

We have studied the Sznajd model in a Barabási-Albert network and have compared the results with available data from legislative Brazilian elections. We have analysed the role of initial conditions (in particular the initial elector's degree), proposing new graphical representations for the evolving dynamics, studying the importance of different topological aspects of the network in it.

We also have studied two modifications in the model dynamics, still in Barabási-Albert network. First we have studied the effect of inhomogeneities in the network, what has been done through the introduction of zealots, electors that do not change their opinion; second, we have modified the model with the introduction of noise, a change that could mimic an advertising campaign. We have found a first order phase transition in the system's behavior, depending on the level of noise. The mean field approach to the model developed by us was able to predict qualitatively the behavior of the system.

At last, we have investigated the consequences of the network topology on which the model evolves, testing lattices, regular chains and the Watts-Strogatz small world network. We have compared our findings in the Sznajd model with known results of literature for Glauber dynamics at zero temperature and the voter model.
\end{abstract}




\section{Sumário}

1 Introdução $\quad 8$

2 Fundamentação teórica $\quad 9$

2.1 Redes complexas . . . . . . . . . . . . . . . . . . 9 9

2.1.1 Definições e propriedades de grafos . . . . . . . . . . . . 10

2.2 Caráter livre de escala de eleições proporcionais . . . . . . . . . . . . 20

2.3 Modelo de Sznajd . . . . . . . . . . . . . . . . . . 22

3 Modelo de Sznajd em uma rede complexa livre de escala 26

3.1 Propriedades do modelo . . . . . . . . . . . . . . 27

3.1.1 Aproximação de campo médio . . . . . . . . . . . . . . 28

3.1.2 Relação entre grau do eleitor inicial o candidato vencedor . . . . . . 32

3.1.3 Candidato solitário . . . . . . . . . . . . . . 33

3.1.4 Horizontes possíveis . . . . . . . . . . . . 35

3.1.5 Visualização da dinâmica . . . . . . . . . . . . . 36

3.1.6 Robustez . . . . . . . . . . . . . . . . . 43

4 Modificações do modelo de Sznajd $\quad 47$

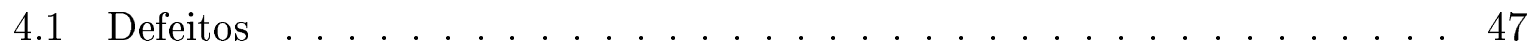

4.2 Ruído . . . . . . . . . . . . . . . . . . 51

4.2 .1 Simulações. . . . . . . . . . . . . . . 52

4.2 .2 Aproximação de campo médio . . . . . . . . . . . . 54

5 Influência da estrutura da rede $\quad 61$

5.1 Os modelos de Glauber e do Votante . . . . . . . . . . . . . . 61

5.1 .1 Modelo de Glauber . . . . . . . . . . . . . . . . . 62

5.1 .2 Modelo do votante . . . . . . . . . . . . . 63

5.2 Modelo de Sznajd em redes complexas . . . . . . . . . . . . . 64

$\begin{array}{llr}6 & \text { Conclusões } & 77\end{array}$ 
A Leis de potência

A.1 Estimação via Máxima Verossimilhança . . . . . . . . . . . . . . 80

A.2 Distribuição Cumulativa . . . . . . . . . . . . . 82

Referências Bibliográficas 


\section{Capítulo 1}

\section{Introdução}

Adiante, apresentaremos os resultados e discussões referentes às duas principais atividades desenvolvidas durante este mestrado, a investigação minuciosa do modelo de Sznajd em uma rede do tipo Barábasi-Albert, como proposto por Bernardes, Stauffer e Kertész [1], e a implementação de modificações no modelo, tanto de sua dinâmica como da rede em que o modelo é simulado.

Poderíamos inserir este trabalho no campo das aplicações interdisciplinares da mecânica estatística, pois sua motivação surge justamente do acordo entre o modelo de Sznajd na rede de Barabási-Albert com resultados de eleições proporcionais brasileiras. No entanto, devido aos aspectos privilegiados durante a pesquisa e ao formato final deste texto, acreditamos ser mais adequado associá-lo à área de estudos de processos dinâmicos em redes complexas.

Organizamos esta dissertação da seguinte forma: no capítulo 2 apresentamos o arcabouço teórico utilizado, que inclui uma (breve) revisão de conceitos da área de redes complexas e teoria de grafos, o caráter livre de escala verificado em algumas eleições proporcionais e a apresentação do modelo de Sznajd; o capítulo 3 versa sobre o a análise detalhada, por nós realizada, do modelo de Sznajd na rede de Barabási-Albert; nos capítulos 4 e 5 dispomos sobre o estudo das modificações na dinâmica do modelo (inclusão de defeitos e ruído) e na rede em que o modelo se desenvolve; por fim, relatamos os principais resultados obtidos e as conclusões no capítulo 6 . 


\section{Capítulo 2}

\section{Fundamentação teórica}

Neste capítulo apresentamos as bases teóricas nas quais se funda esta dissertação. Iniciamos pela apresentação de alguns conceitos de teoria de grafos, comumente utilizados no estudo de rede complexas e particularmente importantes para a compreensão deste texto. Seguimos então à exposição sobre o comportamento encontrado em algumas eleições proporcionais (do legislativo de maneira geral) no Brasil, comportamento este que motivou os principais trabalhos com os quais este texto dialoga. Por fim apresentamos o modelo de Sznajd, sua origem e um pouco de seu desenvolvimento.

\subsection{Redes complexas}

Nos últimos anos tem se mostrado grande o interesse da comunidade científica pelo estudo de redes complexas, fato que pode ser comprovado pelo número de artigos e conferências na área. O estudo de redes, no entanto, é mais antigo. Artigos de revisão sobre o tema ([2] e [3], por exemplo) usualmente associam o nascimento desta área de estudo à resolução do problema das pontes de Königsberg por Euler $(1756)^{1}$. Durante vários anos, matemáticos desenvolveram questões e soluções na área, sedimentando o que hoje é conhecido por teoria de grafos. Uma série de problemas, com aplicações práticas inclusive, foram resolvidos enquanto vários permanecem ainda em aberto.

Nas últimas décadas percebeu-se um deslocamento no tipo de problema a ser investigado na área. Físicos se voltaram para a caracterização experimental de grandes redes, entendendo por rede qualquer sistema que possa ser definido por um conjunto de unidades

\footnotetext{
${ }^{1} \mathrm{O}$ problema das sete pontes de Königsberg consistia em atravessar todas as pontes que uniam os lados de um rio e suas ilhas fluviais de forma ordenada e sem repetir nenhuma delas. Euler mapeou o problema em um problema de teoria de grafos (se um grafo tem um caminho euleriano) e mostrou que, dado que sobre um dos lado incidia um número ímpar de pontes, não existia caminho que satisfizesse o desafio, resolvendo assim o problema.

Para maiores detalhes ver http://en.wikipedia.org/wiki/Seven_bridges_of_K\%C3\%B6nigsberg.
} 
que se relacionam entre si. Provavelmente pelo aumento da capacidade computacional e pela disponibilização de informações, uma enorme quantidade de dados foi compilada: redes de transporte, de chamadas telefônicas, a Internet, a WWW, rede de contatos sexuais, de atores que trabalharam conjuntamente nos mesmos filmes, de autores colaboradores em publicações científicas, cadeias alimentares, neurônios, substâncias químicas participantes de uma mesma reação, entre outras, foram analisadas minuciosamente e tiveram suas estruturas (de redes) detalhadas.

Constatou-se então que várias destas redes apresentam características comuns, bem distintas da rede quadrada ou do grafo randômico (ver seção 2.1.1). Então, um grande esforço foi empreendido pela comunidade científica no sentido de modelar as redes reais de forma a satisfazer estas características. Dois importantes trabalhos neste sentido foram os de Watts e Strogatz [4] e de Barábasi e Albert [5], que se tornaram paradigmas na área de redes complexas.

Hoje, além da contínua acumulação de dados referentes à redes reais e do estudo de características importantes destas, muito do trabalho no campo se concentra na pesquisa de processos que se dão em redes. Propagação de doenças, rumores, tráfego de informações e de matéria e sincronização de osciladores são exemplos de processos estudados em redes complexas e este trabalho se insere neste contexto.

\subsubsection{Definições e propriedades de grafos}

A teoria de grafos constitui um referencial privilegiado para o estudo de redes complexas e, portanto, descrevemos alguns conceitos e propriedades fundamentais. Utilizamos neste texto uma notação similar à utilizada em [6], e nos restringiremos a conceitos básicos de teoria de grafos (resultados mais avançados e interessantes podem ser encontrados em [7], por exemplo).

Matematicamente uma rede (ou, formalmente, um grafo) é definida por dois conjuntos: um conjunto de vértices (também chamados de nós) e outro, associado ao primeiro, de arestas (ou arcos), que são os elementos de conexão entre os vértices. Existe uma grande variedade de possibilidades para o conjunto dos vértices e o conjunto das arestas (como por exemplo admitir tipos distintos de vértices ou então a existência de arestas com pesos e/ou direção). Aqui discutiremos apenas grafos com arestas bidirecionais e de mesmo peso, e vértices indistingüíveis, e é relativamente simples expandir os conceitos apresentados para os outros casos. Denotaremos neste trabalho o número de vértices em um grafo por $N$ e o número de arestas por $E$.

Dizemos que dois vértices são vizinhos se o grafo tem uma aresta que os conecta e que uma aresta aponta para os vértices $i$ e $j$ se liga o vértice $i$ ao $j$; esta aresta será representada por $i j$. Dado um grafo $G$, o grafo $G^{\prime}$ é subgrafo de $G$ se todos os vértices e 
arestas de $G^{\prime}$ são também vértices e arestas de $G$. Um caminho do vértice $v_{1}$ a $v_{N}$ é um grafo com vértices $v_{1}, v_{2}, \ldots, v_{N-1}, v_{N}$, se $v_{i}$ for vizinho apenas de $v_{i-1}$ e $v_{i+1}, i \neq 1, N$. O grafo $G$ é dito conexo se, para qualquer par de vértices $i$ e $j$ distintos, $G$ tem um subgrafo que é um caminho de $i$ a $j$. Chamamos de componente de $G$ um subgrafo $C$ de $G$ conexo cujos vértices $\mathcal{N}_{C}$ não têm vizinhos, em $G$, fora de $\mathcal{N}_{C}$, ou seja, não existe um caminho em $G$ de um vértice em $\mathcal{N}_{C}$ a um vértice fora de $\mathcal{N}_{C}$; são, expressando informalmente, subgrafos isolados.

Um dos mais importantes conceitos utilizados nesta dissertação é o conceito de grau de um vértice. O grau $k_{i}$ de um vértice $i$ é o número de arestas que apontam para $i$. É importante notar que, caso aceitemos mais de uma aresta entre dois vértices, ou arestas que conectam um vértice a ele mesmo, o grau de $i$ não será equivalente ao número de vizinhos de $i$. Mas não discutiremos estes casos e, assim, a ressalva pode ser desprezada. O conjunto dos vizinhos de $i$, a vizinhança de $i$, é expresso por $\Gamma_{i}$. Em grafos direcionados (i.e., cujas arestas têm direção) é conveniente definir o grau de saída (entrada) $k_{i}^{s}\left(k_{i}^{e}\right)$ de um vértice $i$ como o número de arestas que saem de (entram em) $i$, e, neste caso, o grau de $i$ seria $k_{i}=k_{i}^{s}+k_{i}^{e}$.

Num reticulado (ou rede hipercúbica) todos os vértices têm o mesmo grau (que é, neste caso, equivalente à coordenação do reticulado, no jargão da mecânica estatística). Mas em redes complexas o grau dos vértices pode apresentar uma grande variação e então convém definir a distribuição de grau $p(k)$ de um grafo (ou $p_{k}$, explicitando que $k$ só admite valores inteiros) que é a fração de vértices de grau $k$ entre os $N$ vértices ( $p_{k}$ pode ser entendida também como a probabilidade de escolhermos ao acaso um vértice de grau $k$ para grandes valores de $N$ ). O grau médio $\langle k\rangle$ é dado por

$$
\langle k\rangle=\frac{1}{N} \sum_{i=1}^{N} k_{i}=\sum_{k} k p_{k} .
$$

Como o grau de um vértice é o número de arestas que apontam para o vértice, somar o grau de todos os vértices de um grafo é equivalente a somar, portanto, todas as pontas de aresta. Dado que cada aresta tem duas pontas, temos $\sum_{i=1}^{N} k_{i}=2 E, \mathrm{e}\langle k\rangle=\frac{1}{N} \sum_{i=1}^{N} k_{i}=\frac{2 E}{N}$, resultados amplamente utilizados neste texto.

Tanto $p_{k}$ e $\langle k\rangle$ são importantes parâmetros para caracterização de redes complexas.

Outro importante conceito para o estudo da estrutura de redes é a distância entre dois vértices $i$ e $j$ em um grafo, $d_{i j}$, que é o comprimento do menor caminho entre $i$ e $j$ no grafo. Uma série de grandezas importantes no estudo de redes derivam do conceito de distância. O diâmetro de um grafo é a maior distância entre dois vértices e a distância média entre vértices $\ell$ (ou simplesmente a distância média) é definida como: 


$$
\ell=\frac{1}{\frac{1}{2} N(N+1)} \sum_{i \leq j} d_{i j}
$$

Obviamente, no caso de uma rede com mais de uma componente, esta definição tornase desinteressante, pois a distância de vértices em componentes distintas seria infinita. Assim costuma-se utilizar

$$
\ell^{-1}=\frac{1}{\frac{1}{2} N(N+1)} \sum_{i \leq j} d_{i j}^{-1}
$$

Num reticulado de dimensão $d$ a distância média é da ordem do tamanho do sistema $O\left(N^{\frac{1}{d}}\right)$, em claro desacordo com o que é observado em muitas redes da natureza nas quais, em poucos passos, se alcança, de um vértice qualquer, um outro escolhido aleatoriamente. Para diversas redes observou-se empiricamente que a distância média evolui como $O(\ln (N))$ ou menos, para $N \rightarrow \infty$, propriedade essa conhecida como mundo pequeno ${ }^{2}$ (small world).

Ainda relacionado à distância entre dois vértices, temos que existe um caminho de distância $d_{i j}$ entre $i$ e $j$ que passa eventualmente por outros vértices, sendo $l$, por exemplo, um deles. Ao retirarmos $l$ do grafo, $d_{i j}$ possivelmente aumentaria, o que atribui uma certa importância à $l$. Assim, defini-se a carga ou a centralidade de um vértice $l$ pela fração dos menores caminhos entre todos os vértices do grafo que passam por $l$.

O coeficiente de aglomeração $A$ (clustering) também é um conceito comum nas análises de redes complexas. Reflete a probabilidade média de que também sejam vizinhos entre si dois vértices que tenham um terceiro vértice vizinho em comum. É portanto um índice que relaciona a quantidade de triângulos (triplas de vértices totalmente conectadas - um triângulo pode ser considerado como uma unidade do aglomerado) efetivos $T_{e}$ encontrados numa rede com o número de triângulos possíveis $T_{p}$ :

$$
A=\frac{3 T_{e}}{T_{p}}
$$

Esta relação é multiplicada por três devido ao fato de que cada triângulo efetivo "satisfaz" três triângulos potenciais, assegurando que $0 \leq A \leq 1$. Outra forma de definirse o coeficiente de aglomeração, valorizando as contribuições dos vértices de menor grau, é através da média dos coeficientes de aglomeração individuais: um vértice $i$ tem $k_{i}$ vizinhos que somam $E_{i}$ arestas entre si de um máximo de $\frac{1}{2} k_{i}\left(k_{i}-1\right)$ e portanto o coeficiente de

\footnotetext{
${ }^{2} \mathrm{O}$ nome mundo pequeno provém de um trabalho de Stanley Milgram na década de 60, em que constatou a pequena distância média nas redes sociais. É também a partir daí que surge o popular termo "seis graus de separação" (apesar do termo não ter sido cunhado por Milgram). Ver referência [2].
} 
aglomeração $A$ é

$$
A=\sum_{i} A_{i}=\sum_{i} \frac{E_{i}}{\frac{1}{2} k_{i}\left(k_{i}-1\right)}
$$

Uma série de estudos empíricos de diversas redes encontradas na natureza indica que muitas delas apresentam alto coeficiente de aglomeração, que no caso de relações entre pessoas (redes sociais), está associado ao fato ser alta probabilidade de que "o amigo de seu amigo seja também seu amigo" ou do aparecimento de um grupo (clique). Abdo e Moura 3 alertam, no entanto, que talvez seja importante não apenas contar os triângulos, mas os "quadriláteros", e outros "polígonos" de vários tamanho, chegando à uma distribuição de aglomeração. Porém, para este trabalho, a idéia de coeficiente de aglomeração usual nos basta.

Existem outros conceitos relevantes ao estudo de redes complexas (como resistência a ataques e correlação de grau) que não iremos apresentar nessa breve introdução, mas podem ser encontrados nas referências $[2,3,8]$. Daqui em diante apresentaremos alguns dos mais utilizados modelos de redes.

\section{Grafos randômicos}

O estudo de redes aleatórias teve início com Solomonoff e Rapoport e ganhou rigor com Erdös e Renyi, na década de sessenta do século passado. Existem duas formas de construir redes randômicas. A primeira é, a partir de um total de $N$ vértices, escolher exatamente $m$ arestas entre as $\frac{1}{2} N(N-1)$ arestas possíveis e fazer a análise estatística do ensemble formado por todas as diferentes (e equiprováveis) redes, enquanto a segunda consiste em estudar o ensemble formado por todas as redes em que os $N$ vértices serão conectados (i.e. existirá uma aresta entre eles) com probabilidade q. Apesar de diferentes, ambas abordagens são equivalentes nos principais resultados para $N \rightarrow \infty$ e $q=\frac{m}{\frac{1}{2} N(N-1)}$.

Um aspecto interessante dos grafos randômicos é o fato de que em um ensemble, quase todos os grafos apresentam uma mesma característica $Q$ se a probabilidade de $Q$ acontecer tender a $1 \mathrm{com} N \rightarrow \infty$. Um objetivo importante da teoria de grafos é investigar para que probabilidade de existência de arestas entre dois vértices $q(N)$ determinada característica ocorrerá. Erdös e Renyi descobriram que uma série de características surgem, de maneira abrupta, com o crescimento de $q(N)$. Isto é, para uma determinada probabilidade, ou quase todos os grafos têm a característica $Q$, ou quase nenhum a tem. Assim, podese relacionar a existência ou não $(P(Q))$ da característica $Q$ a uma certa probabilidade crítica $q_{c}(N)$ tal que

\footnotetext{
${ }^{3}$ Comunicação pessoal.
} 


$$
\lim _{N \rightarrow \infty} P(Q)=\left\{\begin{array}{lll}
0 & \text { se } & \frac{q(N)}{q_{c}(N)} \rightarrow 0 \\
1 & \text { se } & \frac{q(N)}{q_{c}(N)} \rightarrow \infty
\end{array}\right.
$$

É importante enfatizar que redes randômicas são estudadas com o número de vértices tendendo a infinito e que $q$ é a fração de arestas existentes entre as $\frac{1}{2} N(N-1)$ possíveis. Assim, para uma mesma probabilidade $q$, um grafo com mais vértices terá um número maior de arestas e, conseqüentemente, um poderá expressar determinada característica, enquanto o outro não. Ou seja, diferente de sistemas finitos, em que $q_{c}=$ cte, no caso de grafos randômicos não existe uma $q_{c}$ constante acima da qual acontecerá $Q$. Esta probabilidade crítica depende de $N$, portanto $q_{c}(N)$. Nessa linha, Erdös e Renyi estudaram o aparecimento de componentes com o aumento de $q$. Os mais simples componentes são árvores, circuitos e subgrafos completos. Circuitos de tamanho $n$ são grafos conexos formados por $n$ vértices e $n$ arestas, sendo que cada vértice se conecta com dois vértices adjacentes e apenas à eles, formando um contorno fechado e contínuo. Árvores, por sua vez são grafos conexos que não apresentam circuitos, isto é, uma árvore de grau $n$ apresenta $n$ vértices e $n-1$ arestas, enquanto um subgrafo completo de ordem $n$ é formado por $n$ vértices completamente conectados por $\frac{1}{2} n(n-1)$ arestas - ver figura 2.1.
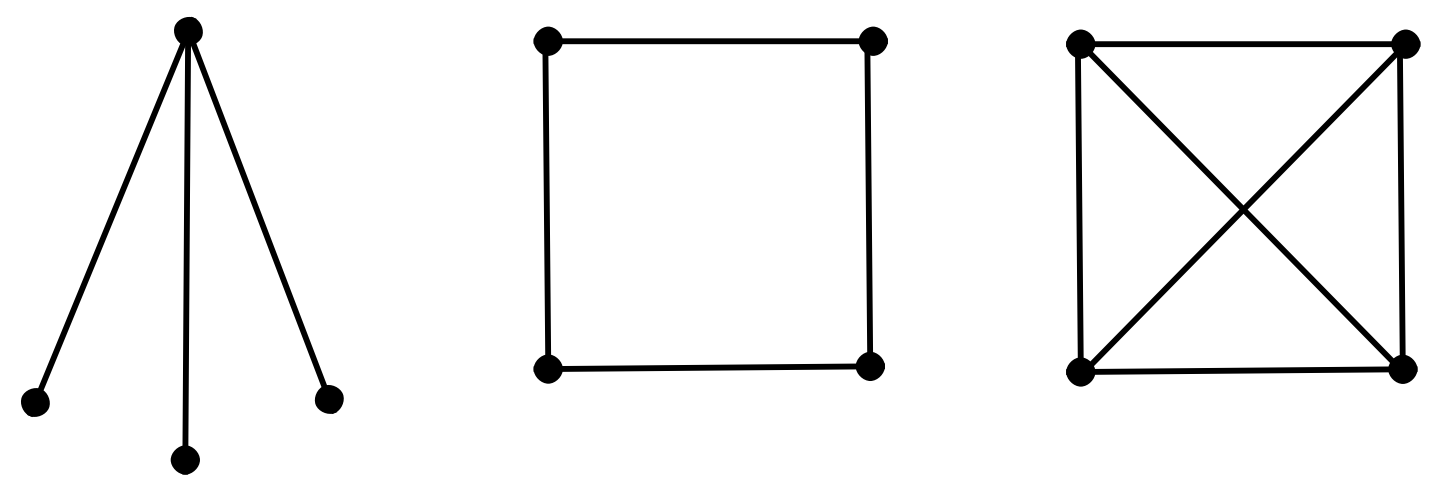

Figura 2.1: Grafos de ordem 4 (árvore, circuito e subgrafo completo).

Existe, na teoria de grafos randômicos, uma prova rigorosa [7] para probabilidade crítica $q_{c}(N)$ referente a existência de subgrafos de $n$ vértices e $h$ arestas, que aqui será apresentada de maneira heurística: em um grafo com $N$ vértices e probabilidade $q$ de existência de uma aresta entre dois vértices, os $n$ vértices do subgrafo podem ser escolhidos do total de $N$ vértices de $C_{N}^{n}$ formas diferentes, enquanto as arestas são formadas com probabilidade $q^{h}$. Podemos ainda permutar os $n$ vértices de $\frac{n !}{a}$ formas diferentes (sendo $a$ o número de subgrafos isomórficos) e obtém-se o número esperado $E(X)$ de subgrafos 


$$
E(X)=C_{N}^{n} \frac{k !}{a} q^{h} \cong \frac{N^{n} q^{h}}{a} \quad(N \gg n)
$$

Esta expressão sugere que, para $q(N) N^{\frac{n}{h}} \rightarrow 0$, com $N \rightarrow \infty$, quase nenhum grafo do ensemble conterá o referido subgrafo. No entanto, para $q(N)=c N^{-\frac{n}{h}}$, aproximadamente $\frac{c^{h}}{a}$ subgrafos existirão, indicando que esta é a probabilidade crítica. Relembrando que um circuito tem $n$ vértices e $h=n$ arestas, a probabilidade mínima para que um circuito exista é $q_{c}(N)=\frac{c}{N}$. O espantoso é que esta probabilidade é válida para circuitos de qualquer ordem (e também para árvores de qualquer ordem), inclusive para subgrafos do tamanho do sistema. O menor valor crítico para que esse fenômeno ocorra é $c=1$. Utilizando este resultado pode-se chegar a um outro interessante resultado: considerando o grau médio de um grafo randômico

$$
\langle k\rangle=\frac{2 m}{N}=\frac{2 q \frac{1}{2} N(N-1)}{N}=q(N-1) \simeq q N
$$

temos que o grau médio vale $\langle k\rangle=1$ para a probabilidade crítica $q=\frac{1}{N}$. Pode-se dizer então que para $\langle k\rangle=1$ o sistema sofre uma transição de fase e podem surgir árvores e ciclos do tamanho do sistema inteiro, isto é, ao invés de uma série de componentes esparsos a maioria dos vértices pertencem a uma única componente, que é muitas vezes chamada de componente gigante.

A distância média em um grafo randômico pode ser obtida através do seguinte argumento: o número $n$ de vértices que distam $\ell$ de um vértice referencial é aproximadamente $\langle k\rangle^{\ell}$. Então, para abranger a totalidade da rede, $\langle k\rangle^{\ell}=N$ e $\ell=\frac{\ln (N)}{\ln (\langle k\rangle)}$ é uma distância típica que satisfaz o critério de mundo pequeno, fazendo com que o modelo de redes randômicas seja um bom candidato para representar redes reais. No entanto, a distribuição de graus de um grafo randômico segue uma distribuição binomial (que tende a uma distribuição de Poisson para $N \rightarrow \infty$ e $\langle k\rangle=$ cte ). Além disso, lembrando que o coeficiente de aglomeração $A$ é a probabilidade média de termos dois vértices conectados a um terceiro, estando eles mesmos conectados, como em um grafo randômico a probabilidade de ocorrência de uma aresta entre dois vértices é totalmente descorrelacionada da existência de outras arestas, e igual a $q$, e o coeficiente de aglomeração nesse caso é $A=q$. Ambos os resultados (distribuição binomial para os graus e $A=q$ ) divergem bastante do comportamento de diversas redes encontradas na natureza e na sociedade, que vêm sendo bastante estudadas na literatura, para as quais a distribuição de graus segue uma lei de potências, a aglomeração é alta e a distância média é pequena. Estas redes são as assim 
chamadas de redes complexas livres de escala ${ }^{4}$.

É possível tornar os grafos randômicos mais adequados para descrever redes complexas impondo uma determinada distribuição de grau $p_{k}$ a priori (grafos randômicos generalizados). A forma de se construir esta rede é interessante: cria-se, partindo da distribuição de grau desejada, uma seqüência de graus e, levando em conta essa seqüência, são sorteados aleatoriamente pares de vértices que se conectam. De maneira figurada, seria como atribuir à cada vértice um numero de "semi-arestas" que obedeça $p_{k}$ e então os pares de "semi-arestas" são sorteados aleatoriamente formando arestas e conseqüentemente a rede. Este modelo de fato incorpora características de redes reais, sendo (obviamente) a distribuição de grau a principal. No entanto, o coeficiente de aglomeração e a distância média são menores do que os valores encontrados na maioria dos casos, e esta é uma abordagem fenomenológica: a escolha de $p_{k}$ não provém de nenhuma tentativa de elucidação de um fenômeno físico ou de mecanismos de crescimento da rede que leve em conta a relação entre os vértices.

\section{Rede de Watts e Strogatz (WS) ou Mundo Pequeno}

Watts e Strogatz [4] propuseram em 1998 um modelo de rede que tinha como principal objetivo obter um alto coeficiente de aglomeração em uma rede que tivesse uma distância média curta. Assim, partiram de uma rede regular em que, a um circuito de $N$ vértices, são adicionadas arestas conectando os vértices que tinham, no circuito original, distância menor ou igual a $K$. Chamaremos esta rede regular inicial de cadeia de grau $K$. Nesse caso, como em redes regulares, o coeficiente de aglomeração é alto. No entanto, sabemos que redes regulares deste tipo não exibem a característica de mundo pequeno, pois, para estes sistemas, com $N$ grande, a distância média é $\ell \propto \frac{N}{K}$, proporcional portanto a $N$. A solução proposta foi então reorientar com probabilidade $\phi$ as arestas da rede regular, de forma a fazer com que algumas arestas interliguem vértices antes distantes, diminuindo assim a distância média. A descoberta importante foi que, com a troca de algumas poucas arestas ( $\phi$ pequeno), e portanto sem diminuir a aglomeração, seria possível diminuir significativamente a distância média. Este modelo de rede, que denominaremos rede de Watts-Strogatz (WS), combina propriedades de uma rede regular $(\phi=0)$ e de uma desordenada $(\phi=1)^{5}$. A figura 2.2 ilustra o modelo.

Vemos na figura 2.3 que esse comportamento de fato ocorre, $\ell$ e $A$ de fato diminuem conforme $\phi$ tende a um. No entanto, Watts e Strogatz mostraram através de simulações numéricas que existe uma janela (ver figura) de valores de $\phi$ para os quais o coeficiente

\footnotetext{
${ }^{4}$ Redes livre de escala são redes para as quais $p_{k}$ segue uma lei de potências. Em geral, as redes livre de escala encontradas na natureza também tem um coeficiente de aglomeração $A$ alto.

${ }^{5} \mathrm{O}$ caso $\phi=1$ não se trata de um grafo randômico pois apenas uma das pontas das arestas é redirecionada, mantendo alguma ordem à rede.
} 


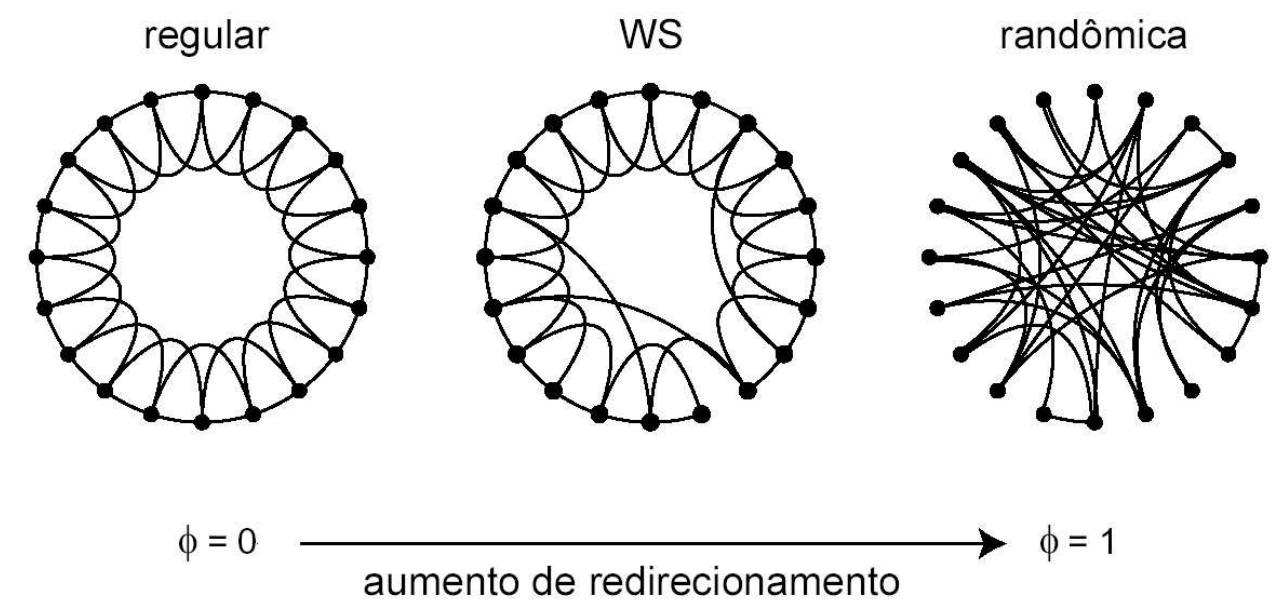

Figura 2.2: Rede WS para diversos valores de $\phi$. Figura retirada de [4].

de aglomeração é alto e distância média baixa, conseguindo reproduzir adequadamente alguns aspectos empíricos de redes estudadas.

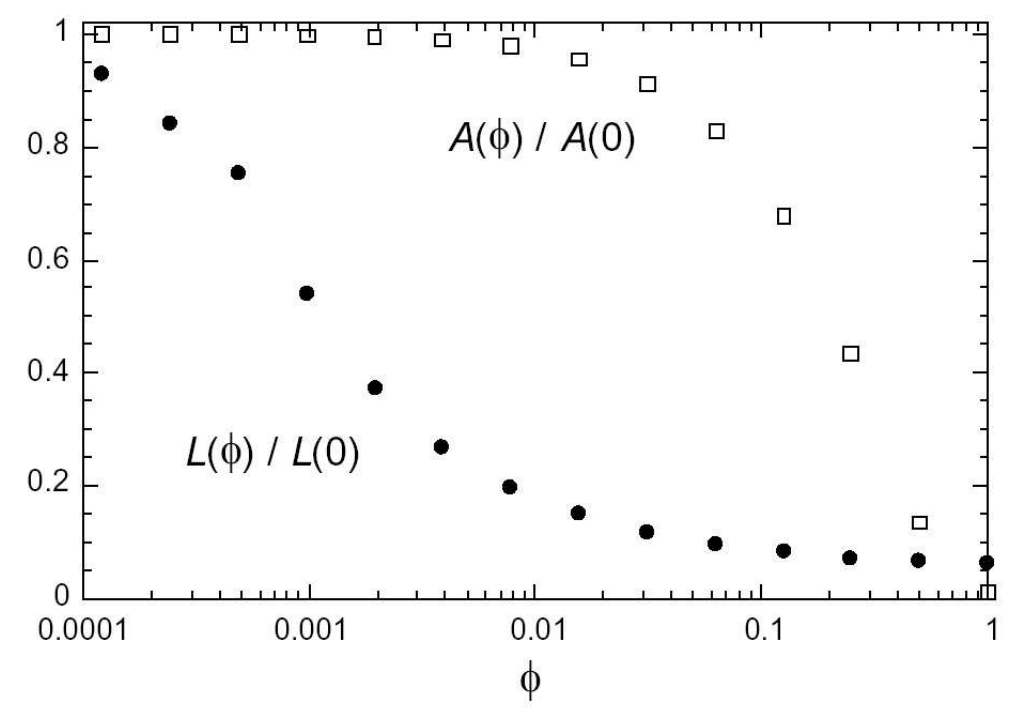

Figura 2.3: Coeficiente de Aglomeração $A$ e distância média $\ell$ normalizados em função da probabilidade de reorientação $\phi$. Figura retirada de [4].

Apesar do sucesso do modelo e do fato de contribuir para uma explicação da topologia de redes com propriedade mundo pequeno, a distribuição de graus do modelo proposto por Watts e Strogatz se assemelha a das redes regulares, não reproduzindo a lei de potências observada nas chamadas redes livres de escala. 


\section{Rede Barabási-Albert}

Desenvolvido de maneira completamente diferente, o modelo de rede proposto por Barabási e Albert [5] enfatiza a dinâmica de formação e crescimento de redes. Suas propriedades (distribuição de grau, distância média e coeficiente de aglomeração) surgem em decorrência desta dinâmica.

Uma série de estudos aborda o tema de redes em crescimento, mas nos concentraremos apenas naqueles que tentam explicar, em algumas redes da natureza, a origem de distribuições de grau que seguem leis de potência (redes livres de escala). O primeiro destes provavelmente foi o modelo de Price, proposto em 1965 (segundo [2, p. 213]).

Price estudou redes de citação de artigos científicos. Por serem estas redes direcionadas, pode-se atribuir a cada artigo (vértice) um grau $k^{e}$ de entrada (número de vezes que o artigo é citado) e outro grau $k^{s}$ de saída (número de artigos que o referido artigo cita), dando assim origem a duas distribuições de graus diferentes $p_{k^{e}}^{e}$ e $p_{k^{s}}^{s}$. A investigação destas redes levou à constatação de que estas duas distribuições de grau seguem uma lei de potência e então Price propôs um modelo que explicasse esse comportamento.

Baseado em conjecturas de Herbert Simon, o modelo de Price para redes em crescimento estabelece que novos vértices são adicionados e, para cada um deles, um número de novas arestas (que varia em torno de uma média de $m$ arestas) os conecta à rede antiga. Este modelo considera maior a probabilidade de um novo vértice se conectar a um outro vértice de alto grau de entrada, que a um vértice de baixo grau de entrada. Esta idéia de que novos vértices tem maior probabilidade de se conectar a vértices com maior grau de entrada - foi utilizada por Simon para pensar a distribuição de riquezas; é conhecida como "o mais rico enriquece mais" e foi rebatizada por Price, no contexto de redes, como vantagem cumulativa (cumulative advantage).

A justificativa para este modelo de citações é razoavelmente simples: um artigo muito citado ( $k^{e}$ alto) tem uma maior probabilidade de ser lido e, conseqüentemente, de ser citado novamente. Não é clara a dependência entre a probabilidade de citação e o número de citações (a não ser o crescimento monotônico) e Price propôs que fosse linear. Obviamente isso leva a um problema: um artigo recém lançado (nó novo) nunca foi citado e, devido a linearidade, a probabilidade de citação seria nula. A correção feita é considerar a probabilidade de citação como uma função afim do grau de entrada $\left(k^{e}+k_{0}^{e}\right)$ e, em seus cálculos, Price postulou $k_{0}^{e}=1$, como se a publicação do artigo fosse uma auto-citação, obtendo $p_{k^{e}}^{e} \sim\left(k^{e}\right)^{-\left(2+\frac{1}{m}\right)}$, uma lei de potência determinada pelo valor médio de arestas adicionadas a cada novo vértice ${ }^{6}$.

O modelo de Price não teve impacto muito grande até que Barabási e Albert, em 1999, redescobriram o modelo, reformulando-o [5]. A rede de Barabási-Albert (BA) é similar

\footnotetext{
${ }^{6}$ Esse resultado continua válido para $k_{0}^{e} \neq 1$.
} 
a de Price, mas considera arestas não-direcionadas. Esta mudança acaba por eliminar a necessidade de um termo constante, pois a probabilidade de nova citação é linearmente proporcional ao grau $k$ do vértice. Barabási e Albert chamaram este efeito de conexão preferencial (preferential attachment), que se assemelha muito à vantagem cumulativa de Price.

A lei de potência encontrada para o modelo de Price também pode ser obtida para a rede de $\mathrm{BA}$, no limite "termodinâmico" $(N \rightarrow \infty)$. A probabilidade de que um novo vértice escolha aleatoriamente um vértice de grau $k$ para se conectar é proporcional ao número relativo de vértices com grau $k$. Mas, segundo o modelo, essa escolha não é neutra, um vértice de grau $k$ tem $k$ vezes mais chance de se conectar ao novo vértice (conexão preferencial). Portanto

$$
\frac{k p_{k}}{\sum_{k} k p_{k}}=\frac{k p_{k}}{\langle k\rangle}=\frac{k p_{k}}{2 m}
$$

é a probabilidade de que um novo vértice se conecte a um vértice antigo de grau $k$. Como a cada novo vértice adicionado, $m$ arestas são adicionadas, o número esperado de arestas que se conectam a vértices antigos de grau $k$ é simplesmente

$$
m \frac{k p_{k}}{2 m}=\frac{k p_{k}}{2}
$$

Como antes da adição deste vértice existiam $N p_{k}$ vértices de grau $k$, após a adição existirão $N p_{k}-\frac{k p_{k}}{2}$, dado que $\frac{k p_{k}}{2}$ vértices ganharão uma aresta e, portanto, terão grau $k+1$. Por outro lado, uma parte dos vértices de grau $k-1$ recebe arestas, aumentando o grau e aumentando o número de vértices com grau $k$.

Portanto o balanço de vértices por grau fica:

$$
(N+1) p_{k}^{N+1}-N p_{k}^{N}=\left\{\begin{array}{ccc}
\frac{1}{2}(k-1) p_{k-1}^{N}-\frac{1}{2} k p_{k}^{N} & \text { para } & k>m \\
1-\frac{1}{2} m p_{m}^{N} & \text { para } & k=m
\end{array}\right.
$$

em que $p_{k}^{N}$ representa a fração de vértices com grau $k$ quando a rede tinha $N$ vértices. Procuramos uma solução estacionária para o sistema de forma que $p_{k}^{N+1}=p_{k}^{N}=p_{k}$ e com isso temos:

$$
p_{k}=\left\{\begin{array}{ccc}
\frac{1}{2}(k-1) p_{k-1}-\frac{1}{2} k p_{k} & \text { para } & k>m \\
1-\frac{1}{2} m p_{m} & \text { para } & k=m
\end{array}\right.
$$

Rearranjando a equação acima temos

$$
p_{m}=\frac{2}{m+2} \quad \text { e } \quad p_{k}=\frac{k-1}{k+2} p_{k-1}
$$


o que leva à

$$
p_{k}=\frac{(k-1)(k-2) \ldots m}{(k+2)(k+1) \ldots(m+3)} p_{m}=\frac{2 m(m+1)}{(k+2)(k+1) k} \sim k^{-3}
$$

Este resultado representa uma lei de potências de expoente -3 , um resultado que não contempla a diversidade de expoentes encontrados empiricamente em redes naturais $(1 \leq$ $\alpha \leq 4$ ), o que por um lado concorda com a simplicidade do modelo e por outro gerou um grande esforço na comunidade científica no sentido de obter modelos nos quais os expoentes pudessem variar pelo menos dentro de certo intervalo.

Cabem ainda algumas observações sobre propriedades da rede BA. Devido à dinâmica de crescimento da rede, pela qual, a partir de um vértice ou aglomerado original se forma toda a rede, pode-se facilmente perceber que todos os vértices são interconectados e portanto essas redes terão uma componente única. Outro aspecto relevante é que não existe uma previsão analítica para o coeficiente de aglomeração desta rede. Cálculos numéricos indicam que estes são aproximadamente cinco vezes maiores que os da rede randômica e que dependem do tamanho da rede [5]. No entanto ainda estão muito abaixo dos valores encontrados em diversas redes sociais de interesse atualmente.

\subsection{Caráter livre de escala de eleições proporcionais}

Costa Filho, Almeida, Andrade Júnior e Moreira publicaram, em 1999, um estudo [9] sobre a distribuição de candidatos por votos em eleições proporcionais (para o legislativo) de 1998, tanto do Estado de São Paulo como para a Câmara de Deputados Federais. Além de formular um modelo para eleições proporcionais (que não será aqui abordado) o trabalho de Costa Filho e colaboradores mostra que a fração de candidatos $f$ que obteve $v$ votos segue uma lei de potências

$$
f(v) \propto v^{-\alpha}
$$

com $\alpha \approx 1$, para um intervalo largo do número de votos, que abrange aproximadamente duas ordem de magnitude. Posteriormente, Gonzáles, Souza e Herrmann [10] verificaram que a distribuição de candidatos por voto nas eleições para a câmara baixa de alguns estados da Índia também obedece uma lei de potência, com $\alpha \approx 1,3$.

A primeira proposta desse trabalho de mestrado foi fazer uma análise semelhante, da distribuição de votos, para o legislativo da cidade de São Paulo (2000 e 2004). Os dados das eleições foram obtidos junto ao Tribunal Regional Eleitoral de São Paulo [11]. As eleições contaram com 5.521.182 e 5.956.963 votos válidos em 2000 e 2004 respectivamente.

Para construir o histograma, numa escala log-log, de uma função que obedece uma lei 
de potências, é necessário tomar alguns cuidados, e lidar com o fato que há muito menos estatística para valores grandes de $v$. Uma alternativa muito usada é empregar intervalos igualmente espaçados em uma escala logarítmica. Newman [12] sugere a utilização de intervalos de contagem ("bins") com tamanho crescente (segundo uma progressão geométrica) com o número de votos $v$, de forma a aumentar a estatística para candidatos com grande número de votos e suavizar a curva obtida. Essa foi a forma adotada nos histogramas em escala log-log deste texto. Outra alternativa possivel é fazer o gráfico da função de distribuição cumulativa

$$
F(v)=\int_{v}^{\infty} f\left(v^{\prime}\right) d v^{\prime}
$$

que mede a fração de candidatos com um número de votos superior a $v$. Se $f(v)$ obedece a equação 2.2 sem desvios para altos valores de $v$, a distribuição cumulativa também obedecerá 2.2 para todos os $v$ (com um valor distinto de $\alpha$ ) [12]. A distribuição cumulativa tem a vantagem de ser menos sensível ao fato de que há menos dados para valores altos de $v$, além de dispensar a escolha de intervalos de contagem.
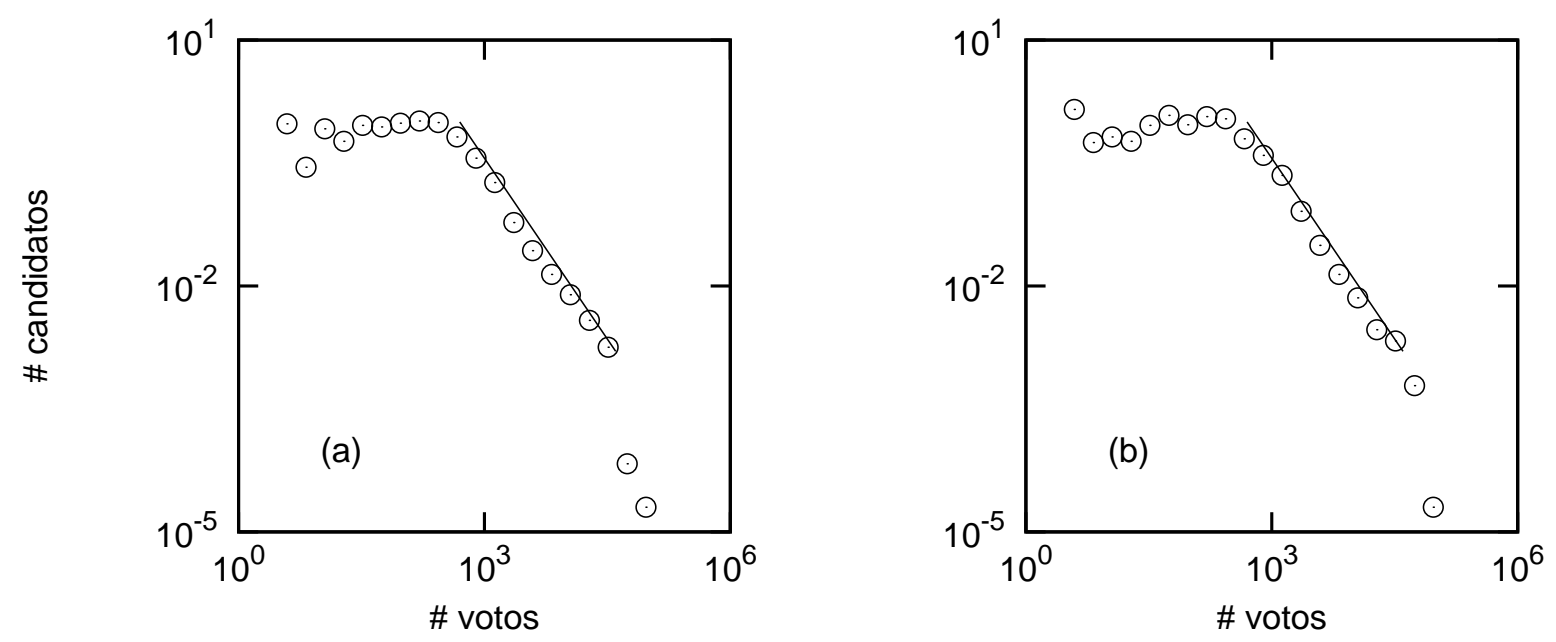

Figura 2.4: Distribuição de candidatos por número de votos, com linha guia $f(v) \propto v^{-1,47}$, para eleições de vereadores de São Paulo em (a) 2000; (b) 2004;

Como pode-se observar no histograma por nós construído (figura 2.4), para um grande intervalo do número de votos, a distribuição de candidatos segue de fato uma lei de potências. Percebe-se, no entanto, desvios para baixos e altos números de votos (sendo que o último impossibilita a utilização da distribuição cumulativa - ver detalhes das contas no apêndice A). Acreditamos que ambos os desvios têm origem no tamanho finito do sistema estudado. $\mathrm{O}$ desvio observado na região de candidatos com poucos votos ( $v$ pequeno) deve-se provavelmente ao fato de que há um número limitado de candidatos 
na eleição, enquanto o desvio na região de $v$ grande deve-se ao fato de que o número de eleitores é finito.

Procedemos, então, ao cálculo do expoente $\alpha$, que usualmente é obtido através do ajuste linear à parte do histograma na escala log-log. Esse procedimento, no entanto, deve ser feito de forma cuidadosa. Não é simples determinar, na prática, onde o comportamento linear começa ou termina. Goldstein atentou também [13] a possíveis problemas oriundos da utilização ingênua do método de mínimos quadrados (normalmente empregado para ajustar uma reta a uma seqüência de pontos numa escala linear) e propôs a utilização de um outro método conhecido como Estimação de Máxima Verossimilhança (EMS). Mas o método proposto por Goldstein é válido apenas para distribuições sem desvios nos eventos raros. Para poder aplicar esse método ao nosso problema (que apresenta desvios tanto para valores altos como valores baixos de $v$ ), nós generalizamos o EMS para estes casos (ver apêndice $\mathrm{A}$ ).

Assim, admitindo que $f(v)$ obedece uma lei de potência $v^{-\alpha}$ entre os valores $v_{\min }$ e $v_{c}$ temos, pelo EMS generalizado, que

$$
\frac{\sum_{i=1}^{N_{c}} \ln \left[v_{i}\right]}{N_{c}}+\frac{1}{1-\alpha}+\left[\frac{\ln \left(v_{\min }\right) v_{\min }^{(1-\alpha)}-\ln \left(v_{c}\right) v_{c}^{(1-\alpha)}}{v_{c}^{(1-\alpha)}-v_{\min }^{(1-\alpha)}}\right]=0
$$

onde $v_{i}\left(v_{\min } \leq v_{i} \leq v_{c}\right)$ representa o número de votos obtidos pelo $i$-ésimo dos $N_{c}$ candidatos com votação entre $v_{\text {min }}$ e $v_{c}$. Resolvendo numericamente a equação 2.3 para os dados indicados, obtivemos $\alpha_{2000}=1,47(4)$ e $\alpha_{2004}=1,47(3)$ (conforme pode ser visto na figura 2.4), sendo as estimativas calculadas via "bootstrap resampling method" [14]: criamos séries de dados artificiais utilizando elementos da série original escolhidos de forma aleatória; para cada série artificial obtivemos um valor de $\alpha$ distinto, obtendo uma distribuição de $\alpha$; por fim, a incerteza atribuída ao $\bar{\alpha}$ desta distribuição corresponde à metade de $\alpha_{0,16}-\alpha_{0,84}$, sendo que $\alpha_{w}$ é o valor de $\alpha$ tal que uma fração $w$ dos $\alpha$ s têm valores mais baixos que $\alpha_{w}$.

\subsection{Modelo de Sznajd}

Pode-se dizer que a Mecânica Estatística se notabiliza por explicar, através de mecanismos microscópicos, comportamentos macroscópicos. Neste sentido, o modelo de Ising [15] é representativo: cada sítio (a unidade microscópica) de um reticulado $d$-dimensional pode assumir dois estados distintos - que podem ser associados, por exemplo, ao spin de um átomo, à ocupação do sítio, ao tipo de substância que ocupa o sítio - e, admitindo determinada interação entre um sítio, seus vizinhos e o meio externo, tenta-se encontrar a distribuição de configurações de equilíbrio para temperaturas e campos externos distin- 
tos, que implica certas manifestações macroscópicas (magnetizações, calores específicos, densidades e etc).

Apesar da simplicidade do modelo, encontrar as configurações de equilíbrio ${ }^{7}$ do modelo de Ising não é trivial (Ising encontrou a solução para 1 dimensão; Onsager para 2; para $d \geq 3$ não se conhece solução fechada [15]). Uma forma alternativa de tratar o problema, que nos possibilita estimar grandezas macroscópicas associadas ao modelo de Ising, é fazer a média de diversos valores desta grandeza para diferentes configurações do sistema. As configurações escolhidas para se estimar essa grandeza, no entanto, devem respeitar a distribuição de equilíbrio. Para encontrarmos estas configurações utiliza-se o método de Monte Carlo [16]: o tempo é discretizado, a cada passo (Passo de Monte Carlo - PMC) escolhe-se um sítio aleatório e atualiza-se o estado deste de acordo com uma regra compatível com as interações propostas no modelo de Ising (como, por exemplo, a dinâmica de Glauber - ver seção 5.1). Deve ser notado que o estado configuracional inicial é escolhido de forma arbitrária, eventualmente longe do equilíbrio, mas após alguns passos chega-se a configurações de equilíbrio devido à compatibilidade entre as regras de atualização e as interações do modelo de Ising. Desprezando este transiente pode-se, portanto, acessar as grandezas macroscópicas de equilíbrio.

O sucesso do modelo de Ising, como, por exemplo, o acordo entre expoentes críticos de transições fase previstos pelo modelo e observados experimentalmente, originou uma série de tentativas de estender este tipo de abordagem à outras classes de fenômenos. Neste sentido, os poloneses Katarzina Sznajd-Weron e Jósef Sznajd formularam [17] um modelo (uma regra de atualização) que visava simular o mecanismo de tomada de decisão, quando só existiam duas opções, em uma comunidade fechada. A principal característica do modelo se resume ao fato de que é a coincidência de opinião entre dois indivíduos vizinhos interagentes a responsável por alterar a opinião dos demais vizinhos.

Sznajd e Sznajd propõe que a comunidade seja representada por uma cadeia unidimensional de indivíduos conectados aos seus dois vizinhos mais próximos e que cada indivíduo tenha uma opinião 1 ou -1 . A cada PMC, escolhe-se de forma aleatória um par de indivíduos vizinhos $i$ e $i+1$, e a regra de atualização é da seguinte forma: caso a dupla esteja de acordo (cada um tenha a mesma opinião) os indivíduos vizinhos ao par $(i-1$ e $i+2)$ adotarão as opiniões do par; caso contrário, ou seja, caso o par inicial escolhido tenha "discordâncias internas" a discordância se espalhará, $i-1$ adotará a opinião de $i+1$ e $i+2$ a de $i$, formando assim uma seqüência de 4 indivíduos "sucessivamente discordantes". Usando a linguagem modelo de Ising para spins e considerando $\sigma(i, t)$ a opinião de um indivíduo no instante $t$, podemos esquematizar a dinâmica do modelo Sznajd da seguinte maneira:

\footnotetext{
${ }^{7} \mathrm{Na}$ realidade, busca-se a função de partição em função das variáveis termodinâmicas.
} 


$$
\begin{aligned}
& \text { se } \sigma(i, t)=\sigma(i+1, t) \Rightarrow \begin{cases}\sigma(i+2, t+1) & \rightarrow \sigma(i, t) \\
\sigma(i-1, t+1) & \rightarrow \sigma(i, t)\end{cases} \\
& \text { se } \sigma(i, t) \neq \sigma(i+1, t) \Rightarrow\left\{\begin{array}{llc}
\sigma(i+2, t+1) & \rightarrow & \sigma(i, t) \\
\sigma(i-1, t+1) & \rightarrow & \sigma(i+1, t)
\end{array}\right.
\end{aligned}
$$

Desta forma o sistema evolui até atingir um dos três estados configuracionais (ou configurações) estacionários possíveis, todos com opinião +1 , todos com opinião -1 , e a alternância regular de opiniões (poderíamos chamar os dois primeiros de ferromagnéticos e o terceiro de antiferromagnético).

O modelo, batizado de USDF ("United we Stand, Divided we Fall" - que numa tradução livre seria "Unidos Vencemos, Divididos somos Derrotados") por seus criadores, foi renomeado por Stauffer, Souza e Oliveira como modelo de Sznajd (MS neste texto) em [18]. Neste trabalho, Stauffer e colegas, além de generalizar o MS para duas dimensões, enfatizam uma das principais características do modelo: diferentemente de outros modelos para a formação de opinião existentes na literatura (e do modelo de Ising), o fluxo da influência, neste caso, é do centro para a periferia e não o contrário.

Este modelo foi generalizado posteriormente de forma a aumentar tanto a dimensão como o número de opiniões que cada indivíduo pode ter. Nesse contexto, Bernardes et al [19] reformularam o MS associando a cada sítio um candidato (um estado), com o intuito de contemplar o comportamento observado por Costa Filho e colegas, já discutido na seção anterior. Nesta reformulação, Bernardes utiliza um reticulado tridimensional como meio em que a dinâmica ocorre, onde cada indivíduo pode ter a intenção de votar em algum candidato $\sigma=1,2, \ldots, N_{c}$ ou de ainda não ter escolhido nenhum $(\sigma=0)$. Inicialmente todos os indivíduos estão indecisos. Em uma primeira etapa atribui-se a alguns indivíduos da rede (os eleitores iniciais) determinada opinião, sendo que esta é colocada de maneira assimétrica, isto é, alguns candidatos têm inicialmente uma maior probabilidade de aceitação ${ }^{8}$. Terminada esta etapa, tem início a dinâmica de Sznajd propriamente dita, em que pares de indivíduos vizinhos são escolhidos aleatoriamente. Caso este par escolhido tenha discordância quanto ao candidato, nada ocorre e então é sorteado outro par. Mas se o par estiver de acordo (i.e. os dois têm a mesma opinião $\sigma$ ) então todos os dez vizinhos deste par serão convencidos a votar em $\sigma$. O modelo leva a estados estacionários em que todos os indivíduos acabam votando em apenas um candidato. No entanto, para estabelecer um contato com a questão eleitoral, a análise é

\footnotetext{
${ }^{8}$ Todos os eleitores são varridos; escolhe-se aleatoriamente um candidato $\sigma$ para cada eleitor e este eleitor votará em $\sigma$ com probabilidade $\left(\frac{\sigma}{N_{c}}\right)^{2}$.
} 
feita no transiente, pois a eleições ocorrem após um curto período de campanha e não se aguarda que todos eleitores tenham mesma opinião. Neste transiente, Bernardes e colaboradores encontraram uma distribuição de candidatos por votos que obedece uma lei de potência, como observado nas eleições reais (ver seção 2.2).

Apesar do grande número de trabalhos sobre variações do MS (Sznajd-Weron revê alguns destes em [20]) concentramos o estudo em uma segunda modificação do MS, por Bernardes e colaboradores [1], em que o modelo é generalizado para uma rede complexa, onde os vértices representam eleitores do sistema, que podem escolher entre alguns candidatos. No próximo capítulo analisamos com detalhe este modelo. 


\section{Capítulo 3}

\section{Modelo de Sznajd em uma rede complexa livre de escala}

Como visto anteriormente em 2.3, a adaptação do modelo de Sznajd em uma rede regular para votações proporcionais apresenta uma distribuição de votos por candidatos que obedece, durante o transiente, uma lei de potência semelhantes as observadas por Costa Filho em votações reais [9] apenas para configurações iniciais bastante assimétricas. Bernardes, Stauffer e Kertész [1] adaptaram o modelo para redes em que os eleitores não têm necessariamente o mesmo grau e estudaram seu comportamento em uma rede de Barabási-Albert.

O modelo (que nesta dissertação será referido por "modelo de Sznajd modificado para uma rede complexa", ou simplesmente MSC) considera os vértices de uma rede como sendo eleitores; as vizinhanças são também definidas pela rede, ou seja, dois eleitores são vizinhos se os vértices a eles associados são vizinhos. A cada eleitor $i$ está associado, a cada instante $t^{1}$, um valor $\sigma(i, t)$ inteiro $\in\left\{0,1, \ldots, N_{c}\right\}$ que corresponde a um dos $N_{c}$ candidatos. $\sigma=0$ representa o eleitor indeciso, ainda sem candidato. Inicialmente todos os eleitores estão indecisos $(\sigma(i, 0)=0$, para qualquer $i)$ e escolhe-se, aleatoriamente, um único eleitor inicial para cada um dos $N_{c}$ candidatos.

A dinâmica de convencimento se dá escolhendo, a cada instante $t$, numa ordem aleatória, cada um dos vértices e aplicando a seguinte regra:

(I) Se o eleitor $i$ escolhido já tiver um candidato, isto é, $\sigma(i, t) \neq 0$ então sorteia-se um vértice $j$ vizinho de $i$;

(IIa) Caso $j$ esteja indeciso, i.e., $\sigma(j, t)=0$, então $i$ convence $j$, ou seja, $\sigma(j, t+$ $1) \rightarrow \sigma(i, t)$ com probabilidade $k_{i}^{-1}$, onde $k_{i}$ é o grau do eleitor $i$ (regra de

\footnotetext{
${ }^{1}$ Como no modelo de Sznajd em redes regulares (seção 2.3), neste caso a evolução se dá em tempos discretos.
} 
convencimento individual);

(IIb) Caso $\sigma(i, t)=\sigma(j, t)$, e portanto os dois eleitores "concordam" sobre qual o melhor candidato, $i$ convence seus vizinhos $i^{\prime} \in \Gamma_{i}$ com probabilidade $k_{i}^{-1}$ e $j$ convence seus vizinhos $j^{\prime} \in \Gamma_{j}$ com probabilidade $k_{j}^{-1}{ }^{2}$, independentemente de $\sigma\left(i^{\prime}, t\right)$ ou $\sigma\left(j^{\prime}, t\right)$, ou seja, os vizinhos de $i$ e $j$ podem mudar de opinião (regra de convencimento por pares);

(IIc) Caso o eleitor $j$ tenha escolhido um candidato diverso de $i$, i. e., $\sigma(j, t) \neq 0$ e $\sigma(j, t) \neq \sigma(i, t)$, nada ocorre;

Em N PMCs o modelo terá escolhido todos os eleitores do sistema. Utilizaremos, então, a unidade Tempo de Monte Carlo (TMC) para designar o intervalo de tempo que o sistema leva para "passar" por todos os eleitores, ou seja, um TMC equivale a $N$ PMCs, e, portanto, para sistemas com número de eleitores distintos o TMC equivale a intervalos de tempos de comprimento distintos.

O sistema tende, após algum tempo $T$, a um estado congelado $(\sigma(i, T)=C$ para todo $i)^{3}$ o que significaria todos eleitores votando num mesmo candidato. No entanto, durante o transiente, a distribuição de candidatos por votos obedece uma lei de potências, o que mostra um acordo entre o MSC e os dados apresentados por Costa Filho e colegas [9]. Bernardes e colegas justificaram que, numa eleição real, o tempo de campanha é curto, e a eleição representaria uma "fotografia" de um momento do transiente. Temos então que o modelo de Sznajd em uma rede de Barabási-Albert, além de se basear em uma rede complexa mais próxima das relações pessoais, chega a resultados compatíveis com os de Costa Filho, com uma distribuição de eleitores iniciais uniforme, diferente da rede cúbica, que demandava uma situação inicial bastante assimétrica para que a distribuição de candidatos por votos durante o transiente obedecesse a uma lei de potências.

\subsection{Propriedades do modelo}

Através de simulações numéricas, reproduzimos o modelo de Sznajd em rede complexa livre de escala, segundo Bernardes, Stauffer e Kertész [1]. Utilizamos uma rede de BarabásiAlbert com 6 vértices iniciais e $m=5$ arestas por vértice adicionado à rede (ver seção

\footnotetext{
${ }^{2} \mathrm{~A}$ determinação desta probabilidade não é fortuita. Claramente o número de vizinhos de $i$ e $j$ convencidos obedece, separadamente, a distribuições binomiais com probabilidade de convencimento $p_{i}=$ $k_{i}^{-1}$ e $p_{j}=k_{j}^{-1}$ (ou, genericamente, $p=k^{-1}$ ). Portanto o número médio de vizinhos convencidos $m$ por cada um será $m=n p$, em que $n$ é o número de vizinhos, $n=k$. Assim, temos $m=n p=k \frac{1}{k}=1$. Ou seja, esta probabilidade de convencimento é escolhida de forma que cada par de vértices convencerá em média, segundo a regra (IIa), dois outros vértices.

${ }^{3}$ Não encontramos resultado analítico na literatura neste sentido, mas em todas as simulações, na rede de Barabási-Albert, o estado congelado foi atingido.
} 
2.1.1). Cabe ainda dizer que as diferentes simulações aqui relatadas seguem a proporção entre o número de eleitores $N$ e de candidatos $N_{c}, \frac{N}{N_{c}}=10^{3}$, próxima da utilizada por Bernardes e colegas $\left(\frac{N}{N_{c}}=5 \cdot 10^{2}\right)$ e da eleição legislativa em São Paulo $\left(\frac{N}{N_{c}} \simeq 5 \cdot 10^{3}\right)$. O tamanho da rede, $N$, variou entre $10^{5} \sim 10^{6}$, conforme o custo computacional em questão.

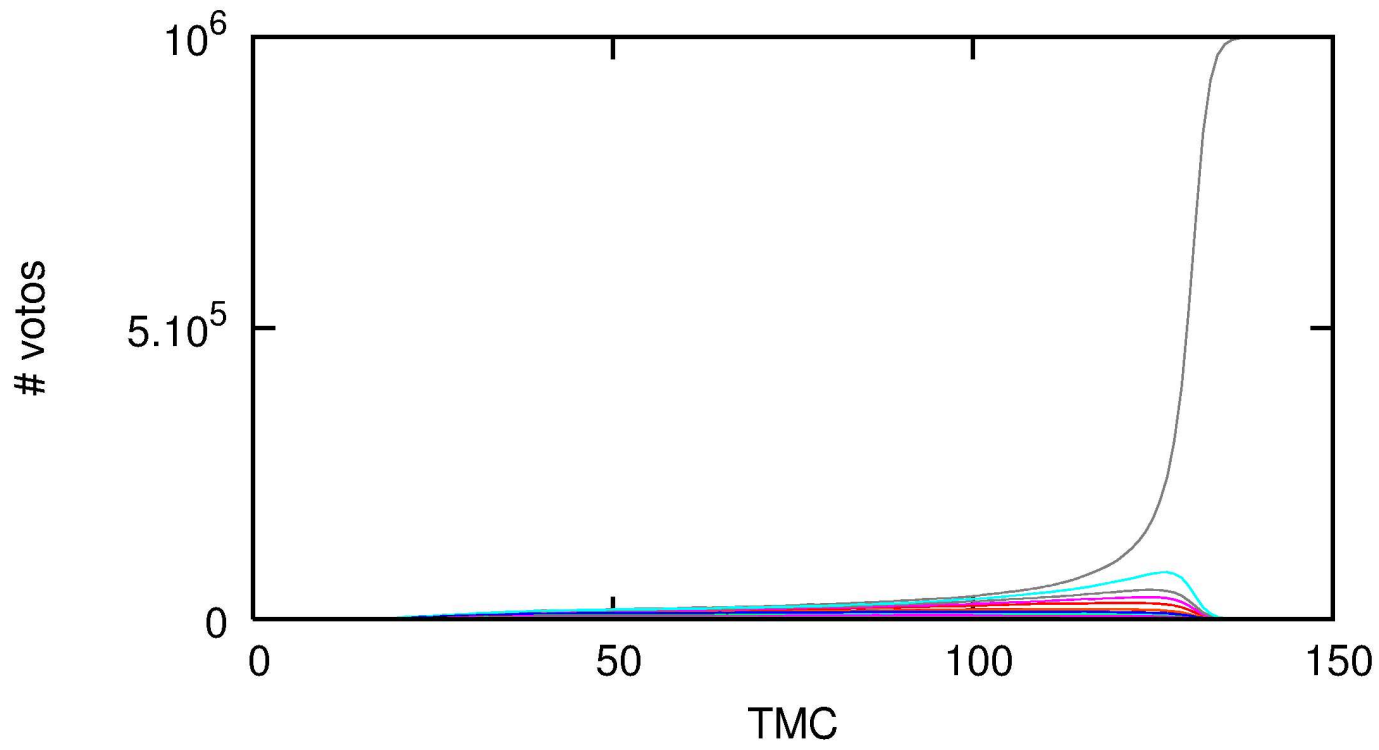

Figura 3.1: Número de votos por candidato pelo tempo. Simulação com $10^{6}$ eleitores e $10^{3}$ candidatos.

Uma evolução típica do número de votos de cada candidato no tempo é apresentada na figura 3.1. A distribuição de candidatos por número de votos se aproxima, durante um longo intervalo do transiente (aproximadamente entre 10 e $70 \mathrm{TMCs}$ ), de uma lei de potências, como pode ser observado na figura 3.2.

Além de reproduzir os resultados obtidos por Bernardes, estudamos outros aspectos do modelo em rede complexa, não restritos à análise de votos durante o transiente. Particularmente, procuramos compreender os fatores que levam à vitória de determinado candidato (ou, abstratamente, que quebram a simetria do sistema, levado-o a uma configuração congelada particular, com um determinado estado dominante).

\subsubsection{Aproximação de campo médio}

Verificamos, através de uma aproximação de campo médio (similar à [21]), as configurações estacionárias do MSC. Definimos $\eta^{\sigma}(i, t)$ como sendo a probabilidade de que o eleitor $i$ tenha escolhido, no instante $t$, o candidato $\sigma$ (a normalização implica que $\left.\eta^{0}(i, t)+\sum_{\sigma=1}^{N_{c}} \eta^{\sigma}(i, t)=1\right)$. Particularmente, $\eta^{0}(i, t)$ representa a probabilidade de que o eleitor $i$ esteja indeciso (não tenha escolhido candidato algum) em $t$. A evolução de $\eta^{0}(i, t)$ 


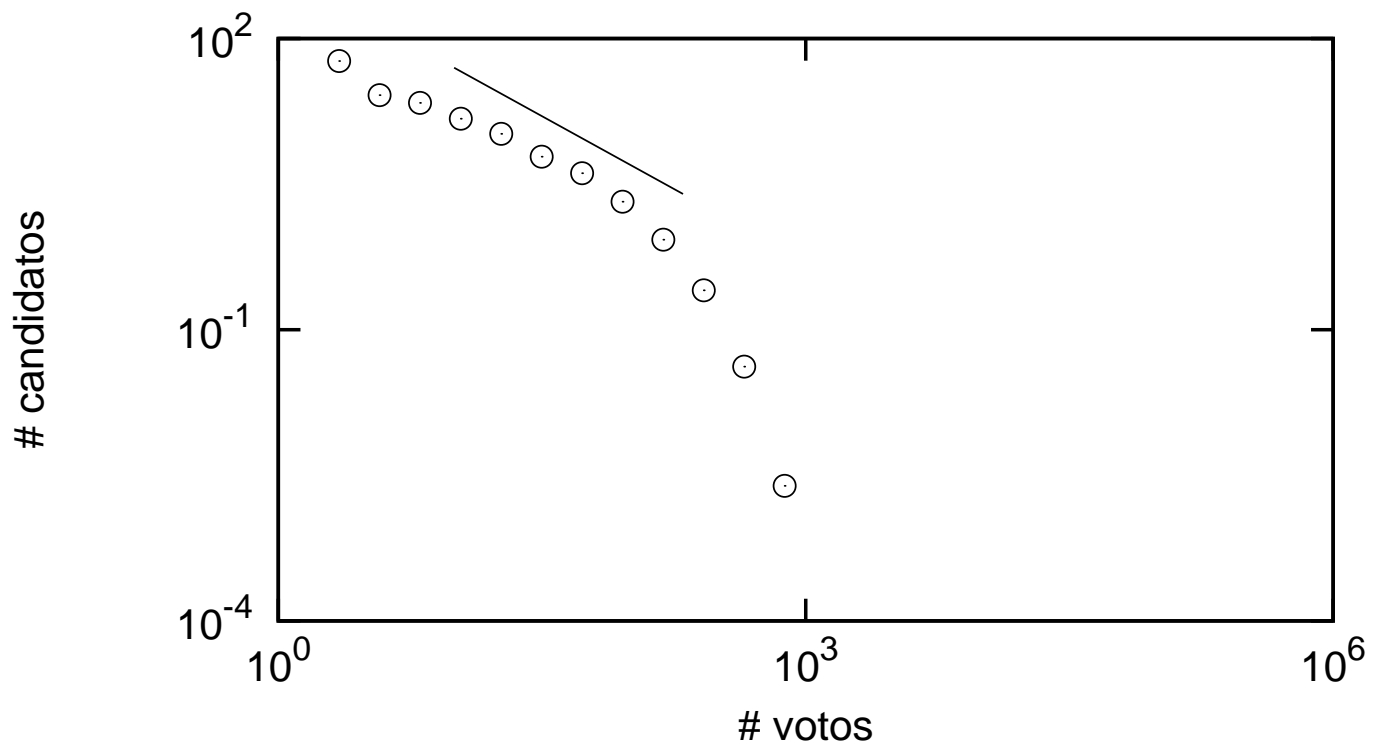

Figura 3.2: Distribuição de candidatos por voto para 15 TMC e linha guia $f(v) \propto v^{-1}$. Simulação com $10^{6}$ eleitores e $10^{3}$ candidatos.

é simples pois, em um TMC, a variação de $\eta^{0}(i, t)$ é probabilidade de que $i$ tenha sido convencido por um de seus vizinhos $j \in \Gamma_{i}$. Note que, neste caso, $i$ pode ser convencido por um vizinho $j$, que vota no candidato $\sigma_{j}$, de duas maneiras distintas: se $j$ escolhe $i$ entre seus $k_{j}$ vizinhos então $i$ será convencido com probabilidade $k_{j}^{-1}$ (regra IIa); ou então $j$ pode escolher um dos $k_{j}^{\sigma_{j}}$ vizinhos de mesma opinião entre seus $k_{j}$ vizinhos, convencendo $i$ com probabilidade $k_{j}^{-1}$ (regra IIb). Assim, a probabilidade de que o eleitor $i$ esteja indeciso em $t$ varia, em 1 TMC, da seguinte forma

$$
\begin{gathered}
\eta^{0}(i, t+1)-\eta^{0}(i, t)=\Delta \eta^{0}(i, t)= \\
=-\sum_{j \in \Gamma_{i}} \frac{1}{k_{j}} \frac{1}{k_{j}} \operatorname{Prob}\left(\sigma_{i}=0, \sigma_{j} \neq 0\right)-\sum_{j \in \Gamma_{i}} \frac{k_{j}^{\sigma_{j}}}{k_{j}} \frac{1}{k_{j}} \operatorname{Prob}\left(\sigma_{i}=0, \sigma_{j} \neq 0\right) \Rightarrow \\
\Delta \eta^{0}(i, t)=-\sum_{j \in \Gamma_{i}} \frac{k_{j}^{\sigma_{j}}+1}{k_{j}^{2}} \operatorname{Prob}\left(\sigma_{i}=0, \sigma_{j} \neq 0\right)
\end{gathered}
$$

onde $\operatorname{Prob}\left(\sigma_{i}=0, \sigma_{j} \neq 0\right)$ é a probabilidade de que o eleitor $i$ esteja indeciso e seu vizinho $j$ já tenha escolhido um candidato.

A evolução de $\eta^{\sigma}(i, t)$ é mais sutil. $\eta^{\sigma}(i, t)$ pode aumentar de duas formas: ou $i$ está indeciso e é convencido por um vizinho $j$, que vota em $\sigma$, pela regra IIa; ou $i$ não escolheu o candidato $\sigma$ (podendo inclusive estar indeciso) mas, agora pela regra IIb, seu vizinho $j$, em conjunto com outro vizinho que também vota em $\sigma$, o faz mudar de idéia. Por outro lado $\eta^{\sigma}(i, t)$ pode diminuir caso $i$ tenha escolhido o candidato $\sigma$, mas $j$, eleitor de um dos 
$N_{c}-1$ candidatos $\sigma^{\prime} \neq \sigma$, faz com que $i$ abandone $\sigma$. Então, a variação de $\eta^{\sigma}(i, t)$ é, em $1 \mathrm{TMC}$,

$$
\begin{gathered}
\Delta \eta^{\sigma}(i, t)=\sum_{j \in \Gamma_{i}} \frac{1}{k_{j}^{2}} \operatorname{Prob}\left(\sigma_{i}=0, \sigma_{j}=\sigma\right)+\sum_{j \in \Gamma_{i}} \frac{k_{j}^{\sigma_{j}}}{k_{j}^{2}} \operatorname{Prob}\left(\sigma_{i} \neq \sigma, \sigma_{j}=\sigma\right)- \\
-\sum_{\sigma^{\prime}=1}^{N_{c}} \sum_{j \in \Gamma_{i}} \frac{k_{j}^{\sigma_{j}}}{k_{j}^{2}} \operatorname{Prob}\left(\sigma_{i}=\sigma, \sigma_{j}=\sigma^{\prime}\right) \\
\sigma^{\prime} \neq \sigma
\end{gathered}
$$

onde as probabilidades conjuntas são definidas da maneira intuitiva.

Estas relações (equações 3.1 e 3.2) são exatas, mas, para resolvê-las, necessitamos das probabilidades conjuntas de pares de eleitores, que levaria a probabilidades conjuntas de mais eleitores. Fazemos então, a aproximação de campo médio, considerando homogeneidade espacial $(\eta(i) \equiv \eta)$ e a independência estatística entre a opinião de cada eleitor e a de seus vizinhos:

$$
\begin{gathered}
\operatorname{Prob}\left(\sigma_{i}=0, \sigma_{j} \neq 0\right)=\operatorname{Prob}\left(\sigma_{i}=0\right) \cdot \operatorname{Prob}\left(\sigma_{j} \neq 0\right)=\eta^{0}\left(1-\eta^{0}\right) \\
\operatorname{Prob}\left(\sigma_{i}=0, \sigma_{j}=\sigma\right)=\operatorname{Prob}\left(\sigma_{i}=0\right) \cdot \operatorname{Prob}\left(\sigma_{j}=\sigma\right)=\eta^{0} \eta^{\sigma} \\
\operatorname{Prob}\left(\sigma_{i} \neq \sigma, \sigma_{j}=\sigma\right)=\operatorname{Prob}\left(\sigma_{i} \neq \sigma\right) \cdot \operatorname{Prob}\left(\sigma_{j}=\sigma\right)=\left(1-\eta^{\sigma}\right) \eta^{\sigma} \\
\operatorname{Prob}\left(\sigma_{i}=\sigma, \sigma_{j}=\sigma^{\prime}\right)=\operatorname{Prob}\left(\sigma_{i}=\sigma\right) \cdot \operatorname{Prob}\left(\sigma_{j}=\sigma^{\prime}\right)=\eta^{\sigma} \eta^{\sigma^{\prime}}=\eta^{\sigma} \frac{\left(1-\eta^{\sigma}-\eta^{0}\right)}{N_{c}-1}
\end{gathered}
$$

Consideramos ainda $k_{i}=\langle k\rangle, k_{j}=\left\langle k_{v}\right\rangle, k_{j}^{\sigma}=\left\langle k_{v}\right\rangle \eta^{\sigma} \mathrm{e}$

$k_{j}^{\sigma^{\prime}}=\left\langle k_{v}\right\rangle \eta^{\sigma^{\prime}}=\left\langle k_{v}\right\rangle \frac{\left(1-\eta^{\sigma}-\eta^{0}\right)}{N_{c}-1}{ }^{4}$, e assim obtivemos

$$
\begin{gathered}
\Delta \eta^{0}=-\frac{\langle k\rangle}{\left\langle k_{v}\right\rangle^{2}}\left[\left\langle k_{v}\right\rangle\left(1-\eta^{0}\right)+1\right] \eta^{0}\left(1-\eta^{0}\right) \\
\Delta \eta^{\sigma}=\frac{\langle k\rangle}{\left\langle k_{v}\right\rangle} \eta^{\sigma}\left[\frac{\eta^{0}}{\left\langle k_{v}\right\rangle}+\left(1-\eta^{\sigma}\right) \eta^{\sigma}-\frac{\left(1-\eta^{\sigma}-\eta^{0}\right)^{2}}{N_{c}-1}\right]
\end{gathered}
$$

Estamos interessados em encontrar as configurações estacionárias do MSC, isto é, as configurações em que $\Delta \eta=0$. Analisando a equação 3.3, a condição de estacionariedade nos indica (supondo a aproximação de campo médio válida) que configurações com $\eta^{0}=0$ ou $1^{5}$ devem implicar num número constante de eleitores indecisos. A estabilidade destas

\footnotetext{
${ }^{4}$ Note que, diferentemente das redes regulares, o grau médio de um vizinho $\left\langle k_{v}\right\rangle$, não necessariamente equivale ao grau médio de um vértice $\langle k\rangle$.

${ }^{5}$ Por esperarmos valores de $\eta^{0}$ entre 0 e 1 , desprezamos a raiz, da equação $3.3, \eta^{0}=1+\frac{1}{\left\langle k_{v}\right\rangle}>1$.
} 
configurações pode ser obtida pela linearização de $\Delta \eta^{0}$ nos valores estacionários, isto é, analisando $\frac{\partial}{\partial \eta^{0}} \Delta \eta^{0}$ nos pontos $\eta^{0}=0,1$. Como

$$
\frac{\partial}{\partial \eta^{0}} \Delta \eta^{0}=-\frac{\langle k\rangle}{\left\langle k_{v}\right\rangle^{2}}\left[\left(\left\langle k_{v}\right\rangle+1\right)-2\left(2\left\langle k_{v}\right\rangle+1\right) \eta^{0}+3\left\langle k_{v}\right\rangle\left(\eta^{0}\right)^{2}\right]
$$

$\left.\operatorname{temos} \frac{\partial}{\partial \eta^{0}} \Delta \eta^{0}\right|_{\eta^{0}=0}=-\frac{\langle k\rangle\left(\left\langle k_{v}\right\rangle+1\right)}{\left\langle k_{v}\right\rangle^{2}}<0$ e $\left.\frac{\partial}{\partial \eta^{0}} \Delta \eta^{0}\right|_{\eta^{0}=1}=\frac{\langle k\rangle}{\left\langle k_{v}\right\rangle^{2}}>0$, indicando a estabilidade da solução $\eta^{0}=0$ e a instabilidade da solução $\eta^{0}=1$. Este resultado obtido era esperado, se analisadas as regras do modelo: a configuração com todos os eleitores indecisos $\left(\eta^{0}=1\right.$ ) é claramente absorvente ${ }^{6}$ (pois $\eta^{\sigma}=0$ para qualquer $\sigma$ ), mas instável, pois apenas um eleitor decidido a votar em um candidato nunca voltaria à indecisão; por outro lado, a configuração em que nenhum eleitor está indeciso $\left(\eta^{0}=0\right)$ também é estacionária, no que toca o número de eleitores indecisos, (segundo o MSC nenhum eleitor pode tornar-se novamente indeciso) mas estável, dado que um pequeno número de indecisos tende a se extingüir.

A análise do MSC não deixa claro, no entanto, quais são as configurações absorventes do sistema no caso $\eta^{0}=0$. Pela equação 3.4 percebemos que a condição de estacionariedade implica em valores de $\eta^{\sigma}=0, \frac{1}{N_{c}}$ e 1 . A estabilidade destas soluções depende de

$$
\frac{\partial}{\partial \eta^{\sigma}} \Delta \eta^{\sigma}=\frac{\langle k\rangle}{\left\langle k_{v}\right\rangle} \frac{N_{c}}{N_{c}-1}\left[-\frac{1}{N_{c}}+2\left(\frac{N_{c}+1}{N_{c}}\right) \eta^{\sigma}-3\left(\eta^{\sigma}\right)^{2}\right]
$$

$\left.\mathrm{e} \frac{\partial}{\partial \eta^{\sigma}} \Delta \eta^{\sigma}\right|_{\eta^{\sigma}=0}=-\frac{\langle k\rangle}{\left\langle k_{v}\right\rangle\left(N_{c}-1\right)}<0,\left.\frac{\partial}{\partial \eta^{\sigma}} \Delta \eta^{\sigma}\right|_{\eta^{\sigma}=\frac{1}{N_{c}}}=\frac{\langle k\rangle}{\left\langle k_{v}\right\rangle N_{c}}>0\left(\right.$ para $\left.N_{c}>1\right) \mathrm{e}$ $\left.\frac{\partial}{\partial \eta^{\sigma}} \Delta \eta^{\sigma}\right|_{\eta^{\sigma}=1}=-\frac{\langle k\rangle}{\left\langle k_{v}\right\rangle}<0$. Na realidade, dado que existem vários candidatos, tratamse de duas configurações distintas. Em uma delas, o candidato $\sigma$ tem a totalidade dos votos enquanto os outros candidatos não tem nenhum e a configuração é estável pois tanto $\eta^{\sigma}=0$ como $\eta^{\sigma}=1$ são estáveis. A outra configuração estacionária, instável, corresponderia a todos os candidatos com o mesmo número de votos $\frac{1}{N_{c}}$, sendo que cada eleitor seria rodeado por vizinhos que discordam de sua opinião, impossibilitando, assim, pares de vizinhos que votem no mesmo candidato. Esta configuração poderia de fato existir em algumas redes, mas na rede BA alguns eleitores têm um número de vizinhos muito maior que $N_{c}$, inviabilizando esta configuração.

Concluímos, então, que o MSC deve de fato levar à configurações em que $\sigma(i, T)=C$ para qualquer $i$, ou seja, todos os eleitores votando num mesmo candidato.

\footnotetext{
${ }^{6}$ Entendemos por configuração absorvente a configuração em que a dinâmica cessa: o sistema "congela" nesta configuração.
} 


\subsubsection{Relação entre grau do eleitor inicial o candidato vencedor}

Lembrando que, segundo o modelo, inicialmente cada candidato conta com apenas 1 eleitor inicial, pode-se esperar que características topológicas dos eleitores iniciais na rede tenham influência sobre a configuração final do sistema. A primeira característica do eleitor inicial, por nós observada, foi o grau do vértice associado ao eleitor inicial. Intuitivamente, podese pensar que quão maior o grau de um eleitor inicial de determinado candidato, maior seriam as chances deste candidato dominar a rede após o transiente.

Utilizamos simulações numéricas para observar uma possível relação entre o grau do eleitor inicial de um candidato e o número de vitórias deste. É importante notar que a distribuição de grau dos eleitores obedece uma lei de potência $p_{k} \sim k^{-3}$ (como visto pela equação 2.1), pois trata-se de uma rede Barabási-Albert. Por serem escolhidos aleatoriamente, a distribuição de eleitores também segue a mesma lei de potência.

Foram feitas $10^{3}$ realizações do sistema, para redes distintas com $10^{6}$ eleitores e $10^{3}$ candidatos. Identificamos, em cada realização, o grau do eleitor inicial referente ao candidato vencedor, formando, assim, uma distribuição de vitórias em função do grau do eleitor inicial. No caso de independência entre grau do eleitor inicial e vitória do candidato, a distribuição de vitórias pelo grau acompanharia a distribuição de grau dos eleitores. Se um eleitor inicial com grau alto aumentasse as chances de vitória de um candidato, deveríamos observar um desvio da distribuição de vitórias com relação à distribuição de grau dos eleitores: a primeira seria maior que a segunda para altos valores de $k$, e vice-versa.

A figura 3.3 apresenta os resultados obtidos, através da distribuição cumulativa do grau dos eleitores da rede, do grau dos eleitores iniciais e do número de vitórias por grau, que contradizem nossa intuição inicial.

Podemos perceber, pela figura indicada, que um alto grau do eleitor inicial, segundo o modelo, influencia negativamente o respectivo candidato. Por exemplo, vemos, pela figura 3.3, que nenhum candidato associado a eleitor inicial com grau $k>10^{2}$ venceu nas $10^{3}$ simulações $(\times)$, apesar de existirem eleitores iniciais com grau $k>10^{2}(\odot)$.

Aparentemente contra-intuitivo, este resultado na verdade é uma decorrência das regras de convencimento do próprio modelo: a probabilidade de convencimento é baseada na regra de convencimento por pares (IIb), que é extendida para a regra de convencimento individual (IIa). Mas, no início do processo, não existem pares e os vértices são convencidos individualmente. Ora, quanto maior o grau de um determinado eleitor inicial, menor a probabilidade de convencimento correspondente ${ }^{7}$ e, portanto, mais dificuldade terá este eleitor inicial de "difundir" sua opinião.

\footnotetext{
${ }^{7}$ Ver regra (IIa).
} 


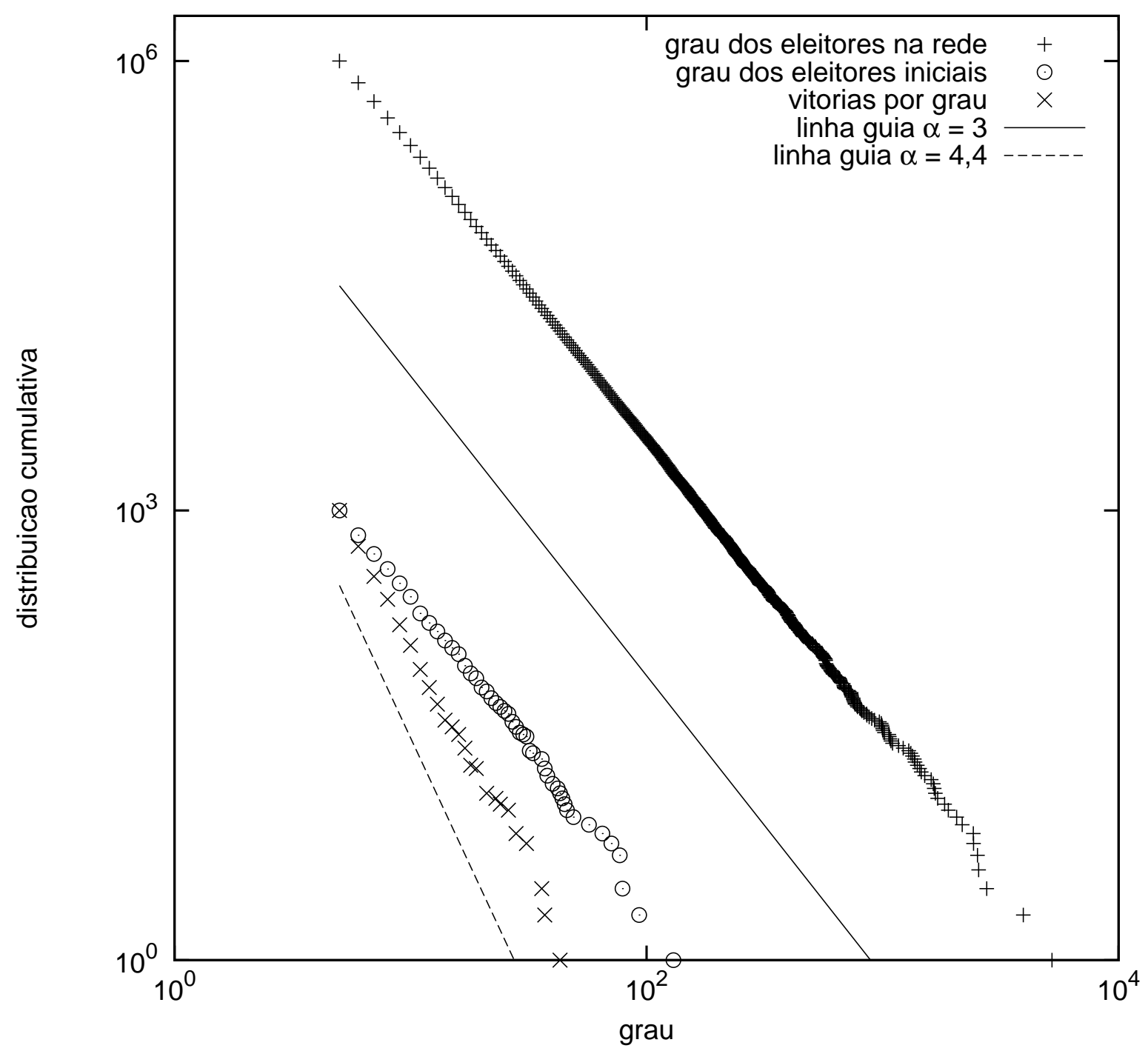

Figura 3.3: Resultados da simulação do modelo: (+) Distribuição cumulativa do grau dos eleitores de uma rede com $10^{6}$ eleitores, que obedece $p_{k} \sim k^{-3} ;(\odot)$ Distribuição cumulativa do grau de uma configuração de $10^{3}$ eleitores iniciais, que também seguem a referida lei de potência; $(\times)$ Distribuição cumulativa de vitórias em função do grau para $10^{3}$ realizações (que segue uma lei de potência $p_{k} \sim k^{-4,4}$ ).

\subsubsection{Candidato solitário}

Para melhor compreensão do papel do grau do eleitor inicial, fizemos uma série de realizações do modelo para apenas um candidato. Assim, temos que cada eleitor $i$ pode assumir apenas duas opiniões: estar indeciso ou votar no candidato, i.e., $\sigma(i, t)=0,1$. Após algum tempo $T$, todos os eleitores compartilham da mesma opinião, $\sigma(i, T)=1 \forall i$.

É interessante notar que, para distintas realizações do modelo com apenas um candidato, as curvas obtidas do número de votos pelo tempo são semelhantes, diferindo qualitativamente apenas por uma fase, como pode ser observado na figura 3.4. Podemos 
dizer que o sistema evolui de uma forma, correlacionada às condições iniciais específicas, e, após um certo número limite de eleitores deixar a indecisão, o desenvolvimento subseqüente é aproximadamente o mesmo em todas as realizações. Estes dois regimes devem-se, provavelmente, ao fato de que, no início, o crescimento do número de votos do único candidato se dá pela regra IIa (configurando o primeiro regime) e, quando o número de eleitores que votam no candidato atinge determinado valor, a ocorrência da regra IIb torna-se maior (segundo regime), por ser mais comum encontrar um vizinho de mesmo voto. Assim, a fase acima citada é, a menos de uma constante, o tempo em que o sistema permanece no primeiro regime ou o tempo que o sistema leva para que a regra IIb torne-se preponderante.

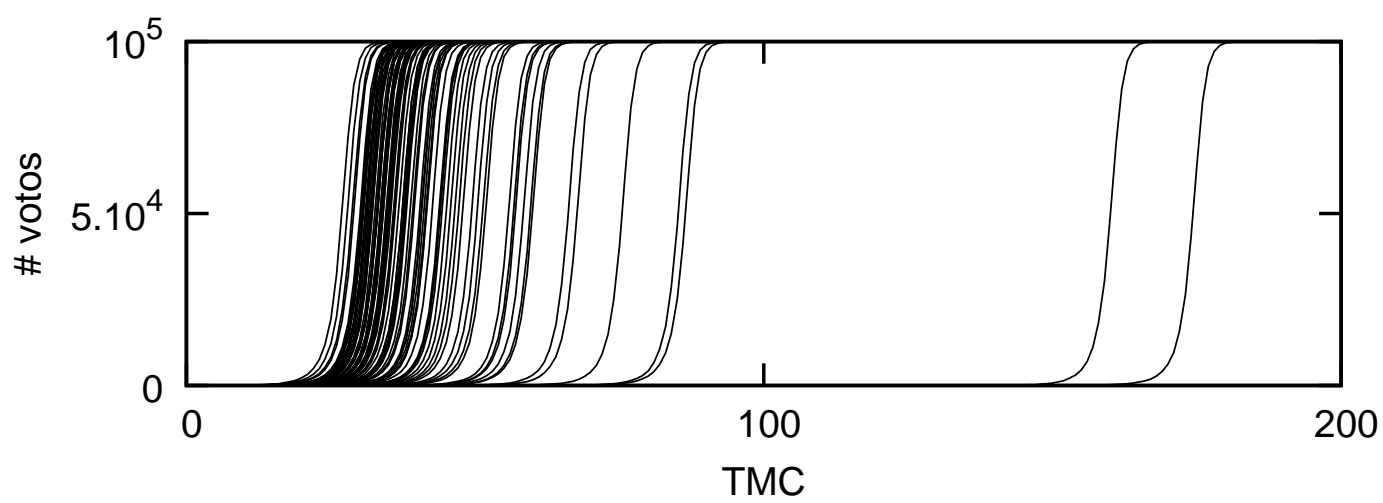

Figura 3.4: Número de votos pelo tempo, em uma rede com $10^{5}$ eleitores e um candidato.

Estudamos a relação desta fase observada com grau do eleitor inicial. Definimos a fase como sendo o tempo médio $\tau$ que o sistema leva para que metade dos eleitores votem no candidato

$$
\sum_{i=1}^{N_{v}} \sigma(i, \tau)=\frac{N_{v}}{2}
$$

A relação $\tau\left(k_{i}\right)$, foi obtida através de simulações numéricas, em que $\tau$ foi medido até 10 vezes para cada faixa de valor de grau inicial, e está apresentada na figura 3.5.

Percebe-se, pela figura 3.5, que existe uma correlação, aproximadamente linear, entre $\tau$ e o grau do eleitor inicial $k_{i}$, ao menos para valores baixos de $k_{i}$. O desvio para grandes valores de $k_{i}$ deve-se, provavelmente, a um limite no tempo de simulação e ao tamanho finito da rede, que inibe altos valores de $\tau$.

Voltemos ao caso em que vários candidatos fazem parte do processo. Supondo que o desenvolvimento inicial das componentes referentes a cada candidato é independente, hipótese razoável ao menos no início, podemos, dada a relação $\tau\left(k_{i}\right)$ obtida, reafirmar a hipótese de que os eleitores iniciais de maior grau serão desfavoráveis ao candidato a eles associados. 


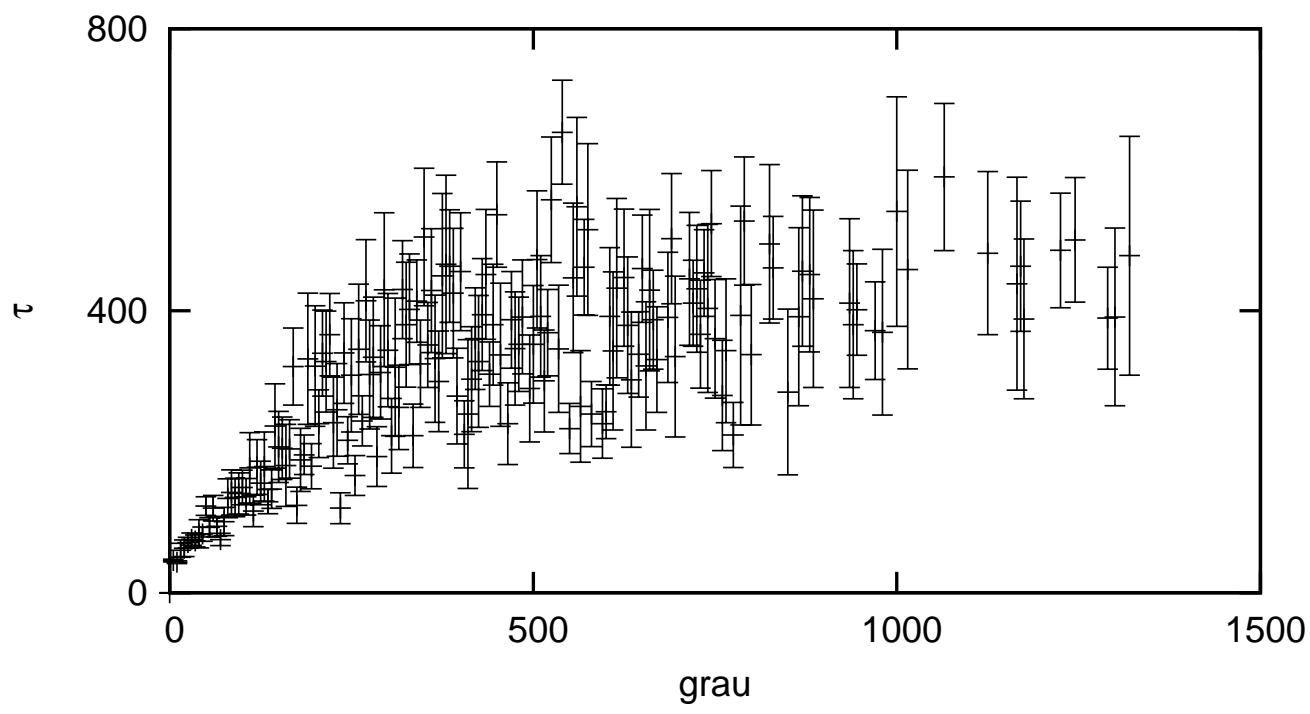

Figura 3.5: Tempo médio de convencimento de metade dos eleitores $\tau$ por grau do eleitor inicial $i, k_{i}$ numa rede com $10^{5}$ eleitores.

Somos então levados à seguinte pergunta: além do grau do eleitor inicial que outros aspectos podem influenciar o desenvolvimento de um agregado de eleitores na rede e o desempenho do respectivo candidato? Estudamos quais características configuracionais levam um determinado candidato à vitória, isto é, estudamos que fator ou variável um candidato tem no instante $t$ (por exemplo, um certo número de eleitores convencidos, um aglomerado de eleitores convencidos, etc.) que pode levá-lo a dominar o sistema em $T$.

\subsubsection{Horizontes possíveis}

Uma forma de lidar com esta questão é, ao invés de tentar descobrir diretamente qual a variável relevante, investigar quando a situação final do sistema está definida com relativa robustez, ou seja, para qual instante $t^{*}$ fica definido, pelo modelo, qual será o candidato vencedor, independente do que ocorrer após $t^{*}$.

Para estimar $t^{*}$ através de simulações, nos baseamos na idéia de que uma configuração que, de maneira robusta, conduza um candidato à vitória, deve fazê-lo com relativa independência em relação aos sorteios referentes à dinâmica do modelo.

Assim, procedemos da seguinte forma: fazemos uma simulação do sistema partindo da condição inicial usual e deixamos o sistema evoluir até o instante $t^{\prime}$; registramos a configuração neste instante $t^{\prime}$ e continuamos a simulação até que um candidato vença; retornamos o sistema para a configuração em $t^{\prime}$ e continuamos a simulação, com sorteios distintos do caso anterior, até que um candidato (eventualmente distinto) vença; repetimos o procedimento anterior $n>N_{c}$ vezes (para possibilitar que todos os candidatos ganhem 


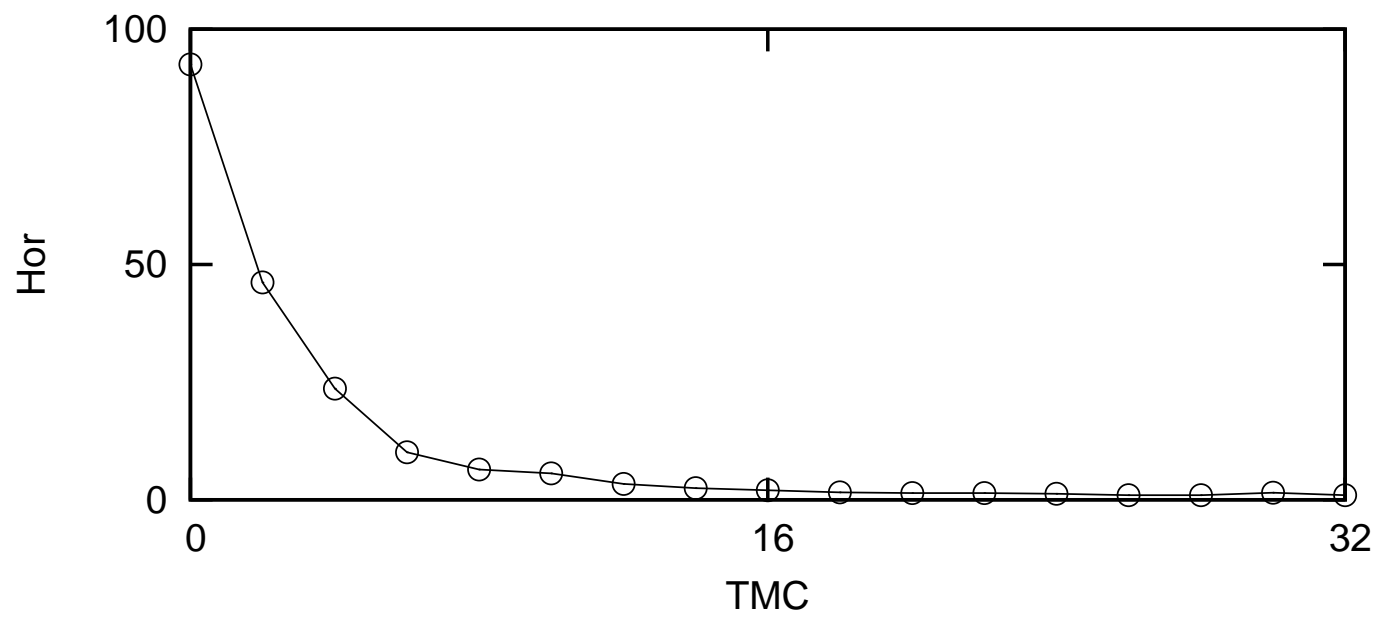

Figura 3.6: Horizontes possíveis em função de t : Média de 100 realizações distintas de $\operatorname{Hor}(t)$, com $n=400$, num sistema com $N=10^{5}$ eleitores.

pelo menos uma vez) e anotamos o número de candidatos distintos que venceu, Hor. Temos então que Hor indica, aproximadamente, o número de candidatos que ainda têm chances de vencer no instante $t^{\prime}$. Ou seja, Hor $(t)$ indica quantos horizontes são ainda possíveis no instante $t$. Fazendo o procedimento para $0 \leq t^{\prime}<T$, obtém-se a relação $H o r(t)$, que estima quantos candidatos ainda podem vencer a cada instante $t$. A figura 3.6 apresenta a média de 100 Hor $(t)$ distintas, para $n=400$, em um sistema sob MSC com $10^{5}$ eleitores e $10^{2}$ candidatos.

Dada a queda abrupta de $\operatorname{Hor}(t)$, podemos dizer que, para uma rede com $10^{5}$ eleitores, após $t^{*} \simeq 20 \mathrm{TMC}$ o sistema está praticamente determinado. Note que, neste instante, apenas uma fração pequena de eleitores (aproximadamente 15\%) já tem opinião. Procuramos então encontrar, neste instante $t^{*}$, alguma característica que indicasse o candidato vencedor.

\subsubsection{Visualização da dinâmica}

Para auxiliar nossa procura da variável que indique a robustez do sistema frente o estado final utilizamos representações gráficas das redes. Criamos convenções de representação gráfica do MSC, que serão descritas a seguir, e as imagens foram geradas pelo programa neato [22].

A primeira definição diz respeito ao grau dos vértices (dos eleitores): representamos os vértices como figuras geométricas cuja área é proporcional ao grau do mesmo. A figura 3.7, por exemplo, deixa clara a relação entre o grau do vértice e a área que tem sua representação (no caso o vértice 1 tem grau $k_{1}=9$, o 2 tem grau $k_{2}=4$ e os restantes 
têm grau 1).

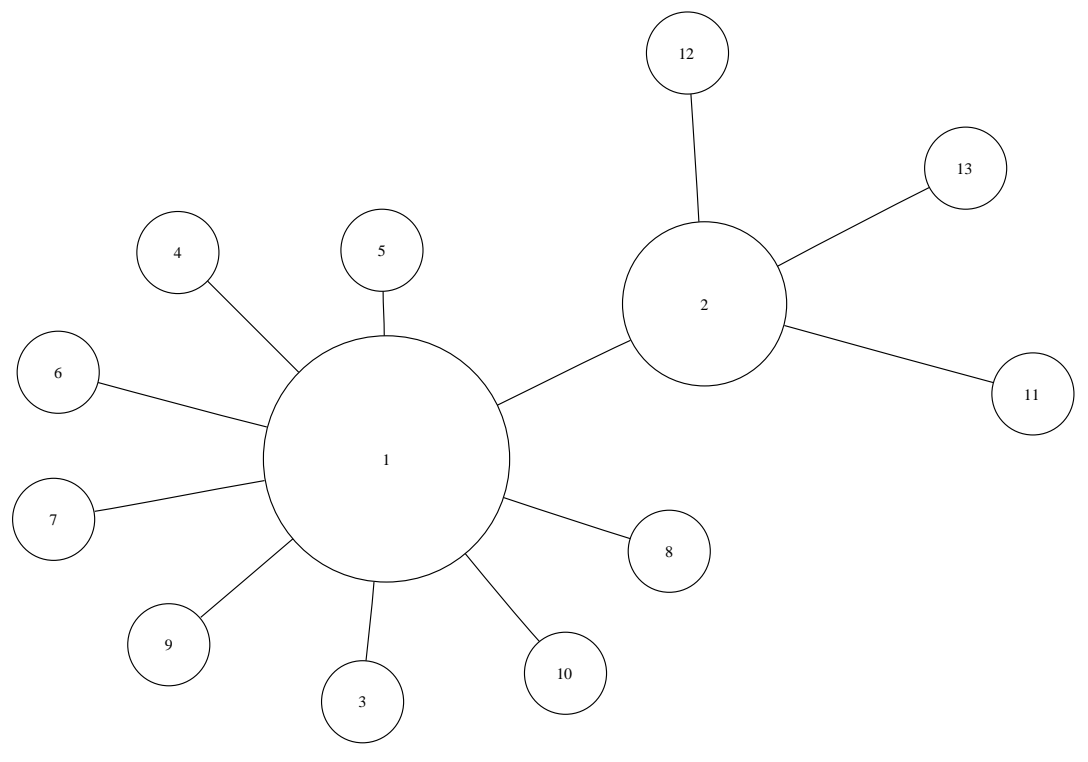

Figura 3.7: Relação entre área do polígono e grau do vértice associado.

Como vemos $k_{1}=9$ e $k_{2}=4$, o que implica em círculos de áreas 9 e 4 respectivamente. Cada candidato é representado por uma cor distinta, e os eleitores iniciais, ao invés de serem representados por círculos, aparecem representados por quadrados (cuja área também é proporcional ao grau do vértice associado) com o rótulo na cor branca.

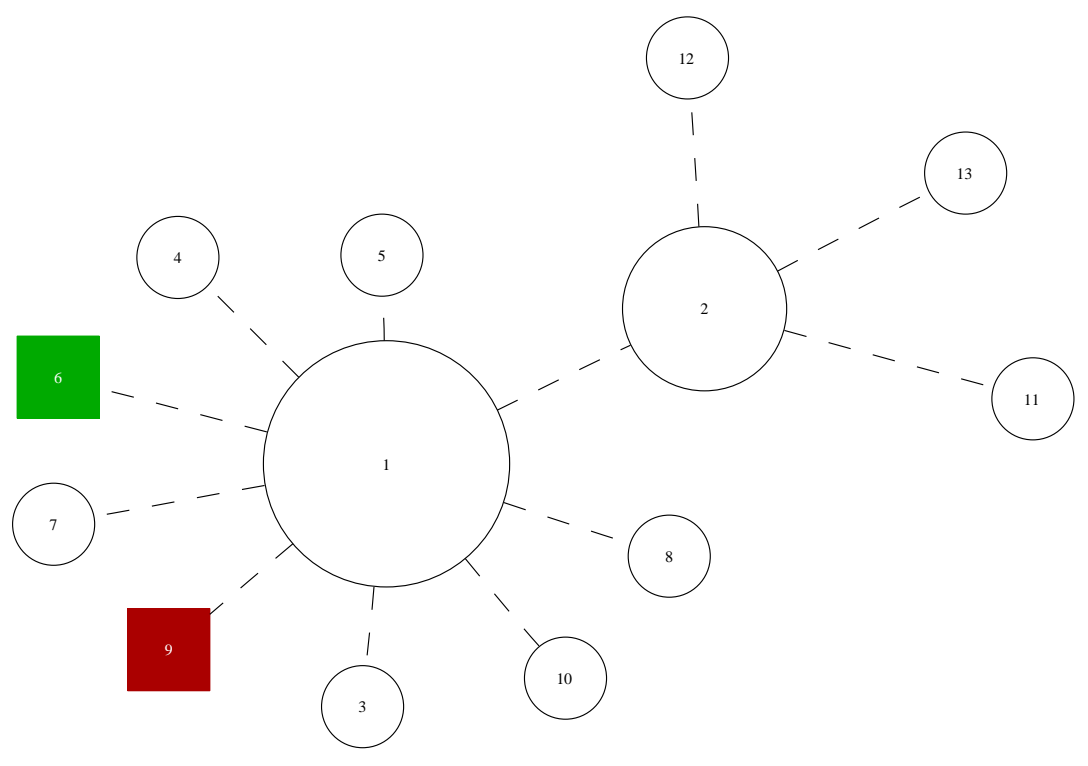

Figura 3.8: Eleitores iniciais tem a forma de um quadrado, cada cor corresponde a um candidato e as arestas são representadas por traços interrompidos.

As arestas da rede subjacente serão representadas por traços interrompidos, como 
em 3.8. No entanto, se porventura um eleitor $i$ convence outro $j$ então a aresta $i j$ será representada por um traço contínuo, como pode-se ver em 3.9 e em 3.10 (chamaremos esta aresta de "principal").

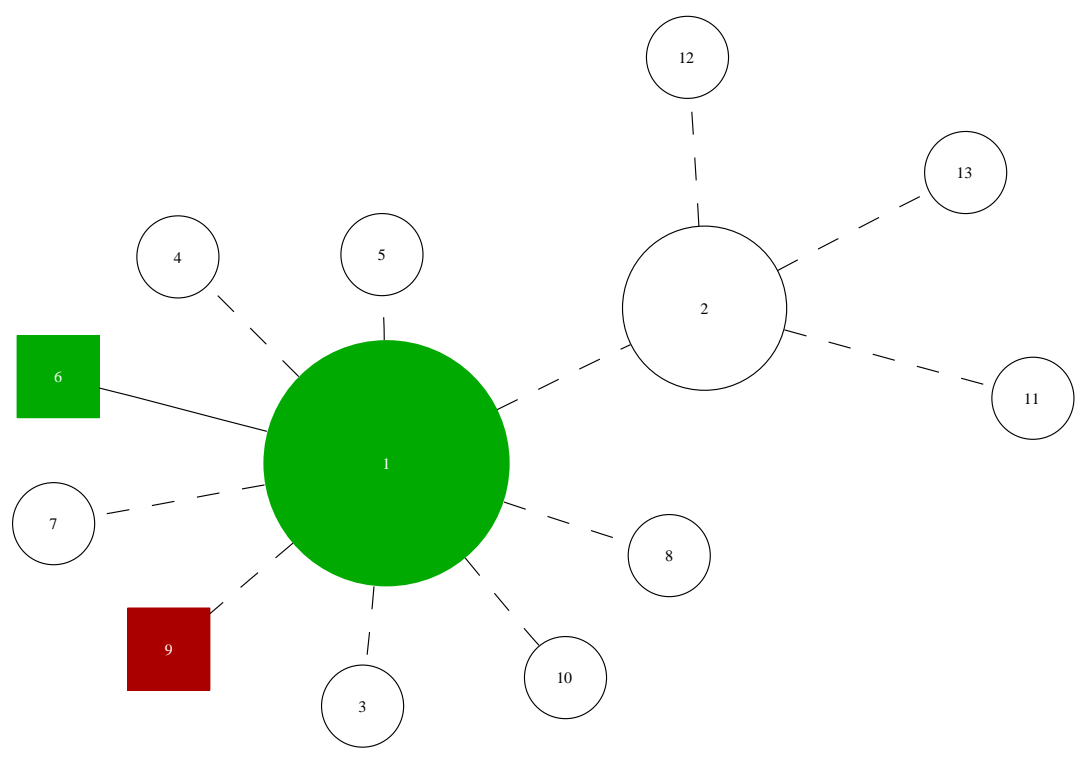

Figura 3.9: 1 foi convencido por 6,6 ganha a cor de 1 e a aresta $1-6$ torna-se contínua.

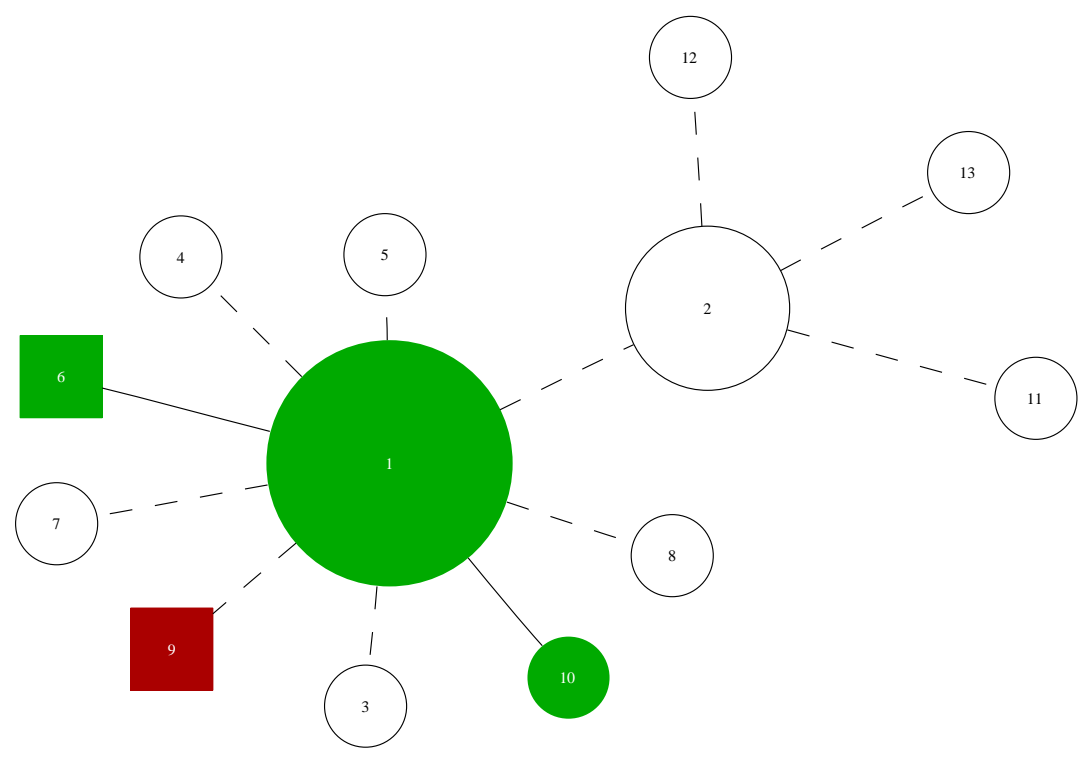

Figura 3.10: 1 escolheu 10 e, com probabilidade $\frac{1}{9}$, o convenceu.

Caso um vértice seja convencido segundo a regra (IIb), seu rótulo será preto e não branco. Pode, ainda segundo (IIb), ocorrer de um vértice $j$ que já escolheu um candidato $(\sigma(j, t) \neq 0)$ ser convencido por outro vértice $i \operatorname{com} \sigma(i, t) \neq \sigma(j, t)$, e neste caso um novo 
círculo, da cor de $\sigma(i, t)$ será adicionado sobre a representação de $j$, e o rótulo indicará, em preto, que o vértice $j$ foi convencido por $i$ através da expressão j.i. A figura 3.11 exemplifica estes casos.

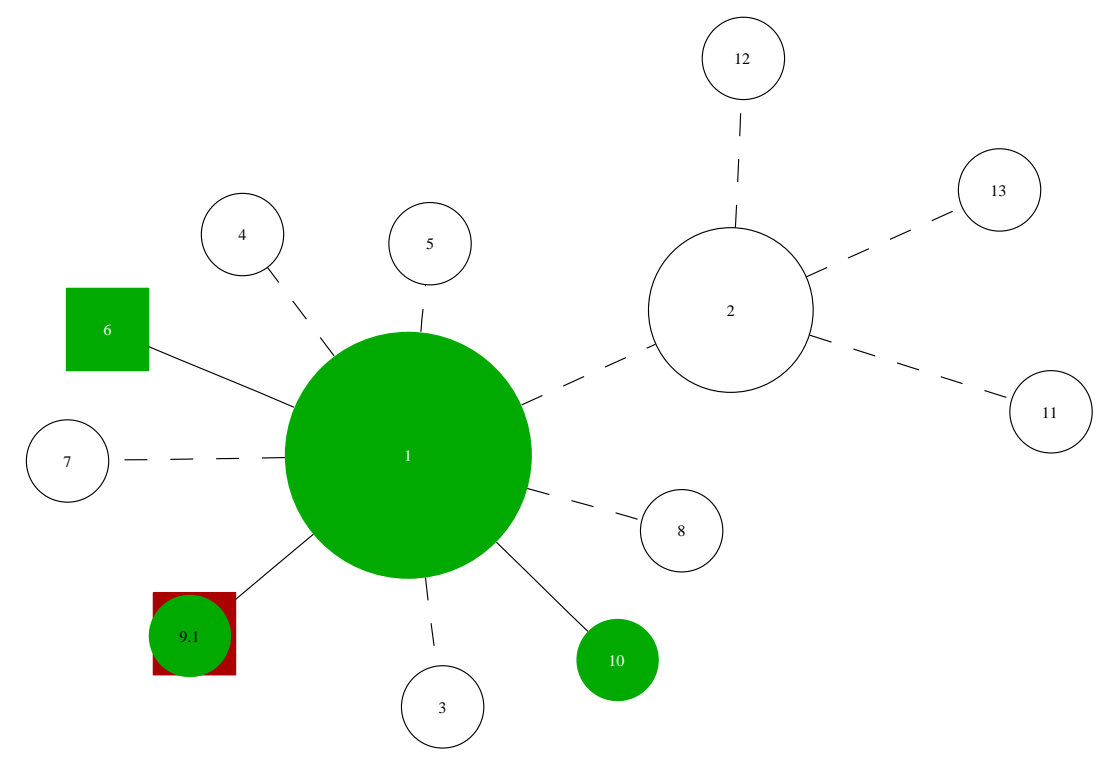

Figura 3.11: Vértice 9 é convencido por 1 em conjunto com 6 ou 10, assim, um círculo com a cor $\sigma(1, t)$ é sobreposto à 9 , e o rótulo 9.1, agora em preto, indica que 9 mudou de opinião por conta de 1 . A aresta $9-1$ tornou-se contínua.

Como para uma rede relativamente pequena a representação gráfica pode se tornar confusa e demasiadamente carregada, optamos por, na maioria dos casos, omitir da representação os vértices indecisos, como vemos em 3.12.

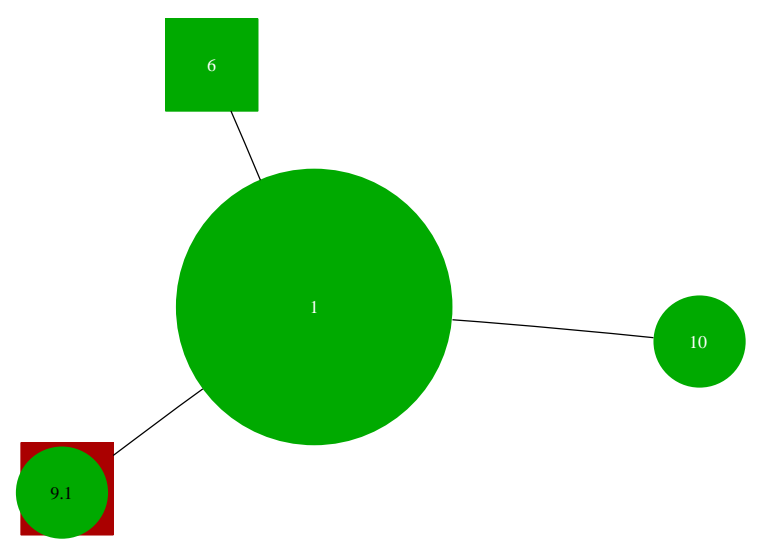

Figura 3.12: Vértices indecisos $l \mid \sigma(l, t)=0$ são omitidos para simplificar visualização.

O próximo passo é obter a representação gráfica de uma rede (um mapa) em um instante $t=t^{*}$. Como visto anteriormente, para uma rede com $10^{5}$ eleitores $t^{*} \simeq 20 \mathrm{TMC}$ 
e, neste instante, aproximadamente $15 \%$ dos eleitores não estão mais indecisos. Teríamos portanto que obter um mapa com $1,5 \cdot 10^{4}$ eleitores, que, além da difícil visualização (numa folha A4 seriam no máximo $4 \mathrm{~mm}^{2}$ por eleitor e rótulo, desconsiderando o espaço entre eleitores e o espaço para as arestas), consumiria um tempo de processamento e uma memória excessivos. Assim, resolvemos fazer a "análise gráfica" para redes menores, com $10^{3}$ eleitores e 10 candidatos, acreditando que características do processo em questão permaneçam válidas. Para esta rede a função $\operatorname{Hor}(t)$ se comporta segundo a figura 3.13.

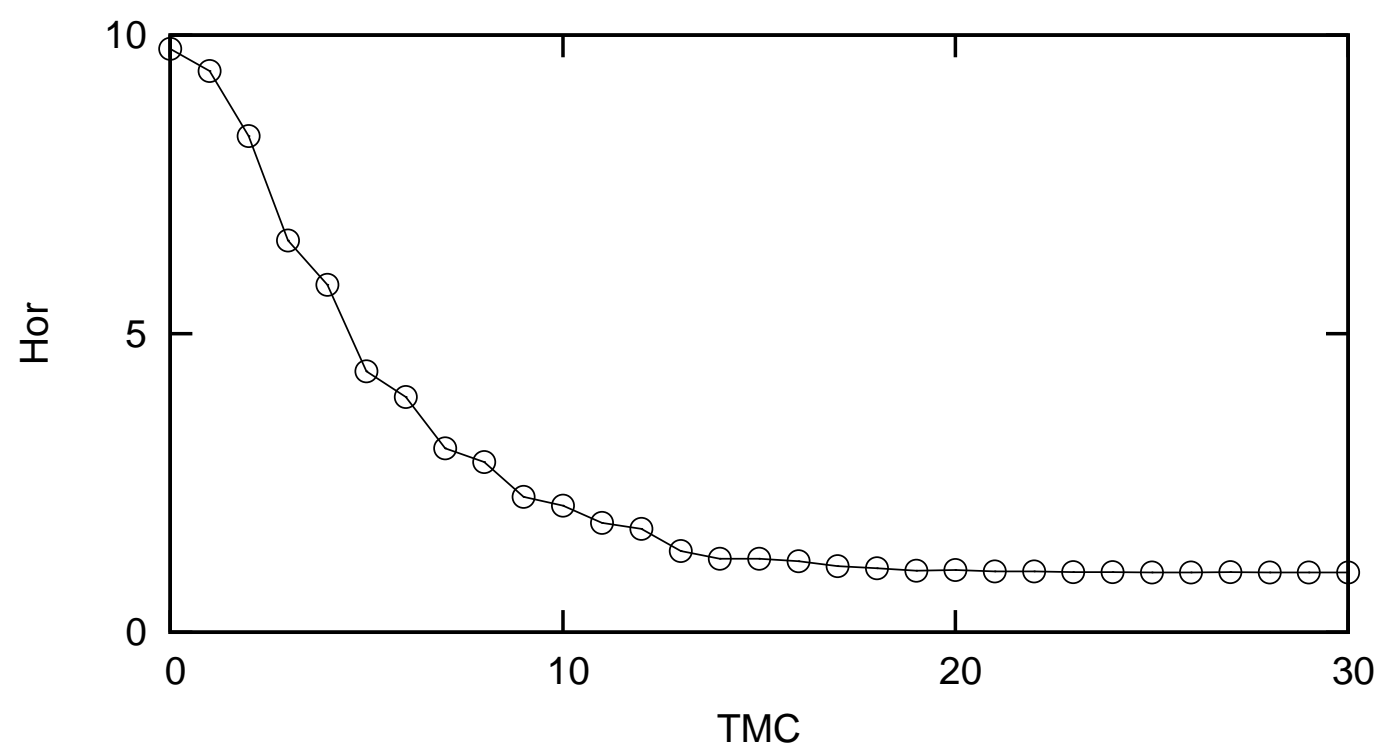

Figura 3.13: $\operatorname{Hor}(t)$ para $10^{3}$ eleitores e 10 candidatos, média sobre $10^{2}$ realizações e $n=40$.

Podemos ver que $t^{*} \simeq 13$ TMC. Fizemos então o mapa (a representação gráfica) de algumas realizações do sistema para $t=13 \simeq t^{*}$, e a figura 3.14 exemplifica o resultado obtido $^{8}$.

Com dificuldade pode-se identificar as comunidades formadas pelos vértices de uma determinada opinião (cor) e optamos por observar também o mapa do mesmo sistema, no mesmo instante, porém incluindo apenas as arestas principais, como pode ser observado na figura 3.15 .

A realização relacionada às figuras 3.14 e 3.15 chega a uma configuração absorvente, que corresponde à vitória de um candidato para $t=T$. No caso, vence o candidato representado pela cor salmão, apesar de perder, em $t=13 \simeq t^{*}$, para o "candidato verdeclaro" - como pode ser visto nos mapas. Assim, deveríamos encontrar, na "componente salmão" alguma característica topológica que levasse o "candidato salmão" à vitória em

\footnotetext{
${ }^{8}$ Apesar de conter $10^{3}$ eleitores a representação inclui apenas os 205 vértices convencidos, conforme procedimento descrito anteriormente.
} 


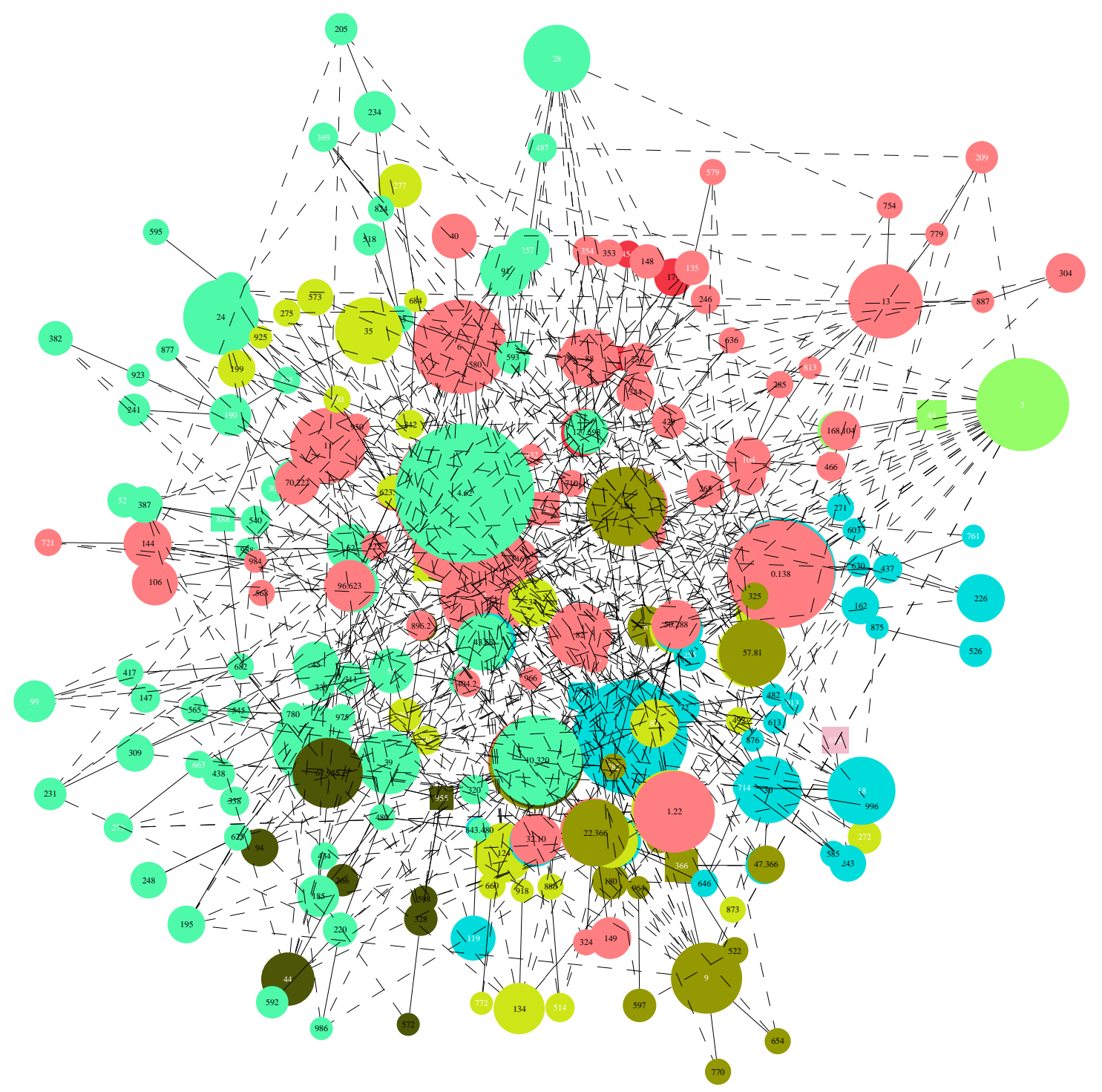

Figura 3.14: Mapa de rede com $10^{3}$ eleitores e 10 candidatos após 13 TMC. 


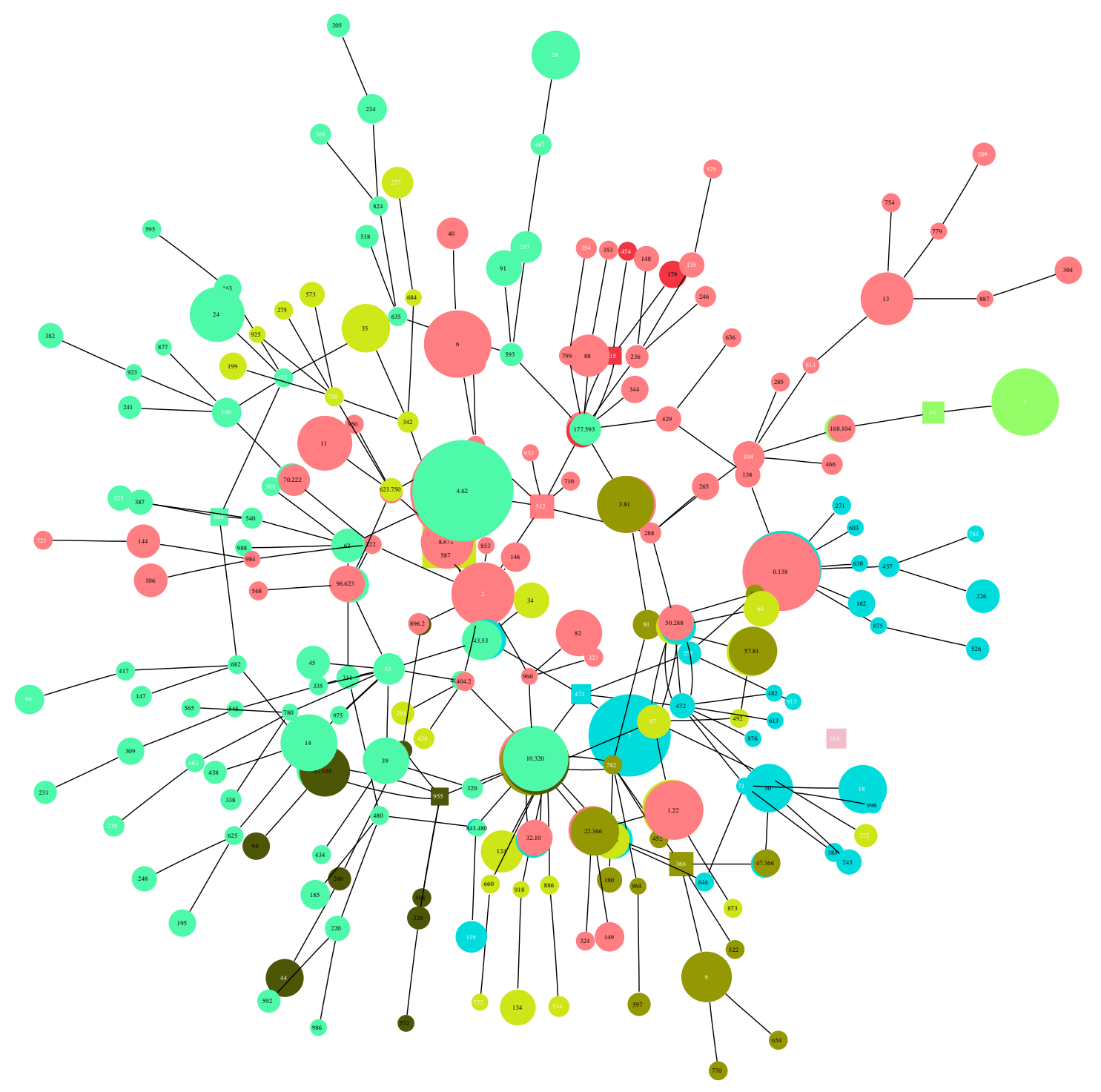

Figura 3.15: Mapa de rede, incluindo apenas arestas "principais", com $10^{3}$ eleitores e 10 candidatos após 13 PMCs. 
$T$.

Apesar de analisarmos uma série de mapas para $t=13 \simeq t^{*}$ percebemos que pouca informação relativa a robustez de determinada "componente" poderia ser obtida desta forma. Como as figuras 3.14 e 3.15 mostram, mesmo para uma rede pequena $\left(10^{3}\right)$ a visualização da rede não nos fornece a intuição esperada para a compreensão do problema.

\subsubsection{Robustez}

Outra possível abordagem da questão da robustez do sistema para $t \simeq t^{*}$ seria procurar, para cada candidato $\sigma$, alguma variável $x(\sigma, t)$ que, para o candidato que vence em $t=T$, fosse máxima em $t \simeq t^{*}$.

Uma hipótese inicial seria considerar $x(\sigma, t)$ simplesmente o número de votos do candidato $\sigma$ no instante $t$. Para verificá-la fizemos $10^{3}$ realizações do sistema $\left(10^{5}\right.$ eleitores e $10^{2}$ candidatos) e, para cada uma delas, encontramos a diferença de votos $\Delta$ votos $(t)$ entre o candidato vencedor $\sigma_{v}$ (aquele que vence em $T$ ) e o candidato mais votado (que não $\sigma_{v}$ ) a cada iteração. Assim, $\Delta$ votos $(t)$ mede a diferença de votos entre o candidato que, ao final do processo, se tornaria hegemônico e o candidato (distinto daquele) com maior votos. A figura 3.16 apresenta os resultados obtidos.

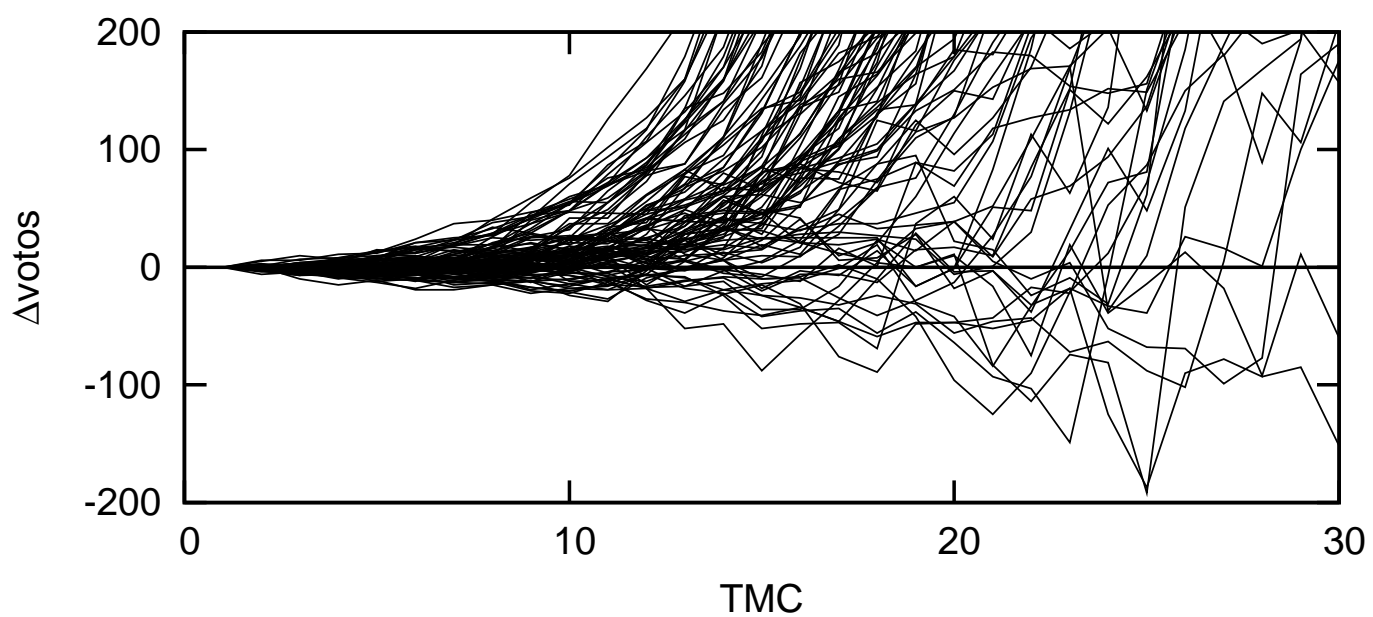

Figura 3.16: Diferença de votos entre o candidato vencedor (em $T$ ) e o candidato melhor votado para $10^{3}$ realizações distintas do sistema, com $10^{5}$ eleitores e $10^{2}$ candidatos.

Para $t \rightarrow T$ temos que $\Delta$ votos $(t) \rightarrow N$, como esperado. Percebemos ainda que, para as $10^{3}$ realizações, apenas em $73(7,3 \%)$ o candidato vencedor não tinha atingido a maioria já em $t \simeq t^{*}\left(\Delta \operatorname{votos}\left(t^{*}\right)<0\right)$ o que nos leva a crer que o número de votos em $t \simeq t^{*}$ é uma forte indicação da configuração final atingida pelo sistema.

Poderíamos ainda nos perguntar sobre alguma outra característica da configuração 
do sistema em $t=t^{*}$ que indicasse, com uma robustez maior que o número de votos, o candidato (em $T$ ) $\sigma_{v}$. Ou seja, procuramos outra função $x(\sigma, t)$ que fosse máxima para $\sigma_{v}$ em $t^{*}$, mesmo que o número de votos de $\sigma_{v}$ não fosse máximo em $t^{*}$. Assim, poderíamos, ao sermos confrontados por um sistema que desconhecemos a evolução até $T$, calcular $x\left(\sigma, t^{*}\right)$, encontrar $\sigma_{v}$ que maximiza esta função e afirmar (ainda em $t^{*}$ ) que o candidato $\sigma_{v}$ dominaria o sistema em $T$.

Observamos, então, a vizinhança $\Gamma(\sigma, t)$ de cada dominio (conjunto de eleitores que votam em um mesmo candidato) referente ao candidato $\sigma$. Mais especificamente, demos atenção ao número de vizinhos $|\Gamma(\sigma, t)|$ de cada domínio, que pode ser compreendido como uma superfície de contato do grupo de eleitores de opinião $\sigma$ com eleitores de opinião distinta. Dado que cada domínio cresce inicialmente, segundo o modelo, de forma conexa, pode-se acreditar que $|\Gamma(\sigma, t)|$ seja uma característica relevante para o sistema. Tendo ainda em mente o modelo, é sabido (pela regra IIa) que eleitores indecisos $(\sigma=0)$ têm uma probabilidade maior de serem convencidos e, portanto, um domínio com muitos vizinhos indecisos teria seu crescimento favorecido, o que nos levou a acompanhar também o número de vizinhos indecisos $\left|\Gamma_{0}(\sigma, t)\right|$.

Outra possível variável intimamente relacionada com as regras do modelo, chamada aqui de $G(\sigma, t)$, seria a estimativa de crescimento de um domínio: a cada iteração o eleitor $i$ tem probabilidade $\frac{k_{i}^{0}}{k_{i}}$ de encontrar um de seus $k_{i}^{0}$ vizinhos indecisos e o convence probabilidade $\frac{1}{k_{i}}$ (regra IIa); por outro lado $i$ pode encontrar, como probabilidade $\frac{k_{i}^{\sigma}}{k_{i}}$, um vizinho entre os $k_{i}^{\sigma}$ de mesma opinião $\left(\sigma_{i}=\sigma_{j}=\sigma\right)$ e $i$ convenceria aproximadamente $\frac{k_{i}-k_{i}^{\sigma}}{k_{i}}$ enquanto $j$ convenceria aproximadamente o mesmo número de vizinhos (regra IIb); espera-se, então, que cada eleitor $i$ convença

$$
g_{i}=1 \frac{k_{i}^{0}}{k_{i}} \frac{1}{k_{i}}+2 \frac{k_{i}^{\sigma}}{k_{i}} \frac{k_{i}-k_{i}^{\sigma}}{k_{i}}=\frac{k_{i}^{0}+2 k_{i}^{\sigma}\left(k_{i}-k_{i}^{\sigma}\right)}{k_{i}^{2}}
$$

vizinhos; o domínio $\sigma$ tem "potencial de crescimento" $G(\sigma, t)^{9}$ dado por

$$
G(\sigma, t)=\sum_{i \mid \sigma_{i}=\sigma} g_{i}
$$

Seria interessante, por fim, acompanhar ainda o desenvolvimento do grau máximo $\Delta(\sigma, t)$ dos domínios pois, ao "conquistar" um eleitor altamente conectado, a dinâmica de crescimento poderia ser alterada.

Realizamos uma série de simulações numéricas acompanhando $|\Gamma|,\left|\Gamma_{0}\right|, G$ e $\Delta$ em

\footnotetext{
${ }^{9} \mathrm{~A}$ dependência de $G$ com relação ao tempo se dá tanto pela modificação dos eleitores que compõe um determinado domínio como pela variação de $k_{i}^{0}$ e $k_{i}^{\sigma}$ de cada eleitor.
} 
função do tempo, esperando que, para $t \simeq t^{*}$, alguma destas variáveis se destacasse para o candidato $\sigma_{v}$, que venceria em $t=T$. A figura 3.17 apresenta os resultados para uma simulação ( $10^{5}$ eleitores e $10^{2}$ candidatos) que expressam qualitativamente o resultado obtido na totalidade das simulações.
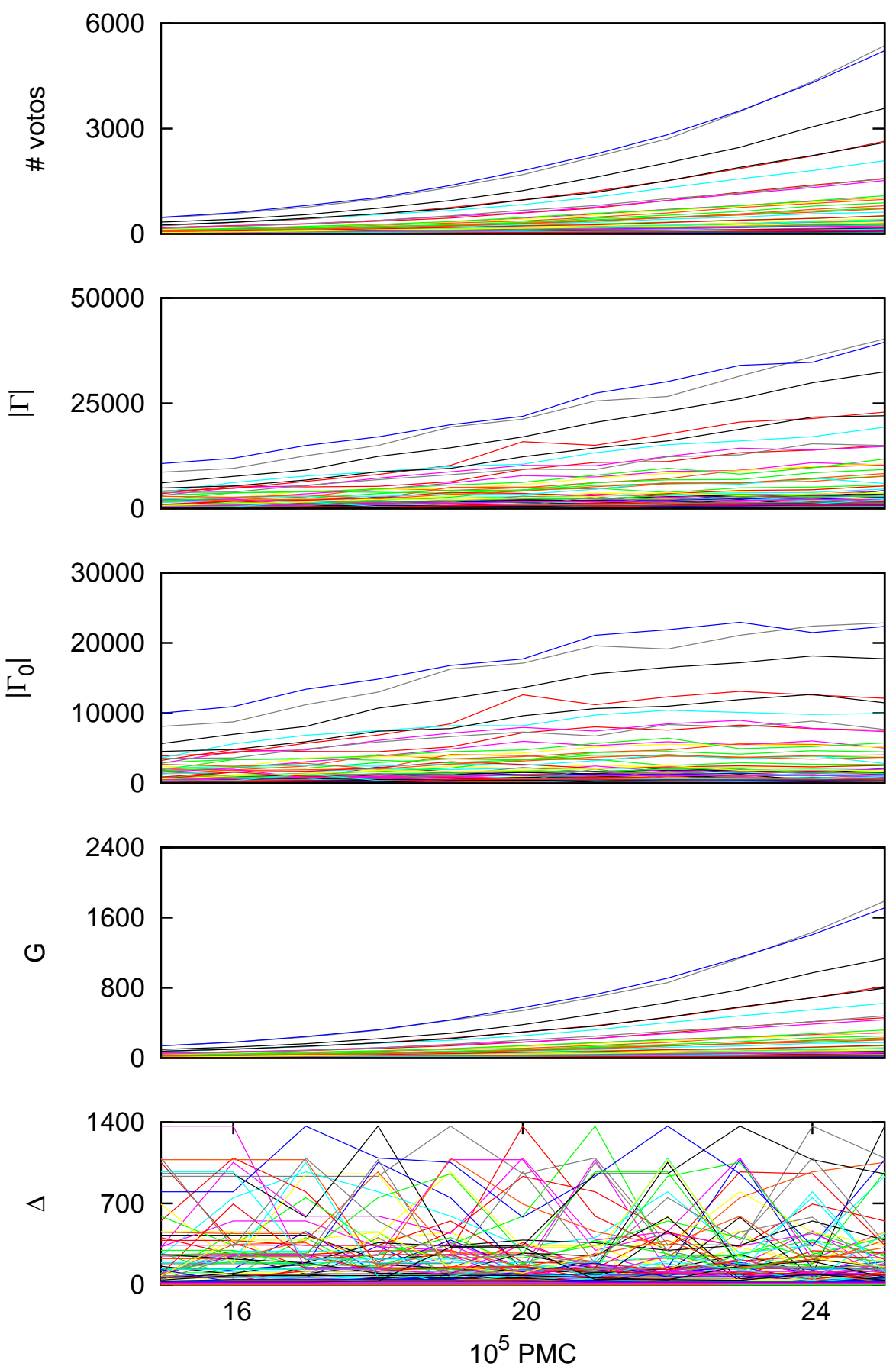

Figura 3.17: Gráficos, para uma simulação com $10^{5}$ eleitores, do número de votos, do número de vizinhos $(|\Gamma|)$, do número de vizinhos indecisos $\left(\left|\Gamma_{0}\right|\right)$, da função $G$ e do grau máximo $(\Delta)$ de cada um dos $10^{2}$ candidatos, entre 15 e 25 TMC. 
O gráfico no topo da figura 3.17 mostra que, na simulação escolhida, o candidato vencedor (cinza) perde para o candidato azul para $t^{*} \simeq t=20$ TMC. Devemos então comparar $|\Gamma|,\left|\Gamma_{0}\right|, G$ e $\Delta$ em $t=20$ para os domínios cinza e azul, com o intuito de verificar se alguma das variáveis tem maior valor para o domínio cinza que para o azul ${ }^{10}$. Percebemos, no entanto, que $|\Gamma|,\left|\Gamma_{0}\right|$ e $G$ acompanham "grosso modo" o número de votos de cada candidato e, portanto, não constituem índices qualitativamente melhores que o número de votos para avaliar a robustez de determinada componente para $t \simeq t^{*}$. Analisando o gráfico de $\Delta(\sigma, t)$ percebemos que os eleitores de maior grau na rede mudam constantemente de opinião (seriam, pictoricamente falando, extremamente volúveis, segundo o modelo), provavelmente pelo "assédio" do grande número de vizinhos. Percebemos ainda que $\Delta(\sigma, t)$ não têm influência direta sobre a configuração final (no caso apresentado os eleitores de maior grau da rede rodiziam entre os candidatos, não estabilizando no cinza).

Concluímos então, após a análise do modelo de Sznajd na rede de Barabási-Albert aqui descrita, que o candidato com eleitor inicial de grau baixo terá um crescimento inicial mais rápido e em um instante $t^{*} \ll T$ a configuração final do sistema estará praticamente definida, sendo o candidato com maior número de votos (em $\left.t^{*}\right)$ aquele que dominará o sistema.

\footnotetext{
${ }^{10}$ Obviamente esta análise foi feita para um conjunto de simulações e não apenas para a realização relatada, que representa suas semelhantes.
} 


\section{Capítulo 4}

\section{Modificações do modelo de Sznajd}

Neste capítulo apresentamos alterações do Modelo de Sznajd introduzidas para verificarmos a influência do que poderíamos chamar, pictoricamente, diferentes estratégias de campanha. Alteramos as regras de convencimento entre os eleitores de forma a mimetizar, durante todo o processo de campanha, dois principais efeitos: a existência de candidatos com cabos eleitorais e a influência de campanhas publicitárias.

A existência de cabos eleitorais é modelada através de inomogeinedades ou defeitos na rede e a campanha publicitária através da inserção de uma probabilidade do eleitor não seguir o que determinaria o modelo e adotar um candidato aleatório, um ruído na dinâmica ${ }^{1}$. Defeitos em redes e ruído em dinâmicas são "ingredientes" comuns a modelos físicos, e assim, menos por adequações empíricas, as modificações aqui implementadas têm o objetivo de colaborar para a compreensão mais geral das características estatísticas das redes complexas, e da influência dessas características no comportamento de modelos como o modelo Sznajd.

\subsection{Defeitos}

A primeira mudança que introduzimos no MSC diz respeito ao que seria a existência de "cabos eleitorais", pessoas que não mudariam de opinião em hipótese alguma mas que continuariam influenciando seus vizinhos, o que representa a introdução de um defeito na rede. Mobilia propôs em [23] uma alteração no modelo do votante em um reticulado (ver seção 5.1) que segue esta proposta: um sítio específico da rede (o cabo eleitoral) tende a ficar no estado +1 . Mobilia resolve o modelo analiticamente e constata que, para uma ou duas dimensões a opinião de todos os outros eleitores será influenciada pelo cabo

\footnotetext{
${ }^{1}$ Apesar da dinâmica original ser probabilística e ter, portanto, um ruído intrínseco, utilizaremos, de acordo com a literatura correlata (ver, por exemplo, [17]), o termo ruído para designar a possibilidade do sistema não seguir as regras originais.
} 
eleitoral, enquanto que, no reticulado cúbico, só uma fração dos eleitores será afetada. Em [24], Mobilia e Georgiev generalizaram este tratamento para um número maior de cabos eleitorais.

Aqui, a modificação proposta é dividida em duas partes. Na primeira fazemos com que cada candidato tenha $q$ eleitores iniciais e não apenas um, minimizando assim os efeitos que uma distribuição de graus de eleitores inicial desigual poderia causar. Então, consideramos que os $q$ eleitores iniciais de um (e apenas um) candidato específico não mudam de opinião durante o processo, mesmo que uma dupla (regra (IIb)) tente convencê-lo.

Acompanhamos realizações deste processo, que chamamos de "modelo de Sznajd com cabo eleitoral na rede de Barabási-Albert", comparando-as com simulações paralelas, em que o número de eleitores iniciais de cada candidato foi $q$, mas sem cabos eleitorais (todos os vértices podiam mudar de opinião). Prosseguimos da seguinte forma: Criamos duas redes idênticas, isto é, listamos todos os vértices e as suas vizinhanças. Sorteamos, para cada candidato, $q$ eleitores iniciais, que serão os mesmos nas duas redes. Então, realizamos o processo paralelamente nas duas redes (a ordem de escolha dos vértices, de seus vizinhos e a tentativa de convencimento) com a diferença que, em uma das rede (a de controle) todos os vértices podem mudar de opinião, enquanto na outra os eleitores iniciais de um candidato são cabos eleitorais e, assim, não mudam de opinião.

Fazendo 100 comparações para sistemas ( $10^{5}$ eleitores) com $q=1,5,10,30,50$ e 100 cabos eleitorais, percebemos que, como pode ser visto na figura 4.1, com o aumento do número de cabos eleitorais o sistema tem uma maior probabilidade de ter seu resultado final alterado ${ }^{2}$, ou seja, aumenta a chance do sistema atingir uma configuração absorvente distinta da que o mesmo sistema, sem cabos eleitorais, atingiria.

Cabe ressaltar que para um número relativamente pequeno de cabos introduzidos, o sistema teve seu comportamento global alterado de maneira robusta (para 100 cabos eleitorais, o que equivaleria a introdução de defeito em $0,1 \%$ da rede, $63 \%$ dos resultados finais foram alterados).

Para qualificar a diferença que os defeitos introduzem ao sistema utilizamos o conceito de distância de Hamming $H(t)$ : a cada TMC contabilizamos o número de vértices que apresenta, na rede de controle, opinião distinta do mesmo vértice na rede com cabo eleitorais. Considerando $\sigma(i, t)$ e $\sigma^{\prime}(i, t)$ a opinião do sítio $i$ nas redes de controle e com cabos eleitorais respectivamente podemos expressar a distãncia de Hamming por:

$$
H(t)=\sum_{i=1}^{N}\left(1-\delta_{\sigma, \sigma^{\prime}}\right)
$$

\footnotetext{
${ }^{2}$ Deve-se notar que, no caso do modelo com cabos eleitorais consideramos, atingida a configuração final quando todos eleitores que não são cabos compartilhassem a mesma opinião. Esta configuração apresentaria possivelmente os cabos eleitorais com opinião distinta dos demais (e não seria rigorosamente absorvente), mas dificilmente o sistema sairia dela, dado o baixo número de cabos eleitorais.
} 


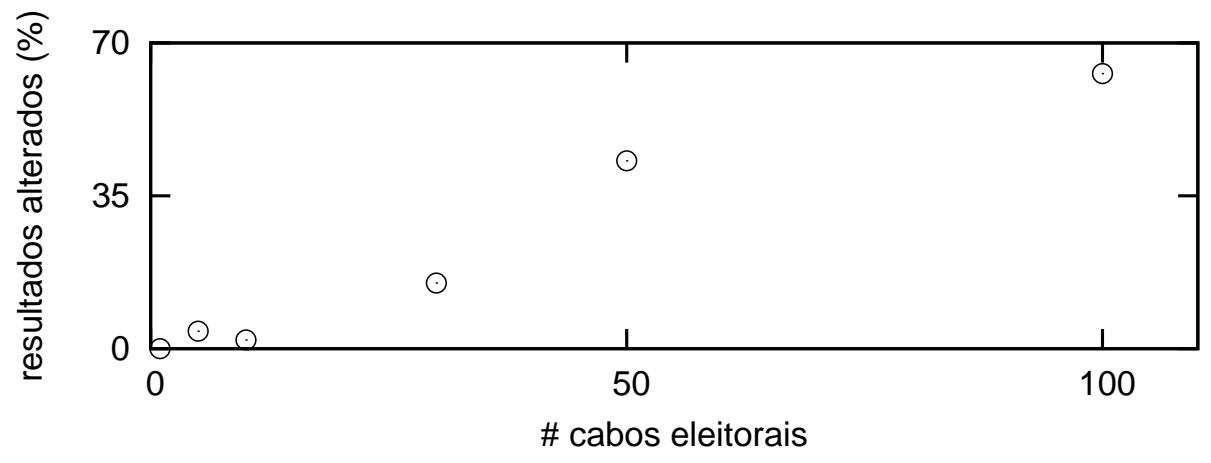

Figura 4.1: Número de vezes, em 100 comparações, em que diferentes estados congelados finais foram atingidos pelos sistemas com e sem cabos eleitorais, em função da quantidade de cabos eleitorais.

onde $\delta$ é a função delta de Kronecker. A figura 4.2 exemplifica o processo, ao mostrar o desenvolvimento nas duas redes (controle e cabos eleitorais) bem como a distância de Hamming em função do tempo associada.
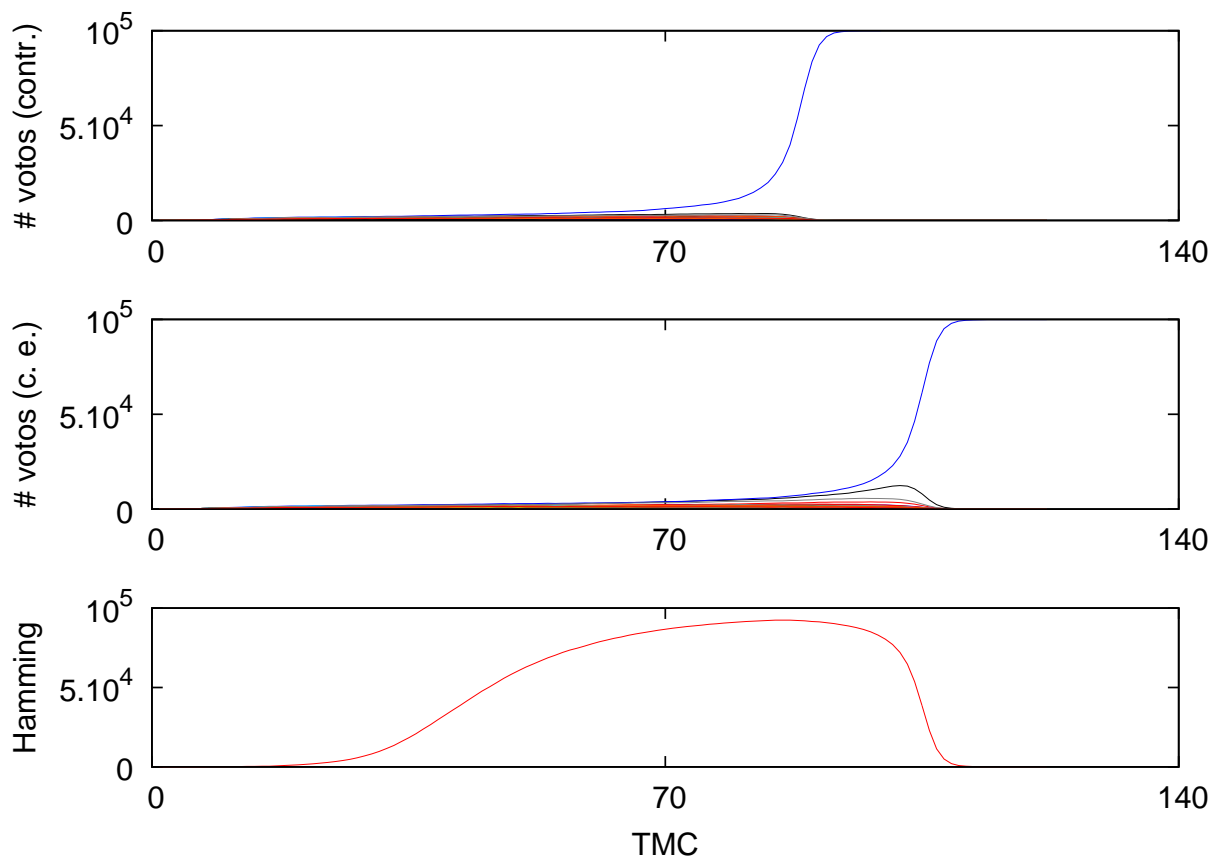

Figura 4.2: Realizações paralelas do modelo em (acima) rede de controle e (centro) rede com cabos eleitorais. Distância de Hamming associada (abaixo).

As figuras 4.3-4.7 apresentam a distância de Hamming em função do tempo para as 100 comparações em sistemas com 1, 5, 10, 30, 50 e 100 cabos eleitorais.

Como pode-se perceber pelas figuras 4.3-4.7, numa rede com 10 cabos eleitorais $(0,01 \%$ da rede), as duas simulações (controle e cabo eleitoral) chegaram em algum momento a 


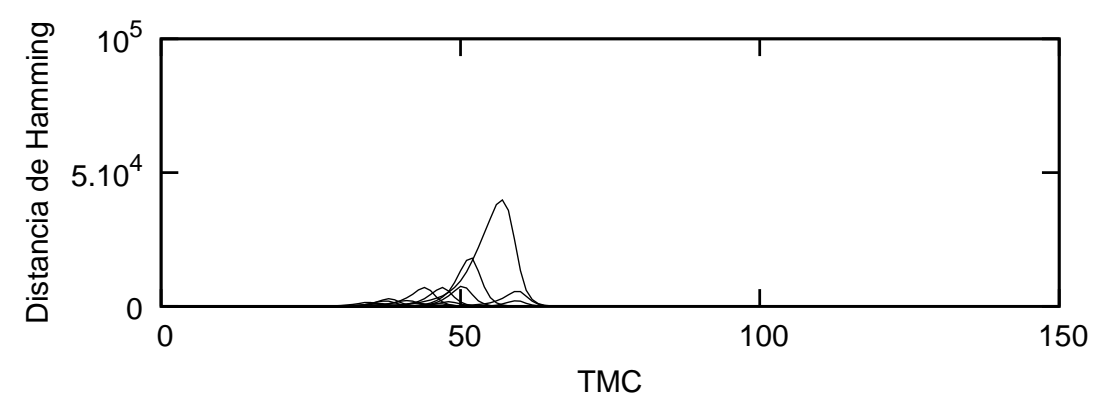

Figura 4.3: Distância de Hamming para $10^{2}$ realizações de sistemas com 1 cabo eleitoral.

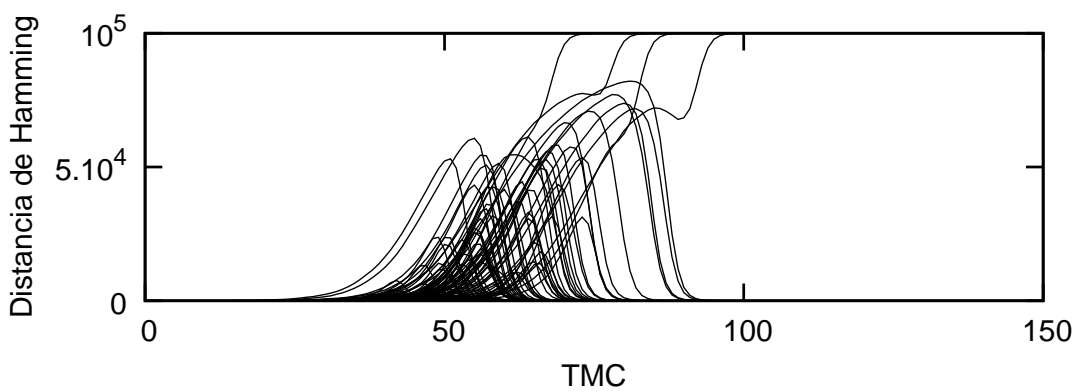

Figura 4.4: Distância de Hamming para $10^{2}$ realizações de sistemas com 5 cabos eleitorais.

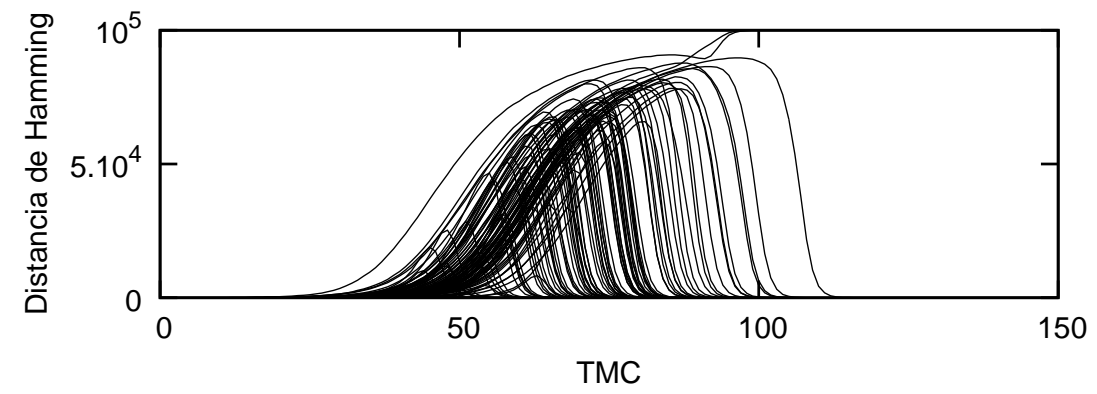

Figura 4.5: Distância de Hamming para $10^{2}$ realizações de sistemas com 10 cabos eleitorais.

ter aproximadamente $90 \%$ de seus vértices com opiniões distintas e, na grande maioria dos casos, o estado congelado foi o mesmo. Esse resultado corrobora a idéia apresentada na seção 3.1.4: pouco tempo depois de iniciado o processo de convencimento, as componentes adquirem uma característica específica, que determinará o desenvolvimento do sistema, isto é, as primeiras iterações levam o sistema a um estado robusto, que evoluirá para um estado congelado independentemente de possíveis perturbações sobre o sistema. 


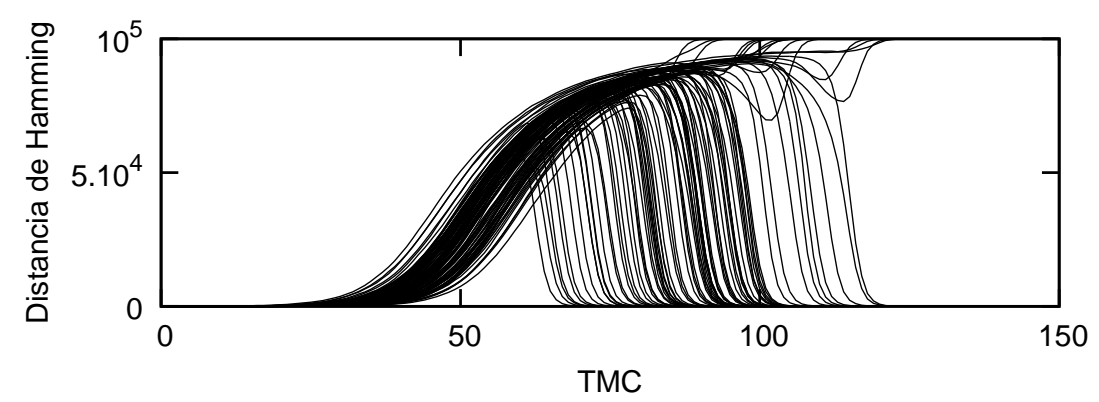

Figura 4.6: Distância de Hamming para $10^{2}$ realizações de sistemas com 30 cabos eleitorais.

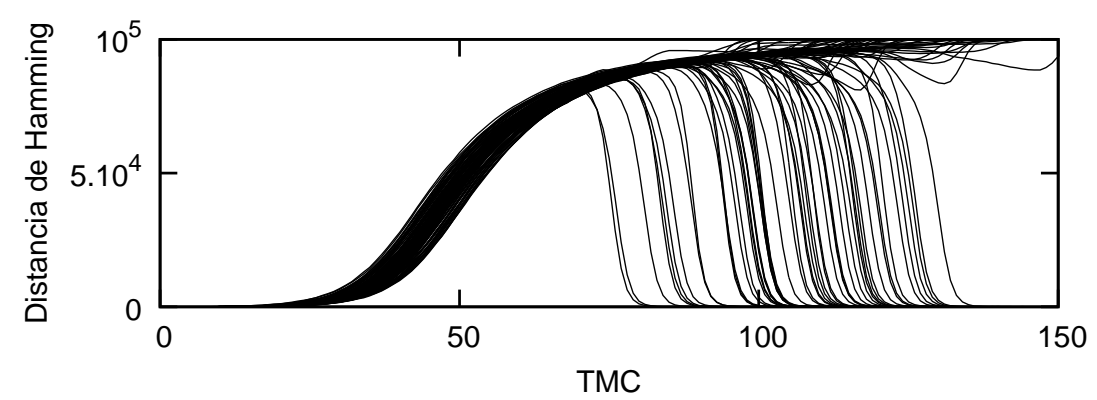

Figura 4.7: Distância de Hamming para $10^{2}$ realizações de sistemas com 50 cabos eleitorais.

\subsection{Ruído}

Um fator notadamente relevante em eleições gerais é a campanha publicitária. Assim, modificamos o modelo de Sznajd em uma rede de Barabási-Albert original para incluirmos o papel do que seria uma campanha publicitária em eleições proporcionais, assim como Sznajd propôs em seu modelo original [17].

O efeito das campanhas publicitárias foi introduzido no modelo através de um parâmetro $w$, que modifica a dinâmica do sistema da seguinte maneira: Como anteriormente, todos os eleitores são visitados, numa ordem aleatória, a cada iteração; o eleitor escolhido tentará convencer seus vizinhos da maneira anteriormente citada com probabilidade $1-w$ e, com probabilidade $w$, mudará seu voto para um candidato aleatório. Ou seja, a campanha publicitária é representada, no modelo, como um ruído que faz com que o eleitor não obedeça a dinâmica original e mude de opinião, escolhendo um candidato (estado) aleatório com probabilidade $w$. O processo pode ser entendido como uma interação não-local, ou como pelo efeito de um campo externo. 


\subsubsection{Simulações}

Uma primeira conseqüência direta desta modificação é o desaparecimento de uma configuração absorvente final. Mesmo partindo de uma configuração inicial em que todos os eleitores votam em um mesmo candidato, o sistema não congela, pois cada eleitor pode, com probabilidade $w$, mudar de opinião, e o número de votos de um candidato flutua com o tempo. Uma segunda conseqüência é a existência de duas fases distintas em função do parâmetro $w$ (e o parâmetro crítico $w_{c}$ é o valor de $w$ em que ocorre a transição entre as duas fases): para $w$ baixo um candidato tem a maioria dos votos e os outros candidatos "dividem" entre si os votos restantes (fase ordenada); para $w$ alto todos os candidatos têm aproximadamente o mesmo número de votos, $\frac{N}{N_{c}}$ (fase desordenada). O comportamento típico do sistema ( $10^{3}$ vértices $)$ nestas duas fases é exemplificado na figura 4.8.
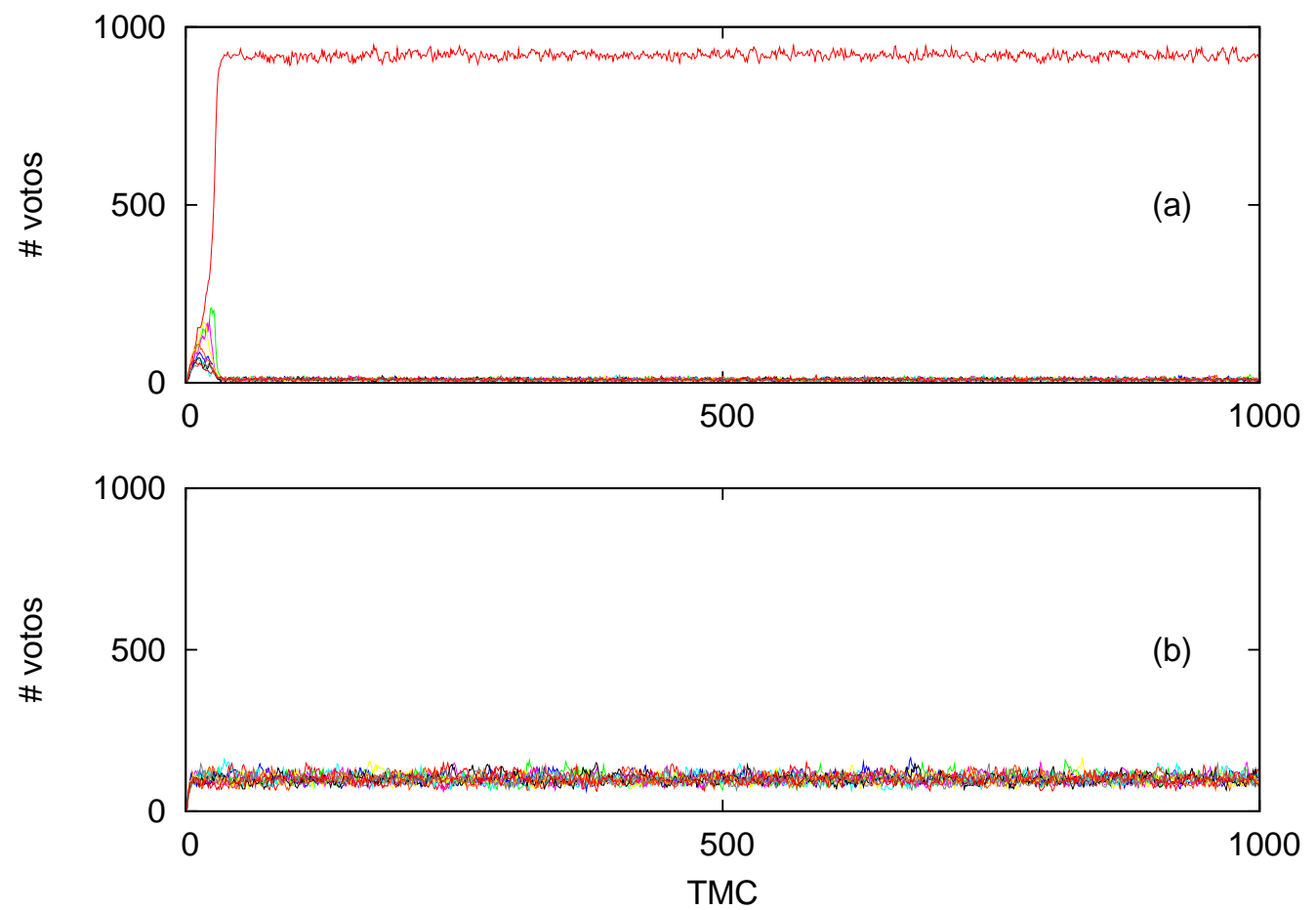

Figura 4.8: Número de votos por candidato em função do tempo para MSC com ruído. (a) $w=0,1$ e (b) $w=0,4$.

Podemos caracterizar quantitativamente as fases pelo parâmetro de ordem $\Psi(w)=M-\frac{N}{N_{c}}$, onde $M$ é a média temporal (após o sistema entrar em regime) do número de votos do candidato com maior votação, $N$ o número total de eleitores e $N_{c}$ o número de candidatos. Procedemos então à obtenção, através de simulações numéricas ${ }^{3}$, dos valores de $\Psi$ em função do parâmetro $w$. Levando em conta a possibilidade do sistema

\footnotetext{
${ }^{3} \mathrm{As}$ simulações foram realizadas em sistemas com $10^{3}$ eleitores e 10 candidatos, durante $10^{4}$ TMC.
} 
apresentar algum tipo de memória (i.e., correlação temporal), fizemos simulações, para cada $w$, com duas condições iniciais distintas: um eleitor inicial para cada candidato (todos os outros eleitores indecisos - a condição inicial padrão no MSC) e, a outra, todos eleitores votando no mesmo candidato. Chamamos estas condições iniciais de desordenada e ordenada, respectivamente.

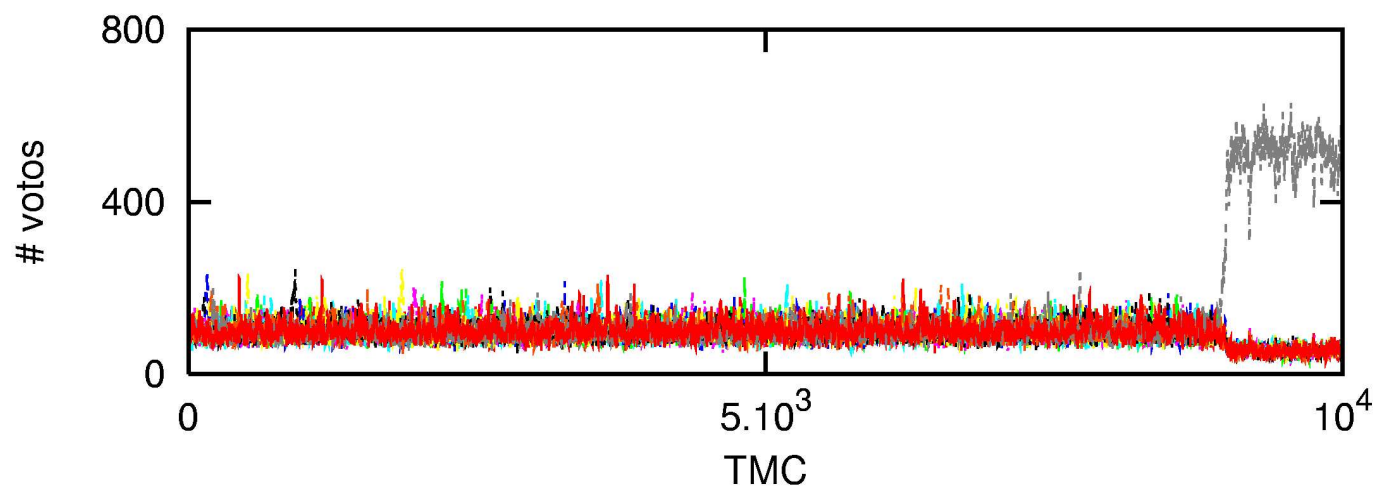

Figura 4.9: Número de votos por candidato em função do tempo para MSC com ruído $(w=0,312)$ com condição inicial desordenada.

Para valores de $w$ próximos de $w_{t}$ (tais que $0,31<w<0,32$ ), torna-se difícil avaliar se o sistema de fato entra em regime (como pode ser visto na figura 4.9). Assim, realizamos simulações mais longas ( $10^{5}$ TMCs) para estes valores de $w$, com o intuito encontrar a fase em que o sistema estabilizaria.

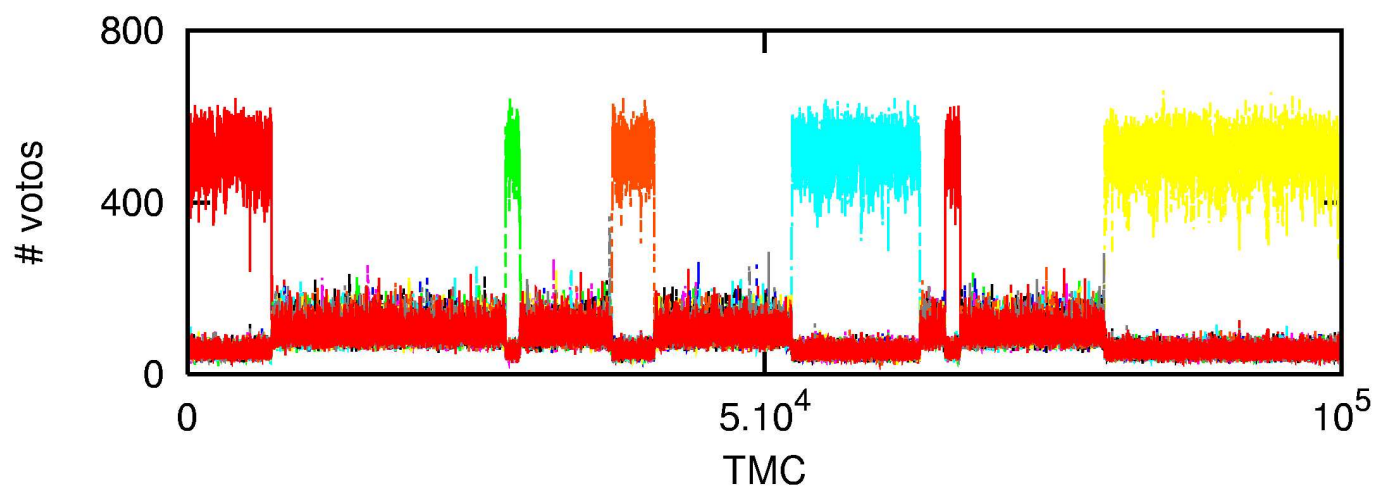

Figura 4.10: Número de votos por candidato em função do tempo para MSC com ruído $(w=0,312)$ e condição inicial ordenada.

A figura 4.10, exemplo de uma destas realizações, sugere que o sistema de fato tem, para estes valores, uma dinâmica intermitente, estando ora em uma fase ora em outra.

Dada, portanto, a dificuldade de estabelecermos em que fase o sistema se encontra quando próximo à região de transição, estabelecemos o seguinte procedimento: conside- 
ramos que a fase em que o sistema se encontra momentaneamente é definida pelo número de votos $v_{\max }$ do candidato com mais votos naquele momento; contabilizamos durante o tempo, para cada valor de $w$, quantas vezes o sistema esteve em $v_{\text {max }}$; construímos o histograma de contagens de $v_{\max }$ (figuras 4.11 e 4.12).

Nos casos em que se mostra difícil decidir em qual das fases se encontra o sistema, consideramos o sistema na fase em que permanece maior tempo (que, nas figuras $4.11 \mathrm{e}$ 4.12, é determinado pela região, esquerda ou direita, de maior área). Deve-se ressaltar que as figuras 4.11 e 4.12, apesar de utilizadas para determinar em que fase o sistesma se encontra para cada $w$, na realidade atestam a coexistência de fases próximo à transição. Obtivemos então o comportamento do parâmetro de ordem $\Psi(w)$, em função de $w$, expresso na figura 4.13 .

Trata-se de uma transição de fase de $1^{a}$ ordem, com probabilidade de transição $w_{t}$. Para $N=10^{3}$ o parâmetro de transição situa-se na faixa $0,312<w_{t}<0,315$.

\subsubsection{Aproximação de campo médio}

Assim como no caso do MSC sem ruído (ver seção 3.1.1) podemos fazer uma aproximação de campo médio para o MSC com ruído. As equações, análogas à 3.3 e 3.4 ficariam

$$
\begin{gathered}
\Delta \eta^{0}=-(1-w) \frac{\langle k\rangle}{\left\langle k_{v}\right\rangle^{2}}\left[\left\langle k_{v}\right\rangle\left(1-\eta^{0}\right)+1\right] \eta^{0}\left(1-\eta^{0}\right)-w \eta^{0} \\
\Delta \eta^{\sigma}=(1-w) \frac{\langle k\rangle}{\left\langle k_{v}\right\rangle} \eta^{\sigma}\left[\frac{\eta^{0}}{\left\langle k_{v}\right\rangle}+\left(1-\eta^{\sigma}\right) \eta^{\sigma}-\frac{\left(1-\eta^{\sigma}-\eta^{0}\right)^{2}}{N_{c}-1}\right]+ \\
+w\left[\left(1-\eta^{\sigma}\right) \frac{1}{N_{c}}-\eta^{\sigma}\left(1-\frac{1}{N_{c}}\right)\right]
\end{gathered}
$$

Os termos das equações 4.1 e 4.2 originados da aproximação de campo médio do MSC sem ruído são aqui multiplicados pelo fator $(1-w)$, que representa a fração de vértices que seguirá a dinâmica original (convencimento de vizinhos). Os outros termos expressam os vértices que optaram pela escolha aleatória de um candidato, e, por isso, são multiplicados por $w$. Assim, $-w \eta^{0}$ seria a fração de eleitores indecisos que, em 1 TMC, escolheriam algumum candidato; $w\left(1-\eta^{\sigma}\right) \frac{1}{N_{c}}$ a fração de eleitores que não votavam em $\sigma$ mas, escolheria (via escolha aleatória) o candidato $\sigma$ entre os outros $N_{c}$ candidatos; e $-w \eta^{\sigma}\left(1-\frac{1}{N_{c}}\right)$ a fração de eleitores que votava em $\sigma$, porém mudou de opinião para escolher aleatoriamente entre um de seus adversários.

Impondo $\Delta \eta^{0}=0$ encontramos os valores de $\eta^{0}$ estacionários: $\eta^{0}=0 \mathrm{e}$ 

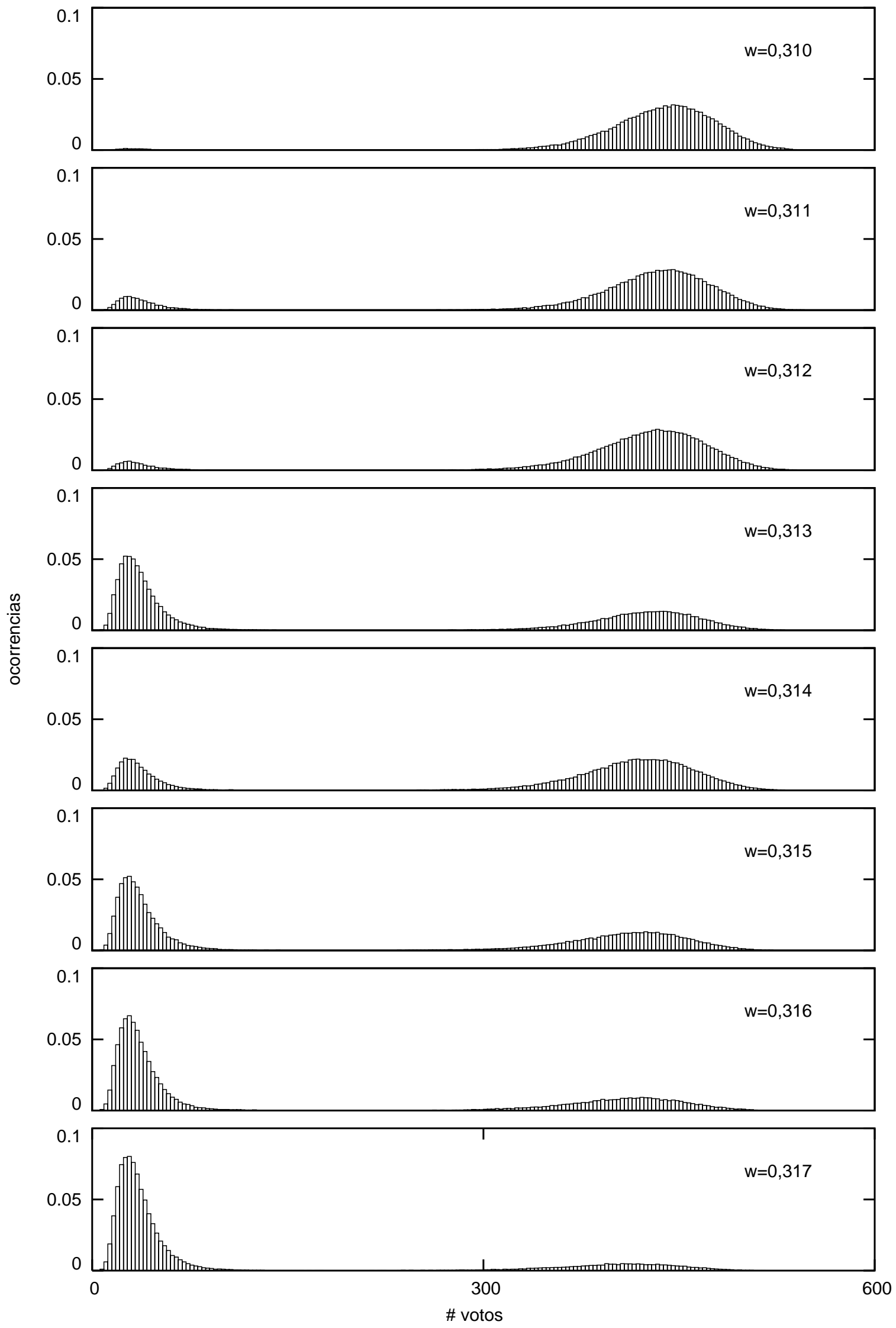

Figura 4.11: Número de vezes em que o sistema esteve com $v_{\max }$ votos para distintos $w$ (condição inicial ordenada). 

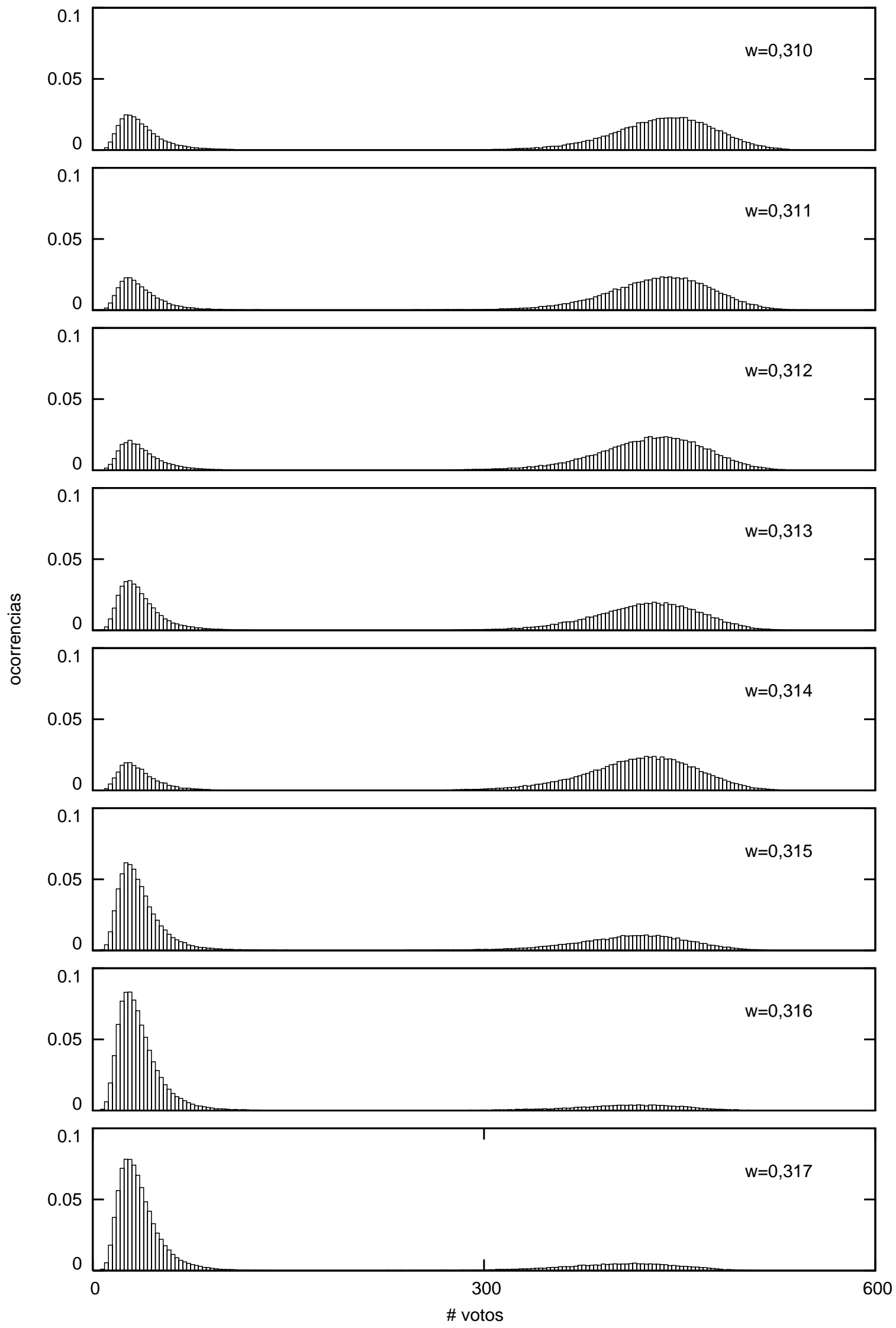

Figura 4.12: Número de vezes em que o sistema esteve com $v_{\max }$ votos para distintos $w$ (condição inicial desordenada). 


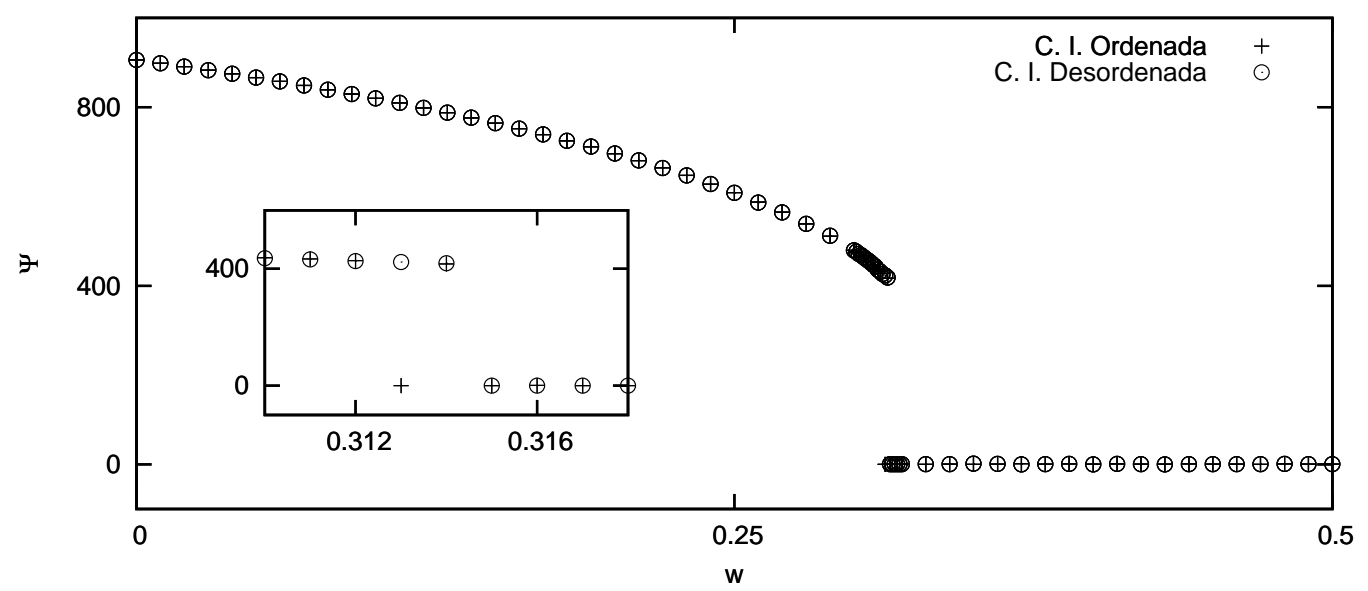

Figura 4.13: Comportamento do parametro de ordem $\Psi$ em função de $w$ para distintas configurações iniciais, sendo + para a configuração inicial ordenada e $\circ$ para a desordenada.

$\eta^{0}=1+\frac{1}{2\left\langle k_{v}\right\rangle} \pm \sqrt{\frac{1}{4\left\langle k_{v}\right\rangle^{2}}-\frac{w}{1-w} \frac{\left\langle k_{v}\right\rangle}{\langle k\rangle}}>1$. Os valores estacionários $\eta^{0}$ não nulos existem apenas para $w \leq\left(\frac{4\left\langle k_{v}\right\rangle^{3}}{\langle k\rangle}+1\right)^{-1}$, mas são maiores que 1 para $w \neq 0^{4}$. Dado que esperamos $\eta^{0}$ entre 0 e 1, a única solução estacionária é $\eta^{0}=0$. Analisando a estabilidade da solução temos que

$$
\left.\frac{\partial}{\partial \eta^{0}} \Delta \eta^{0}\right|_{\eta^{0}=0}=-\left[(1-w) \frac{\langle k\rangle\left(\left\langle k_{v}\right\rangle+1\right)}{\left\langle k_{v}\right\rangle^{2}}+w\right]<0
$$

e constatamos que a solução é estável. Assim, se houver algum ruído, por menor que seja, o número de eleitores indecisos vai a zero obrigatoriamente (mesmo que inicialmente todos os eleitores estejam indecisos).

Tendo então que $\eta^{0}=0$ é a solução estacionária, analisemos então os valores estacionários de $\eta^{\sigma}$. Rearranjando a equação 4.2 e fazendo $\Delta \eta^{\sigma}=0$ (e lembrando que $\eta^{0}=0$ ) temos:

$$
\begin{aligned}
\Delta \eta^{\sigma} & =(1-w) \frac{\langle k\rangle}{\left\langle k_{v}\right\rangle}\left[\left(1-\eta^{\sigma}\right) \eta^{\sigma}-\frac{\left(1-\eta^{\sigma}\right)^{2}}{N_{c}-1}\right] \eta^{\sigma}+\frac{w}{N_{c}}-\frac{w \eta^{\sigma}}{N_{c}}-w \eta^{\sigma}+\frac{w \eta^{\sigma}}{N_{c}} \\
& =(1-w) \frac{\langle k\rangle}{\left\langle k_{v}\right\rangle}\left[\eta^{\sigma}-\frac{\left(1-\eta^{\sigma}\right)}{N_{c}-1}\right]\left(1-\eta^{\sigma}\right) \eta^{\sigma}+\left(\frac{1}{N_{c}}-\eta^{\sigma}\right) w \\
& =(1-w) \frac{\langle k\rangle}{\left\langle k_{v}\right\rangle}\left(\frac{N_{c} \eta^{\sigma}-\eta^{\sigma}-1+\eta^{\sigma}}{N_{c}-1}\right)\left(1-\eta^{\sigma}\right) \eta^{\sigma}+\left(\frac{1}{N_{c}}-\eta^{\sigma}\right) w
\end{aligned}
$$

\footnotetext{
${ }^{4} w=0$ corresponde ao MSC sem ruído, analisado no capítulo 3.
} 


$$
\begin{aligned}
& =(1-w) \frac{\langle k\rangle}{\left\langle k_{v}\right\rangle} \frac{N_{c}}{N_{c}-1}\left(\eta^{\sigma}-\frac{1}{N_{c}}\right)\left(1-\eta^{\sigma}\right) \eta^{\sigma}+\left(\frac{1}{N_{c}}-\eta^{\sigma}\right) w \\
& =\left[(1-w) \frac{\langle k\rangle}{\left\langle k_{v}\right\rangle} \frac{N_{c}}{N_{c}-1}\left(1-\eta^{\sigma}\right) \eta^{\sigma}-w\right]\left(\eta^{\sigma}-\frac{1}{N_{c}}\right)
\end{aligned}
$$

e fazendo $\Delta \eta^{\sigma}=0$

$$
\left[(1-w) \frac{\langle k\rangle}{\left\langle k_{v}\right\rangle} \frac{N_{c}}{N_{c}-1}\left(1-\eta^{\sigma}\right) \eta^{\sigma}-w\right]\left(\eta^{\sigma}-\frac{1}{N_{c}}\right)=0
$$

e as soluções estacionárias são $\eta^{\sigma}=\frac{1}{N_{c}}$ e $\eta^{\sigma}=\frac{1}{2} \pm \sqrt{\frac{1}{4}-\frac{w}{1-w} \frac{\left\langle k_{v}\right\rangle\left(N_{c}-1\right)}{\langle k\rangle N_{c}}}$ que, simplificando a notação, serão denominadas $\bar{\eta}^{\sigma}, \eta_{+}^{\bar{\sigma}}$ e $\eta_{-}^{\bar{\sigma}}$, sendo que as duas últimas existem apenas para $w \leq\left(\frac{4\left\langle k_{v}\right\rangle\left(N_{c}-1\right)}{\langle k\rangle N_{c}}+1\right)^{-1}<1$. Chamaremos de $w_{t 2}$ o valor máximo de $w$ para que $\bar{\eta}_{+}^{\sigma}$ e $\eta_{-}^{\sigma}$ existam, isto é, $w_{t 2}=\left(\frac{4\left\langle k_{v}\right\rangle\left(N_{c}-1\right)}{\langle k\rangle N_{c}}+1\right)^{-1}$. Seguimos, então, à analise de estabilidade das soluções. Temos que

$$
\begin{aligned}
& \frac{\partial}{\partial \eta^{\sigma}} \Delta \eta^{\sigma}=(1-w) \frac{\langle k\rangle}{\left\langle k_{v}\right\rangle} \frac{N_{c}}{N_{c}-1}\left[-\frac{1}{N_{c}}+2 \eta^{\sigma}\left(\frac{N_{c}+1}{N_{c}}\right)-3\left(\eta^{\sigma}\right)^{2}\right]-w \\
& \left.\frac{\partial}{\partial \eta^{\sigma}} \Delta \eta^{\sigma}\right|_{\eta^{\sigma}=\eta^{\bar{\sigma}}}=(1-w) \frac{\langle k\rangle}{\left\langle k_{v}\right\rangle N_{c}}-w \\
& \left.\frac{\partial}{\partial \eta^{\sigma}} \Delta \eta^{\sigma}\right|_{\eta^{\sigma}=\eta_{+}^{\bar{\sigma}}}=(1-w) \frac{\langle k\rangle}{\left\langle k_{v}\right\rangle} \frac{N_{c}}{N_{c}-1}\left[-\frac{1}{2}-\left(\frac{N_{c}-2}{N_{c}}\right) \sqrt{\frac{1}{4}-\frac{w}{1-w} \frac{\left\langle k_{v}\right\rangle\left(N_{c}-1\right)}{\langle k\rangle N_{c}}}\right]+2 w \\
& \left.\frac{\partial}{\partial \eta^{\sigma}} \Delta \eta^{\sigma}\right|_{\eta^{\sigma}=\eta_{-}^{\bar{\sigma}}}=(1-w) \frac{\langle k\rangle}{\left\langle k_{v}\right\rangle} \frac{N_{c}}{N_{c}-1}\left[-\frac{1}{2}+\left(\frac{N_{c}-2}{N_{c}}\right) \sqrt{\frac{1}{4}-\frac{w}{1-w} \frac{\left\langle k_{v}\right\rangle\left(N_{c}-1\right)}{\langle k\rangle N_{c}}}\right]+2 w
\end{aligned}
$$

Pela equação 4.3 chegamos à conclusão de que $\bar{\eta}^{\sigma}$ é estável para $w>\left(\frac{\left\langle k_{v}\right\rangle N_{c}}{\langle k\rangle}+1\right)^{-1}$, e definiremos $w_{t 1}=\left(\frac{\left\langle k_{v}\right\rangle N_{c}}{\langle k\rangle}+1\right)^{-1}$ (note que, para $N_{c}>2, w_{t 1}<w_{t 2}$ ). Procuramos, então, os valores de $w$ para que $\eta_{+}^{\sigma}$ seja estável:

$$
\begin{gathered}
(1-w) \frac{\langle k\rangle}{\left\langle k_{v}\right\rangle} \frac{N_{c}}{N_{c}-1}\left[-\frac{1}{2}-\left(\frac{N_{c}-2}{N_{c}}\right) \sqrt{\left.\frac{1}{4}-\frac{w}{1-w} \frac{\left\langle k_{v}\right\rangle\left(N_{c}-1\right)}{\langle k\rangle N_{c}}\right]}+2 w<0\right. \\
\frac{1}{2}+\left(\frac{N_{c}-2}{N_{c}}\right) \sqrt{\frac{1}{4}-\frac{w}{1-w} \frac{\left\langle k_{v}\right\rangle\left(N_{c}-1\right)}{\langle k\rangle N_{c}}}>\frac{2 w}{(1-w)} \frac{\left\langle k_{v}\right\rangle}{\langle k\rangle} \frac{N_{c}-1}{N_{c}}
\end{gathered}
$$


Percebe-se que, excluindo o ponto $w_{t 2}$, o lado esquerdo da desigualdade 4.6 é estritamente maior que $\frac{1}{2}$. Note que, para que $\bar{\eta}_{+}^{\sigma}$ seja solução, a probabilidade $w$ deve ser tal que $\frac{w}{1-w} \frac{\left\langle k_{v}\right\rangle\left(N_{c}-1\right)}{\langle k\rangle N_{c}} \leq \frac{1}{4}$ e, com isso, o lado direito da desigualdade 4.6 é menor ou igual a $\frac{1}{2}$. Assim, a desigualdade 4.6 é satisfeita para todos os valores de $w$ tais que $\eta_{+}^{\bar{\sigma}}$ é solução estacionária (menos no ponto $w_{t 2}$ ), e $\eta_{+}^{\sigma}$ é, então, estável.

Analisamos agora a estabilidade de $\eta_{-}^{\bar{\sigma}}$. De maneira análoga ao procedimento seguido para $\overline{\eta_{+}^{\sigma}}$ obtemos o seguinte:

$$
\left(\frac{N_{c}-2}{N_{c}}\right) \sqrt{\frac{1}{4}-\frac{w}{1-w} \frac{\left\langle k_{v}\right\rangle\left(N_{c}-1\right)}{\langle k\rangle N_{c}}}<\frac{1}{2}-\frac{2 w}{(1-w)} \frac{\left\langle k_{v}\right\rangle}{\langle k\rangle} \frac{N_{c}-1}{N_{c}}
$$

Utilizando o mesmo argumento usado na análise da solução $\eta_{+}^{\bar{\sigma}}$ (sobre o valor máximo de $w$ para que $\eta_{-}^{\bar{\sigma}}$ seja solução), constatamos que ambos os lados da desigualdade são positivos, o que nos possibilita elevar ao quadrado cada um dos lados da desigualdade sem que esta deixe de ser satisfeita. Temos então que

$$
\left(\frac{N_{c}-2}{N_{c}}\right)^{2}\left(\frac{1}{4}-\frac{w}{1-w} \frac{\left\langle k_{v}\right\rangle\left(N_{c}-1\right)}{\langle k\rangle N_{c}}\right)<4\left(\frac{1}{4}-\frac{w}{(1-w)} \frac{\left\langle k_{v}\right\rangle\left(N_{c}-1\right)}{\langle k\rangle N_{c}}\right)^{2}
$$

e, excluindo o caso em que $w=w_{t 2}$, podemos dividir ambos membros por $\frac{1}{4}-\frac{w}{1-w} \frac{\left\langle k_{v}\right\rangle\left(N_{c}-1\right)}{\langle k\rangle N_{c}}$ e obter que

$$
\begin{gathered}
\left(\frac{N_{c}-2}{N_{c}}\right)^{2}<4\left(\frac{1}{4}-\frac{w}{(1-w)} \frac{\left\langle k_{v}\right\rangle}{\langle k\rangle} \frac{\left(N_{c}-1\right)}{N_{c}}\right) \\
\frac{w}{(1-w)} \frac{\left\langle k_{v}\right\rangle}{\langle k\rangle} \frac{\left(N_{c}-1\right)}{N_{c}}<\frac{1}{4}-\frac{N_{c}^{2}-4 N_{c}+4}{4 N_{c}^{2}}=\frac{N_{c}-1}{N_{c}^{2}} \\
w<\left(\frac{\left\langle k_{v}\right\rangle N_{c}}{\langle k\rangle}+1\right)^{-1}=w_{t 1}
\end{gathered}
$$

para que $\eta_{-}^{\bar{\sigma}}$ seja estável. Note que, no ponto $w_{t 1}, \bar{\eta}_{-}^{\bar{\sigma}}\left(w_{t 1}\right)=\frac{1}{N_{c}}=\overline{\eta^{\sigma}}$.

Podemos esquematizar estes resultados da seguinte forma: para $0 \leq w<w_{t 1}, \eta_{-}^{\bar{\sigma}}<$ $\bar{\eta}^{\sigma}<\eta_{+}^{\bar{\sigma}}$, sendo que $\bar{\eta}^{\bar{\sigma}}$ é instável e $\eta_{-}^{\bar{\sigma}}$ e $\eta_{+}^{\bar{\sigma}}$ são estáveis; entre $w_{t 1}$ e $w_{t 2} \bar{\eta}^{\bar{\sigma}}<\bar{\eta}_{-}^{\bar{\sigma}}<\bar{\eta}_{+}^{\bar{\sigma}}$, com $\bar{\eta}^{\sigma}$ e $\eta_{+}^{\bar{\sigma}}$ estáveis e $\eta_{-}^{\bar{\sigma}}$ instável; por fim, para $w>w_{t 1}$ apenas $\bar{\eta}^{\sigma}$ é solução estacionária, e é estável. A análise dos pontos críticos deve ser feita com maior cuidado. Tanto em $w_{t 1}$ como em $w_{t 2}$, existem apenas duas soluções, sendo uma estacionária $\left(\eta_{+}^{\bar{\sigma}}\right.$ para $w_{t 1}$ e $\bar{\eta}^{\sigma}$ para $w_{t 2}$ ) e a outra constitui o encontro de dois ramos estacionários (um estável e o outro instável), $\bar{\eta}_{-}^{\bar{\sigma}}$ e $\overline{\eta^{\sigma}}$ no ponto $w_{t 1}$ e $\eta_{-}^{\sigma}$ e $\eta_{+}^{\sigma}$ no ponto $w_{t 2}$, e nestes casos deveríamos fazer a análise de estabilidade para ordens superiores. 
Utilizando os mesmos valores de $N_{c}=10,\langle k\rangle=10$ e $\left\langle k_{v}\right\rangle=25,3^{5}$ das simulações anteriores (seção 4.2.1) construímos o gráfico da figura 4.14. Os pontos de transição obtidos valem $w_{t 1}=0,0380$ e $w_{t 2}=0,0989$.

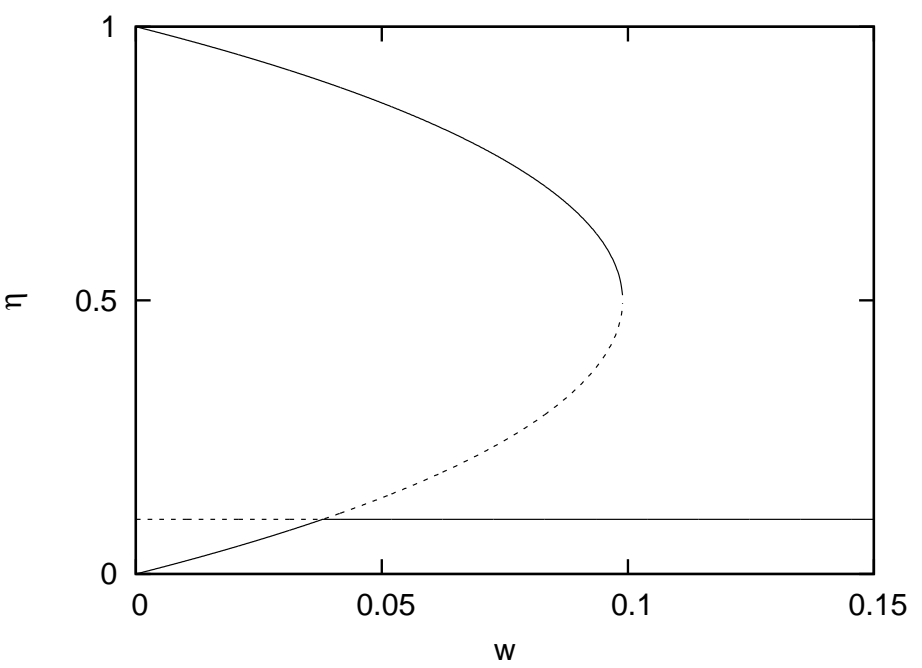

Figura 4.14: Soluções estacionárias, estáveis e instáveis, para aproximação de campo médio do MSC com ruído

Comparando com a figura 4.13, percebemos que a aproximação de campo médio reproduz qualitativamente bem a transição de primeira ordem encontrada nas simulações. Caberia, no entanto, uma análise mais aprofundada sobre os motivos da diferença entre o valor do ponto de transicão $w_{t}$ encontrado nas simulações e os valores $w_{t 1}$ e $w_{t 2}$ obtidos na aproximação de campo médio.

\footnotetext{
${ }^{5} \mathrm{O}$ valor para o grau médio do vizinho $\left\langle k_{v}\right\rangle$ foi obtido da seguinte forma: para cada eleitor de uma rede obtivemos o grau médio de seus vizinhos, então, fizemos a média deste valor para todos os sítios.
} 


\section{Capítulo 5}

\section{Influência da estrutura da rede}

É sabido que o comportamento de diversos modelos estatísticos depende fortemente da rede em que estes modelos se processam. O modelo de Ising, por exemplo, apresenta magnetização espontânea, para temperaturas não nulas, em reticulados de 2 ou 3 dimensões, o que não é observado para $d=1$.

No capítulo 3 analisamos o modelo de Sznajd em uma rede livre de escala do tipo Barabási-Albert. Podemos, seguindo a idéia de que o comportamento do sistema deve ser influenciado pela topologia da rede, nos perguntar como se dá o MSC em redes distintas.

Em [1], Bernardes e colaboradores já haviam comparado resultados do MS em um reticulado cúbico e numa rede BA. No entanto é importante notar que a versão do modelo adotada no primeiro caso é distinta ${ }^{1}$ da adotada para a rede BA. Esta última, que foi a versão por nós utilizada (o MSC) no presente trabalho e que pode ser utilizada em qualquer tipo de rede, nunca tinha sido estudada em reticulados, o que nos levou a incluir esse caso entre os analisados.

Faremos aqui uma comparação entre o papel das diversas topologias de redes no MSC com o papel das mesmas redes em dois modelos dinâmicos bem estabelecidos, o modelo de Ising com dinâmica de Glauber (para temperatura nula) e o chamado modelo do votante.

\subsection{Os modelos de Glauber e do Votante}

Tanto no modelo de Ising com dinâmica de Glauber a temperatura nula (que chamaremos daqui para a frente simplesmente de modelo de Glauber), como no modelo do votante,

\footnotetext{
${ }^{1}$ Nesta versão do MS um sítio era escolhido e então sua opinião era comparada à opinião de um vizinho qualquer: caso concordassem, todos os $2(2 d-1)$ vizinhos do par passariam ao mesmo estado do par; caso contrário nenhuma alteração ocorreria. Essa versão só faz sentido em um reticulado, no qual todos os sítios tem o mesmo número de vizinhos. Para não apresentar um comportamento trivial, no qual o primeiro par de vizinhos de mesma opinião que incluísse um eleitor com alto grau convenceria quase que instantaneamente o resto do sistema, a regra foi modificada, conforme apresentado no capitulo 3 .
} 
atribui-se a cada sítio uma variável $S$ (o estado do sítio), que pode assumir dois valores, +1 ou -1. Para ambos, a dinâmica se dá por atualizações assincrônica, i.e., a cada passo um sítio é escolhido aleatoriamente e seu estado é alterado (ou não) em função do estado de seus vizinhos. A diferença entre os dois modelos se dá na forma como os sítios interagem.

\subsubsection{Modelo de Glauber}

Na dinâmica de Glauber a temperatura nula [15], [16] associa-se uma certa energia à interação entre dois sítios vizinhos, energia essa que depende do estado de cada um dos sítios. A energia total do sistema é então

$$
H=-J \sum_{(i j)} \sigma_{i} \sigma_{j}
$$

onde $(i j)$ indica que a soma é feita sobre todos os pares de vizinhos $i \neq j$, e o termo $J$ refere-se à energia de interação entre os dois vizinhos ${ }^{2}$. A atualização do estado do sítio escolhido aleatoriamente é feita de forma a minimizar a energia total do sistema. Assim, se a maioria dos sítios vizinhos ao sítio $i$ escolhido estiver em $+1, S_{i}$ passa a ser +1 , caso o estado da maioria dos vizinhos seja $-1, S_{i}$ assume o valor -1 e se não há maioria (metade está em +1 e metade em -1) $S_{i}$ muda de valor ${ }^{3}$. Só iremos tratar o caso de temperatura nula e portanto, daqui em diante, sempre que nos referirmos ao modelo de Glauber, estaremos supondo a temperatura igual a zero.

Sabe-se que, em reticulados, o modelo de Glauber para $d=1$ evolui para uma configuração ordenada, i.e., dada uma condição inicial em que cada sítio está em um dos dois estados com igual probabilidade e sem correlação entre o estado dos sítios, após algum tempo todos os sítios se encontrão num mesmo estado, seja ele +1 ou -1 (este processo corresponderia a um esfriamento do sistema).

Para $d=2$ e $d=3$, porém, também sob esfriamento, o modelo de Glauber apresenta outro comportamento. Segundo Spirin, Krapivsky e Redner [25], para $d=2$, apesar de em um grande número de simulações o sistema atingir o estado ordenado, existe uma probabilidade não nula, mesmo no limite termodinâmico, de que configurações especiais sejam atingidas. Nessas configurações formam-se aglomerados de sítios em um mesmo estado - os assim chamados domínios - que têm a forma de faixas, verticais ou horizontais. Se a largura das faixas é maior que 2, estas configurações são absorventes, pois nenhum sítio na fronteira mudará mais de estado (a mudança acarretaria num aumento na energia do sistema) e o sistema congela nesta configuração. No caso $d \geq 3$, ainda de acordo com

\footnotetext{
${ }^{2}$ No caso $J>0$ a interação é ferromagnética, se $J<0$ é antiferromagnética.

${ }^{3}$ Neste último caso várias regras são possíveis, como "altera seu valor com determinada probabilidade". Variações como essa apenas modificam a escala de tempo em que se dá a dinâmica.
} 
[25], torna-se improvável atingir tanto as configurações ordenadas \pm 1 , bem como outras configurações absorventes, pois o sistema vagueia através de configurações metaestáveis de mesma energia.

Podemos quantificar o ordenamento do sistema através da densidade de arestas que apontam para sítios em estados distintos, a densidade de interface. Diferentemente do parâmetro de ordem $\Psi$ utilizado no capítulo anterior, que estava associado à densidade de sítios em determinado estado, aqui faz-se necessário um parâmetro de ordem mais sutil: duas configurações distintas, uma com dois grandes domínios de sítios em estados distintos (ambos de mesmo tamanho) e outra com sítios em estados de valores +1 ou -1 descorrelacionados entre si e com igual probabilidade, apresentariam o mesmo $\Psi=0$, apesar de claramente a ordenação da primeira configuração ser maior que a da segunda. Chamaremos este parâmetro de ordem de densidade de interface $\rho(t)$, que pode ser expressa por

$$
\rho=\frac{1}{2|E|} \sum_{i=1}^{N} \sum_{j \in \Gamma_{i}} \frac{1}{2}\left(1-S_{i} S_{j}\right)
$$

onde $|E|=\frac{1}{2} \sum_{i=1}^{N} k_{i}$ é o número total de arestas da rede. No caso do modelo de Glauber, $\rho$ está associado à energia do sistema (devido ao termo $S_{i} S_{j}$ ), e em um reticulado unidimensional $\langle\rho(t)\rangle \sim t^{-\frac{1}{2}}$, sendo $\langle\cdot\rangle$ uma média em diversas realizações ${ }^{4}$.

Recentemente o modelo de Glauber foi estudado em redes complexas. Boyer e Miramontes estudaram [26] o modelo de Glauber em uma rede WS (no caso sem retirada de arestas - ver seção 2.1.1). Utilizaram como base para a rede WS reticulados de dimensão 1 e 2, e perceberam que dificilmente o sistema evolui para configurações ordenadas. A evolução do sistema leva a configurações em que os sítios de maior grau não mudam mais de estado e acabam constituindo fronteiras "eternas" entre domínios.

Ainda sobre o modelo de Glauber em redes complexas, Castellano et al [27] apresentam resultados do modelo em grafos completos, randômicos e na rede BA. Nesta última constatou-se o seguinte panorama: em uma fração das simulações o sistema atinge uma configuração metaestável, com dois domínios com aproximadamente o mesmo tamanho. A fração de simulações na qual este comportamento é observado aumenta com o tamanho do sistema e diminui com o grau médio da rede.

\subsubsection{Modelo do votante}

No modelo do votante [16], [21] a regra de atualização é tal que o estado do sítio a ser atualizado $i$ é o mesmo de um vizinho $j \in \Gamma_{i}$ escolhido de forma aleatória e equiprovável

\footnotetext{
${ }^{4} \mathrm{O}$ caráter difusivo de $\langle\rho(t)\rangle$ neste caso está relacionado ao movimento das fronteiras entre domínios \pm 1 que segue um passeio aleatório.
} 
entre seus $k_{i}$ vizinhos, ou seja, $S_{i} \rightarrow S_{j}$. Este modelo simularia, por exemplo, a evolução das opiniões de um conjunto de pessoas com opiniões que podem assumir dois valores $( \pm 1)$, e que as mudam seguindo a opinião de seus vizinhos - daí o nome, modelo do votante. A probabilidade do sítio $i$ mudar de estado é

$$
P\left(S_{i} \rightarrow-S_{i}\right)=\frac{1}{2}\left(1-\frac{S_{i}}{k_{i}} \sum_{j \in \Gamma_{i}} S_{j}\right)
$$

e as configurações ordenadas $S_{i}= \pm 1$ são claramente absorventes.

Em reticulados, assim como na dinâmica de Glauber, o comportamento do modelo varia com a dimensão. Para $d=1,2$ os únicos estados estáveis são os ordenados e o sistema ordena (um consenso é atingido), enquanto para $d \geq 3$ outros estados estacionários podem ser atingidos ([16]). Quanto ao parâmetro de ordem, temos que, no caso unidimensional $\langle\rho(t)\rangle \sim t^{-\frac{1}{2}}$ e na rede quadrada $\langle\rho(t)\rangle \sim(\ln t)^{-1}$ [28]. Em reticulados de maior dimensão ([29]), inicialmente $\langle\rho(t)\rangle$ decresce até atingir um certo platô com $\rho=\rho_{p}$. Após este instante, $\langle\rho(t)\rangle$ permanece oscilando em torno de $\rho_{p}$, sendo que, para sistemas de tamanho finito, as flutuações levam finalmente, de forma estocástica, as realizações ao estado ordenado e a densidade de interface média segue, portanto, $\langle\rho(t)\rangle \sim \exp \left[-\frac{t}{\tau}\right]$ (para $d=3 \tau \sim N$ ). Para redes de tamanho infinito o sistema não ordenaria nunca.

Suchecki, Eguíluz e Miguel analisam em [29] o modelo do votante em uma série de redes distintas. Concluem, no caso da rede BA, que o comportamento se aproxima da evolução do modelo em um reticulado de $d>2,\langle\rho(t)\rangle \sim \exp \left[-\frac{t}{\tau}\right], \operatorname{com} \tau \sim N^{0,88}$. Além disso, constatam que o valor de $\rho_{p}$ aumenta conforme o grau médio da rede BA considerada, indicando que o ordenamento do sistema torna-se mais difícil com o aumento da conectividade dos sítios. Para a rede WS o comportamento é semelhante: o redirecionamento de uma fração $\phi$ das arestas, mesmo para baixos valores de $\phi$, faz com que $\langle\rho(t)\rangle$ atinja um patamar $\rho_{p}$ e então $\langle\rho(t)\rangle \sim \exp \left[-\frac{t}{\tau}\right] \operatorname{com} \tau \sim N$ (ver também [30]).

Em ambos os modelos, a influência flui da vizinhança para o sítio a ser atualizado, ou, coloquialmente, de fora para dentro. É interessante notar que, também em ambos os casos, a capacidade do sistema de atingir configurações ordenadas diminui com o aumento do grau médio ou com o aumento da desordem na rede, se $N \gg 1$. A exceção é o caso da dinâmica de Glauber a temperatura nula na rede de BA.

\subsection{Modelo de Sznajd em redes complexas}

Como dito no início deste capítulo o MS generalizado para várias opiniões e para rede complexa (MSC), na versão utilizada neste texto (regras I, IIa, IIb e IIc apresentadas no capítulo 3), não foi, pelo que temos conhecimento, estudado em outras redes. Inicialmente 
comparamos a dinâmica do MSC na rede BA, já detalhada anteriormente, com a evolução do mesmo modelo em um reticulado de dimensão 5 (uma rede hipercúbica com $d=5$ ). Escolhemos $d=5$ para que o grau médio fosse o mesmo, $\langle k\rangle=10$, em ambas as redes comparadas $^{5}$. A evolução no tempo dos votos de cada candidato pode ser observados na figura 5.1 .
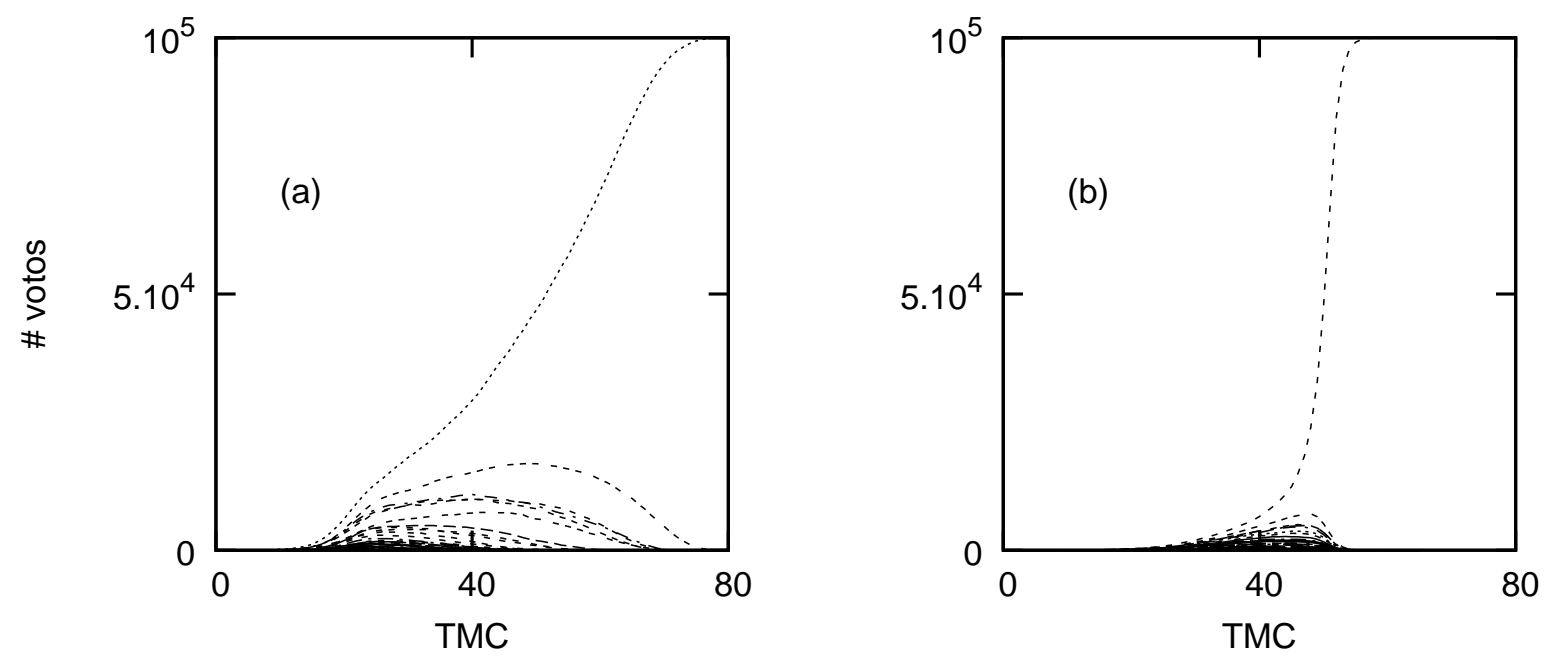

Figura 5.1: Comparação da evolução do número de votos dos candidatos para reticulado (a) e rede $\mathrm{BA}(\mathrm{b})$, tendo ambas $\langle k\rangle=10$

É interessante notar que, diferentemente do reportado por Bernardes e colegas em [1], a distribuição de candidatos por votos durante o transiente, neste reticulado, acompanha uma lei de potência com $\alpha \approx 1$ para condições iniciais simétricas, assim como no caso do modelo na rede BA (ver figura 5.2). Essa discrepância é causada provavelmente por Bernardes não ter utilizado exatamente o mesmo modelo em ambas redes, ou pelo fato de ter utilizado um reticulado de dimensão $d=3(\langle k\rangle=6)$ - o que indicaria uma influência da dimensão (ou do grau médio) da rede sobre a evolução do modelo.

Analisamos em seguida o MSC em redes com distintos valores de grau médio $\langle k\rangle$. Como no caso da dinâmica de Glauber e do modelo do votante, investigamos a influência deste parâmetro sobre o ordenamento do sistema e, para tanto, acompanhamos a densidade de interface média $\langle\rho(t)\rangle$, definida anteriormente, para diversas simulações.

Fizemos simulações para reticulados com $\langle k\rangle=k=2,4,6,8,10$ (redes hipercúbicas de dimensão $d=1,2,3,4,5$ com condições periódicas de contorno) e podemos observar $\langle\rho(t)\rangle^{6}$ na figura 5.3.

\footnotetext{
${ }^{5}$ Nesta seção, a menos que explicitamente indicado, utilizamos nas simulações $10^{5}$ eleitores e $10^{2}$ candidatos.

${ }^{6}$ Quando não indicado, a densidade de interface média foi obtida de $10^{2}$ realizações distintas sobre
} 


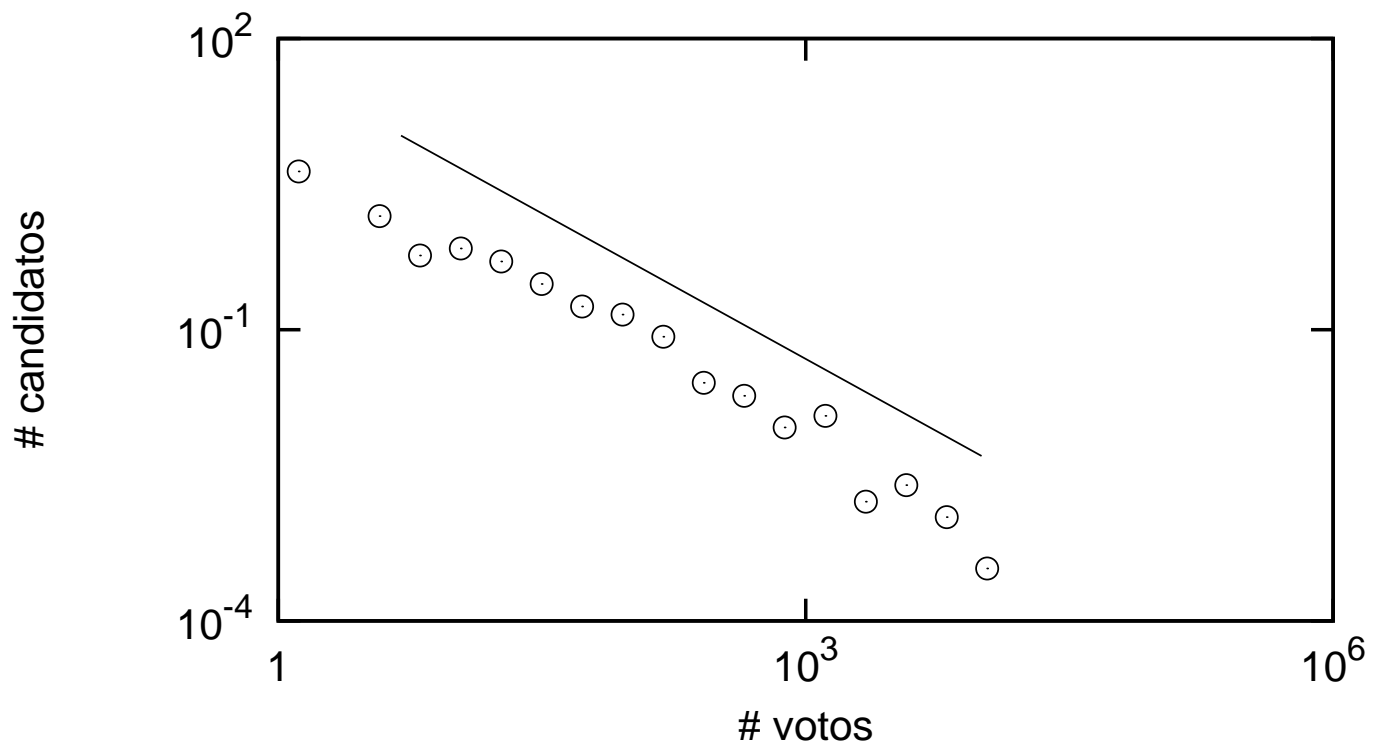

Figura 5.2: Distribuição de candidatos por número de votos para o MSC em reticulado de $\langle k\rangle=10$ após 25 TMC e linha guia $f(v) \propto v^{-1}$.

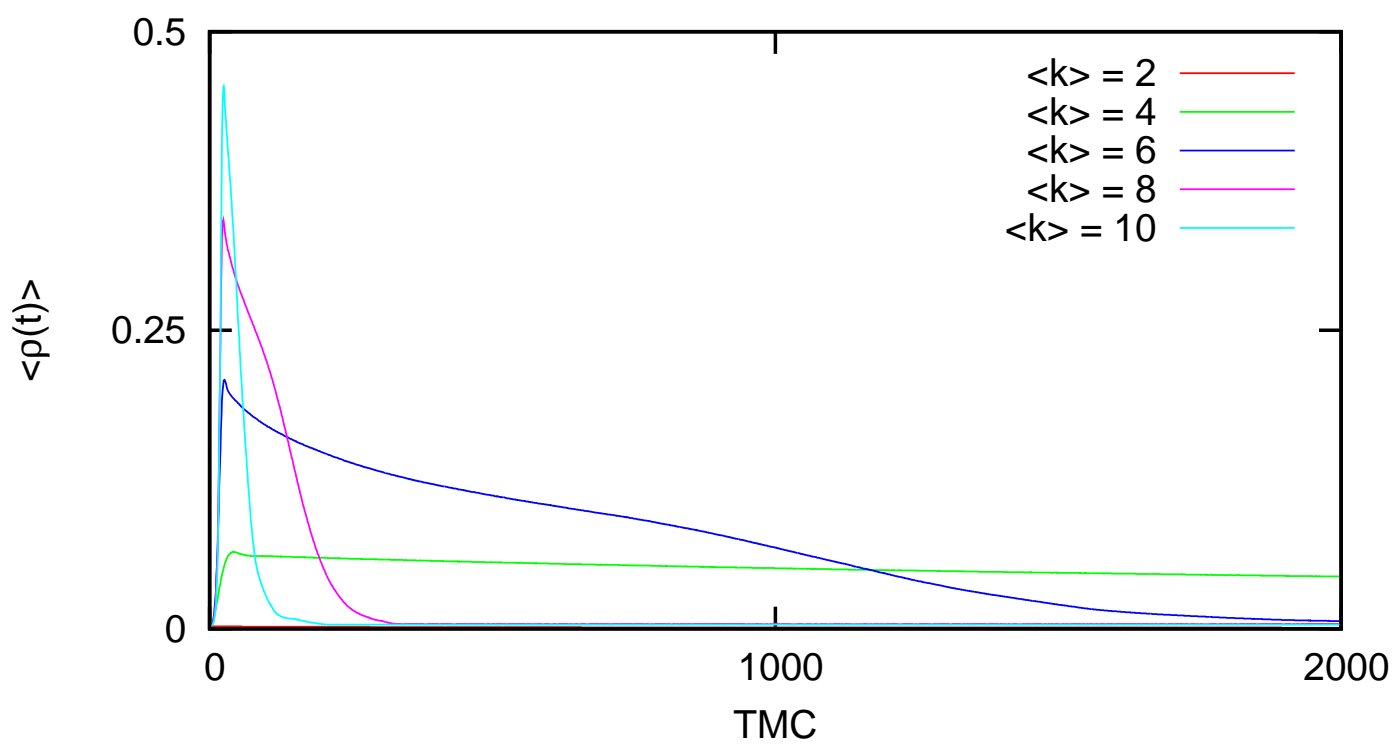

Figura 5.3: Densidade de interface média em reticulados, para diversos valores de $\langle k\rangle$. A média foi feita sobre $10^{2}$ realizações.

Pode-se perceber que para altos valores de $\langle k\rangle$ o sistema ordena, isto é, $\langle\rho(t)\rangle$ vai a zero para $t$ suficientemente grande, na grande maioria das realizações. No entanto observamos que, em algumas poucas simulações, a densidade de interface caía até se estabilizar em determinada rede. No caso específico dos reticulados de $d=2,3,4$ utilizamos $99856=316^{2}, 97336=46^{3}$ e $104876=18^{4}$ eleitores respectivamente. 
um determinado platô $\rho_{p}>0$. Ou seja, o sistema fica preso em uma configuração em que mais de um candidato ainda tem votos. Ressaltamos que, apesar de aprisionado nestas configurações em que $\rho \neq 0, \rho$ flutua com o tempo e que, em princípio, poderia atingir a configuração absorvente em que $\rho=0$ e todos eleitores votariam no mesmo candidato. Na tabela 5.1 apresentamos a freqüência $f$ com que o sistema ficou aprisionado e o valor aproximado da densidade de interface para estas configurações $\rho_{p}$, em função do grau médio $\langle k\rangle$. Note que, nem sempre, para os mesmos parâmetros, $\rho_{p}$ tem o mesmo valor.

\begin{tabular}{|c|c|c|}
\hline$\langle k\rangle$ & $f$ & $\rho_{p}$ \\
\hline \hline 3 & 0,14 & 0,0370 \\
\hline 4 & 0,05 & 0,0794 \\
\hline 5 & 0,03 & $0,1176 \mathrm{e} 0,1226$ \\
\hline
\end{tabular}

Tabela 5.1: Freqüência $f$ com que o sistema ficou aprisionado em configuração não absorvente e valores de $\rho_{p}$ destas configurações para diversos valores de $\langle k\rangle$. Foram observadas $10^{2}$ realizações. Note que o valor $\rho_{p}$ do platô pode assumir diferentes valores.

No reticulado de $\langle k\rangle=4$ (rede quadrada) o comportamento é distinto: inicialmente a desordem (expressa por $\langle\rho\rangle$ ) no sistema cresce até um determinado valor. Após 45 TMC, $\langle\rho\rangle$ alcançou o valor máximo 0,0645, num instante em que, com visto na figura $5.4,17 \%$ dos eleitores ainda estariam indecisos; então o sistema se ordena de forma lenta (aparentemente de forma exponencial com o tempo), de acordo com a figura 5.5.

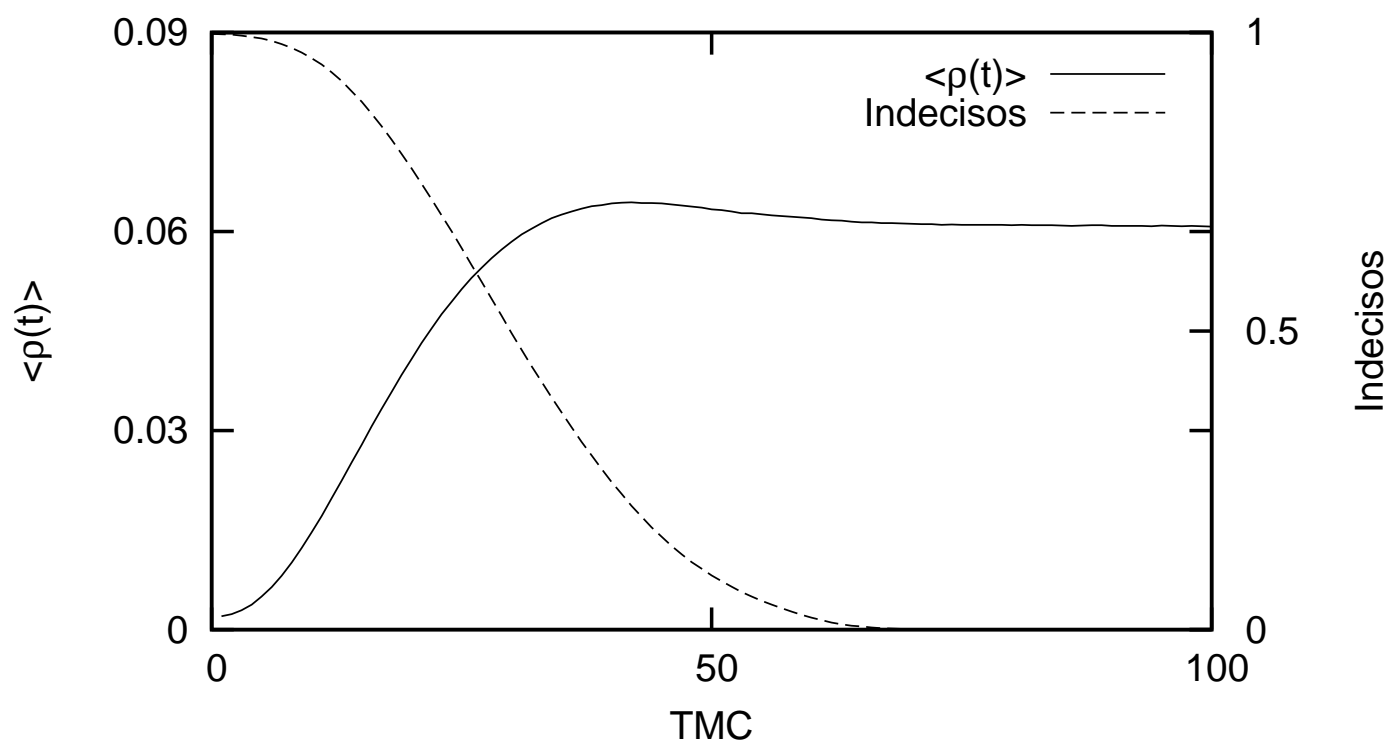

Figura 5.4: Densidade de interface $\langle\rho(t)>$ média (linha sólida) e fração de indecisos (linha interrompida) em função do tempo para reticulado quadrado, $<k>=4$. 


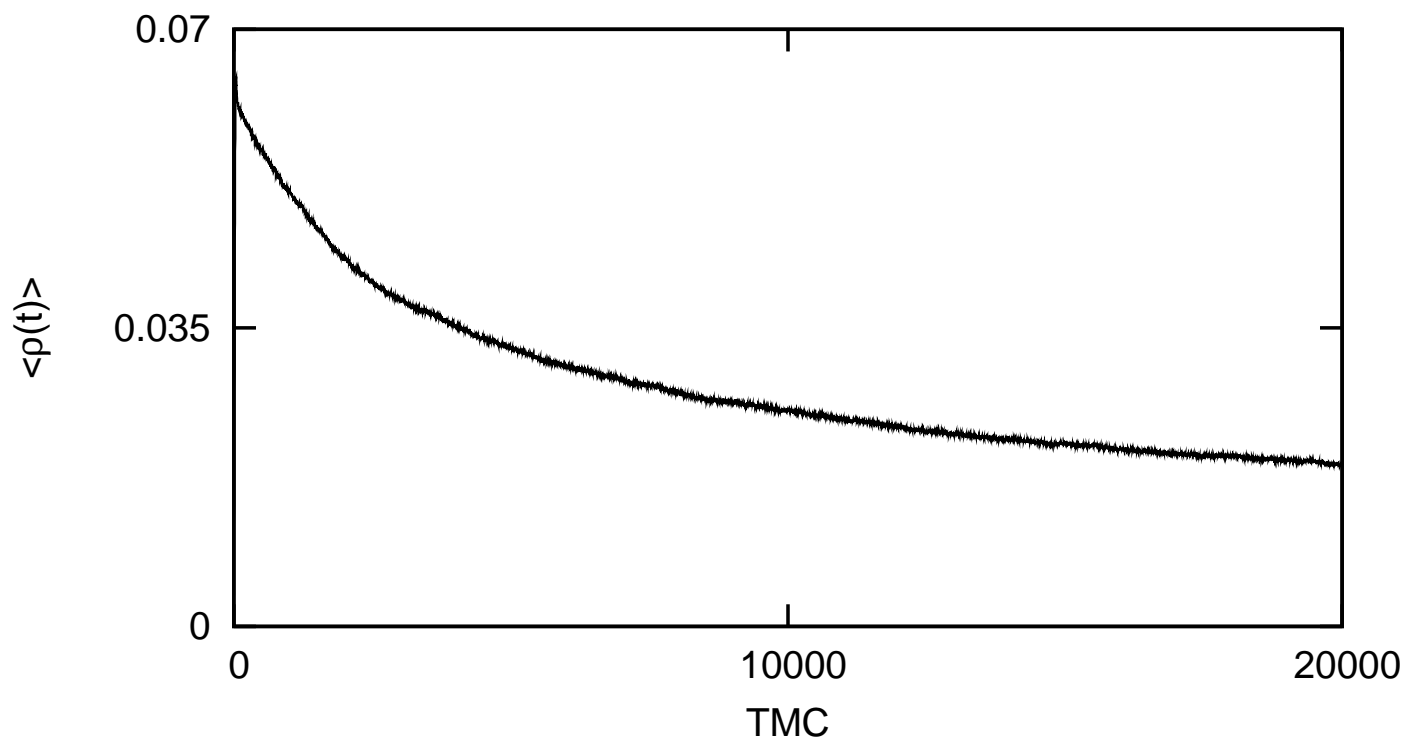

Figura 5.5: Densidade de interface $\langle\rho(t)>$ média, em 10 realizações, para reticulado quadrado, $<k>=4$.

Acompanhamos a evolução no tempo da configuração microscópica do sistema, em uma das simulações, (ainda para $\langle k\rangle=4$ ) para tempos longos, com o intuito de verificar a ordenação do sistema. Utilizando cores distintas para cada domínio, imprimimos imagens de alguns instantes desta realização. Estas podem ser vistas na figura 5.6. Percebe-se que, ao menos nesta realização, o sistema de fato continua se ordenando com o tempo (pela figura percebemos cada vez menos domínios, que são cada vez maiores). O sistema levou 87.824 TMC para ordenar completamente.

No caso $\langle k\rangle=2$, que corresponde a uma cadeia linear, a densidade de interface média não cresce como nos casos anteriores: cai, aparentemente acompanhando a queda de eleitores indecisos, do valor inicial até atingir $\rho_{p}=0,001$, após aproximados $3 \cdot 10^{3} \mathrm{TMC}$, então continua decrescendo, de forma muito lenta, num regime diferenciado em relação ao inicial (figura 5.7).

A seguir analisamos a densidade de interface média para o MSC em redes BA para distintos valores de grau médio. O resultado pode ser acompanhado pela figura 5.8. Em todos os casos o sistema ordena após algum tempo. Inicialmente $\langle\rho(t)\rangle$ cresce, atingindo valores máximos próximos de 1 , sendo que quanto menor o grau médio mais rápido este máximo é atingido. Nota-se que, o valor máximo de $\langle\rho(t)\rangle$ aumenta com o aumento de $\langle k\rangle$. Percebe-se ainda que, após atingir o valor máximo, $\langle\rho(t)\rangle \rightarrow 0$ mais rapidamente para as redes de maior grau médio.

Depois de atingido o valor máximo de desordem $\left(\langle\rho\rangle\right.$ atinge $\left.\langle\rho\rangle_{\max }\right)$ o comportamento observado pode ser classificado de suas formas: para $\langle k\rangle>4$ o ordenamento é rapido, 

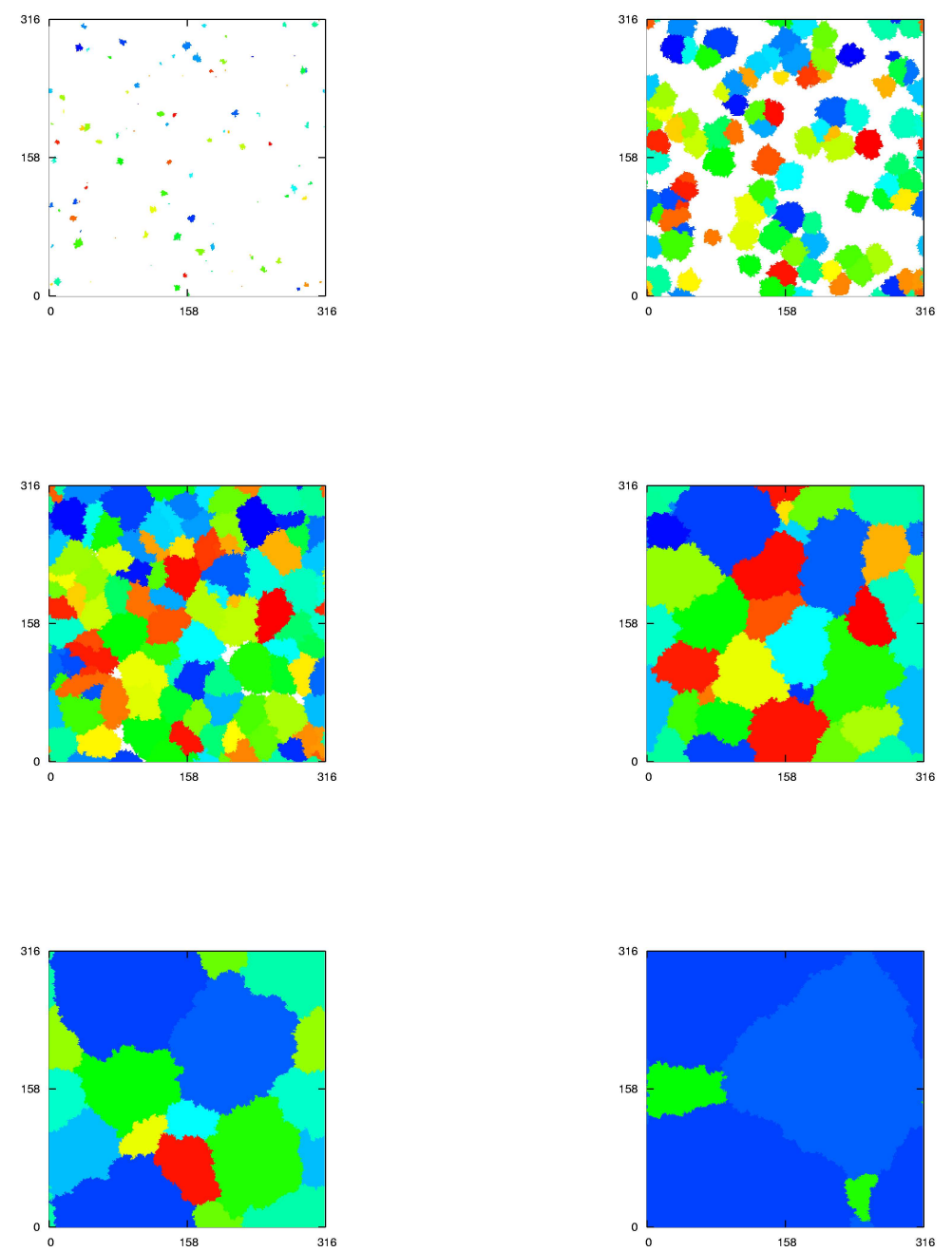

Figura 5.6: Mapas das configurações do MSC em rede quadrada para 7, 31, 63, 4095, 16383, e 65535 TMC (esquerda para direita, de cima para baixo). 


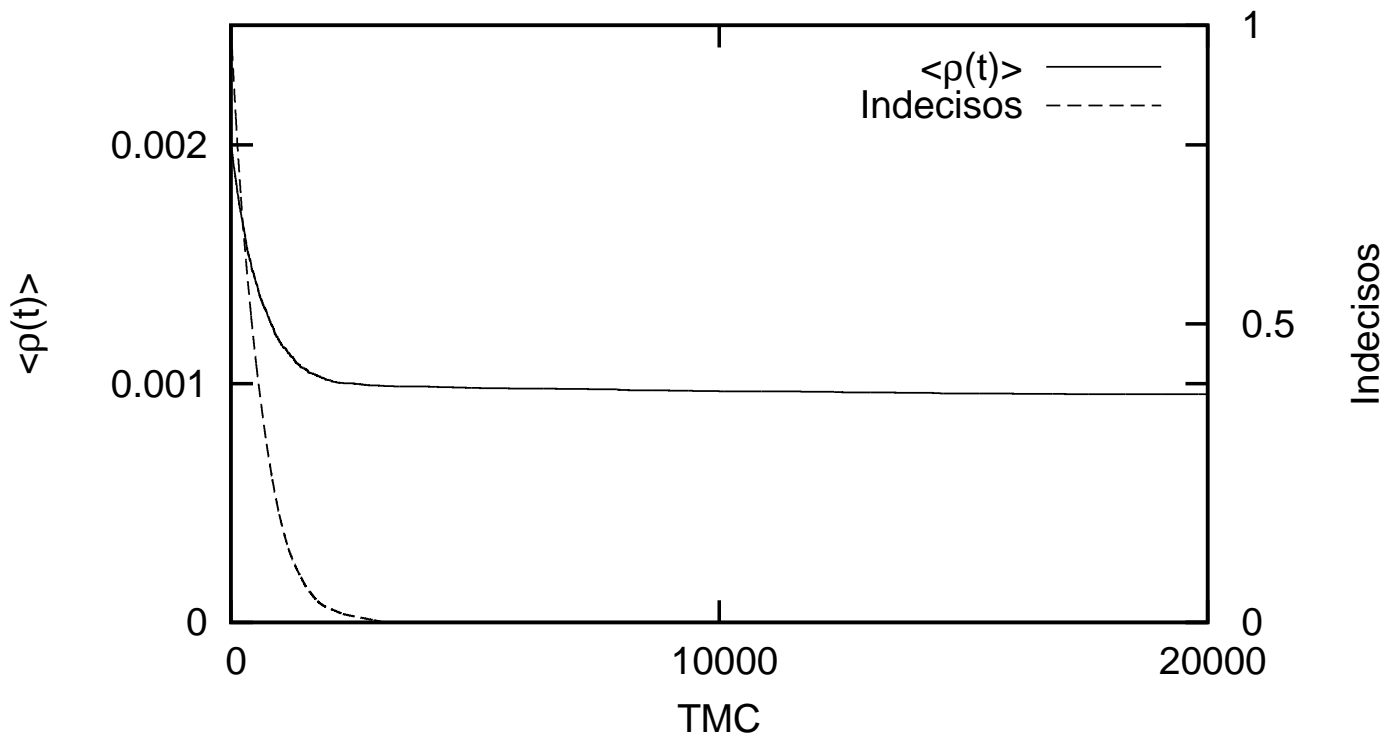

Figura 5.7: Densidade de interface $\langle\rho(t)\rangle$ média (linha sólida) e fração de indecisos (linha interrompida) em função do tempo, para cadeia linear, $\langle k\rangle=2$.

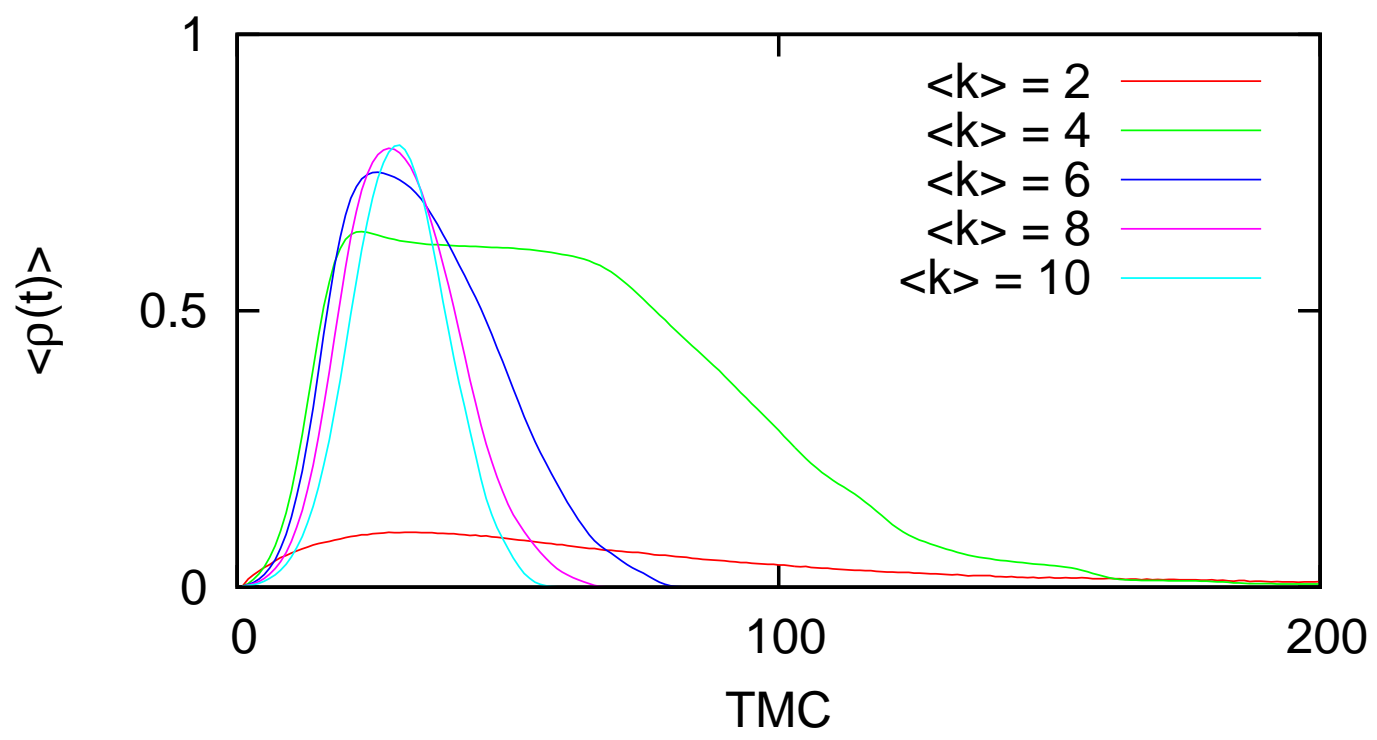

Figura 5.8: Densidade de interface média na rede BA para diversos valores de $\langle k\rangle$. As médias foram feitas considerando-se $10^{2}$ realizações.

enquanto para $\langle k\rangle<4$ a queda de $\langle\rho\rangle$ é lenta, sendo que $\langle k\rangle=4$ parece indicar uma transição entre esses comportamentos.

Estudamos ainda como a desordem na estrutura da rede influencia o comportamento do MSC. Para tanto, utilizamos a rede WS, que é uma rede regular em que uma fração $\phi$ das arestas é redirecionada aleatoriamente (ver seção 2.1.1). Utilizamos a versão original 
desta rede [4] em que a rede regular subjacente é uma cadeia e não um reticulado. Notamos que, apesar da cadeia ser também uma rede regular, o MSC nela se desenvolve de maneira distinta do que observado em reticulados. Na figura 5.9 apresentamos a evolução temporal de $\langle\rho(t)\rangle$ para o MSC em cadeias sem desordem $(\phi=0)$ de grau médio distintos.

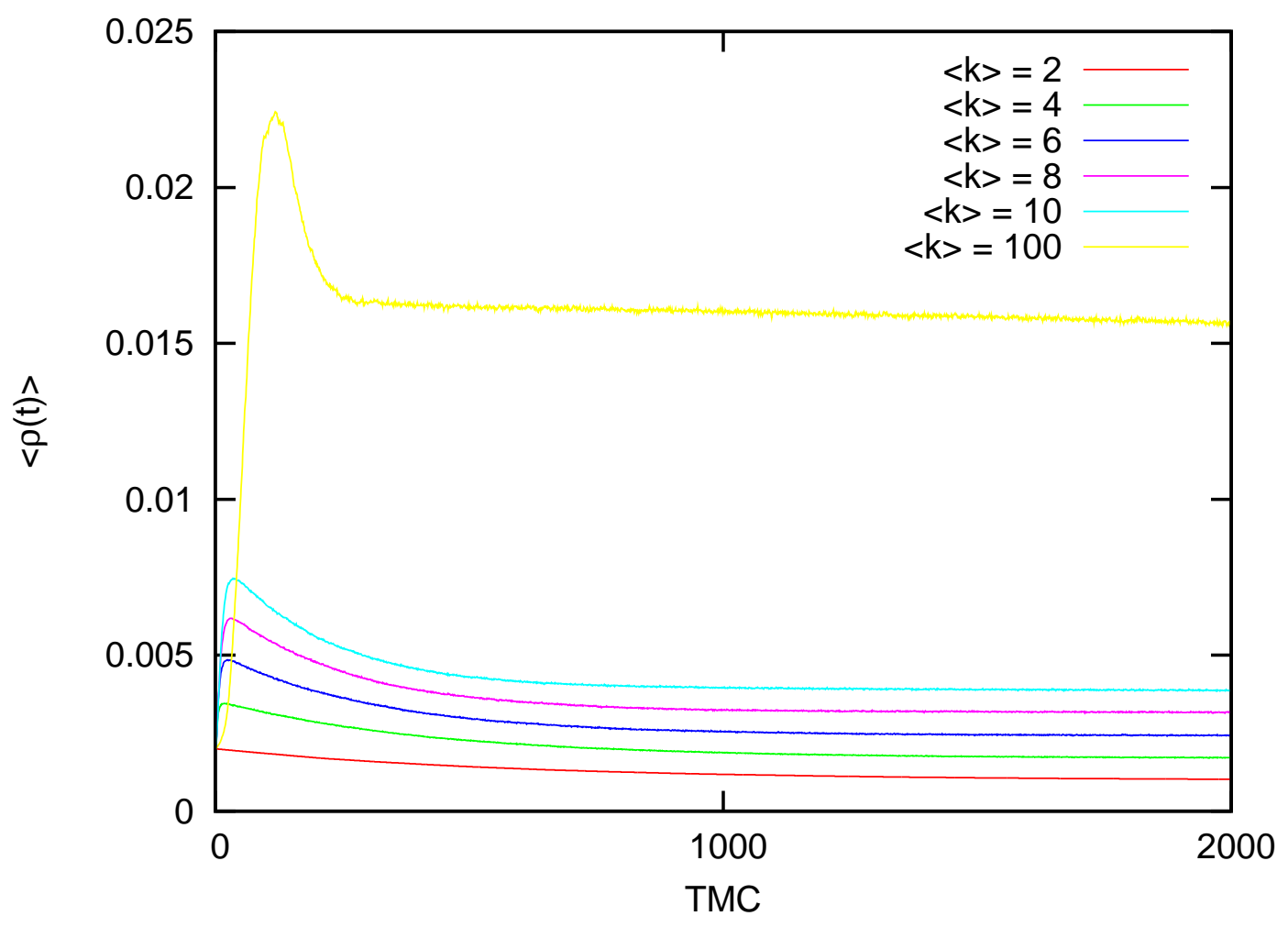

Figura 5.9: Densidade de interface média do MSC em cadeias, (modelo WS com $\phi=0$ ), com grau médio distintos.

O resultado para a cadeia de grau médio $\langle k\rangle=1$ é exatamente o mesmo do reticulado com $d=1$ (figura 5.7), o que é um resultado esperado, pois trata-se da mesma rede. No entanto, para $\langle k\rangle>2$, obtemos um comportamento bem distinto do MSC em reticulados: nesse caso $\langle\rho(t)\rangle$ cresce, atinge um máximo, mas agora decai até um platô $\langle\rho(t)\rangle=\rho_{p}$. Verificamos que, para cadeias com baixo $\langle k\rangle, \rho_{p}$ segue $\langle k\rangle$ linearmente.

Com a introdução de desordem, através de redirecionamento da fração $\phi$ de arestas, o quadro se altera. Fizemos simulações para cadeias com $\langle k\rangle=4$ e 10 (usando baixos valores de $\phi$ de forma a manter a aglomeração alta - ver [4]) e ambos os casos apresentaram comportamentos similares (figuras 5.10 e 5.11). No início $\langle\rho(t)\rangle$ cresce, atingindo valores máximos (quanto maior $\phi$, mais alto o máximo de $\langle\rho(t)\rangle$ alcançado). Para poucos redirecionamento $(\phi<0,01)\langle\rho(t)\rangle$ atinge um patamar $\rho_{p}$ e o comportamento subseqüente é semelhante ao observado nas cadeias sem redirecionamento (ou seja, com $\phi=0$ ), apesar dos valores de $\rho_{p}$ serem substancialmente mais altos. De forma diferente, quando 
$\phi>0,01$ a densidade de interface média, após o máximo, cai para um platô em que permanece pouco, e logo $\langle\rho(t)\rangle \rightarrow 0$ (para $\phi=0,01$ este platô é praticamente inexistente).

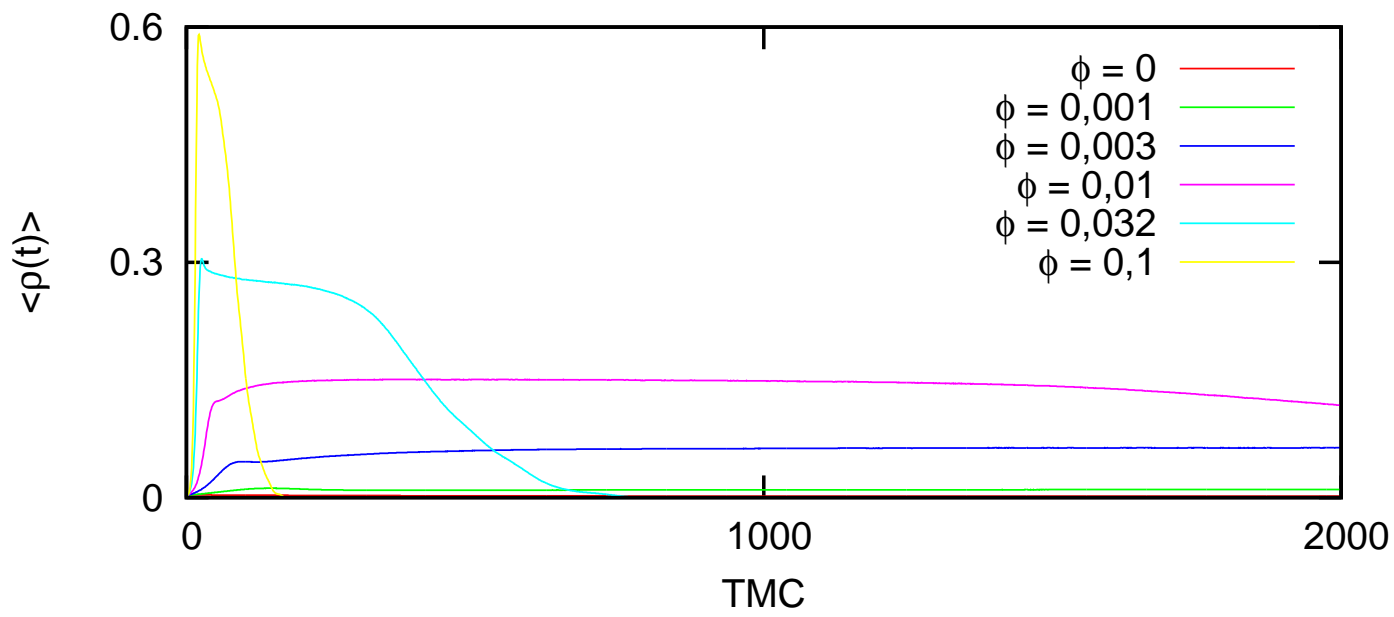

Figura 5.10: Densidade de interface média do MSC em cadeia com $\langle k\rangle=4$, para distintos valores de redirecionamento de arestas.

Valores em torno de $\phi \approx 0,01$ corresponderiam à uma transição entre estes dois comportamentos.

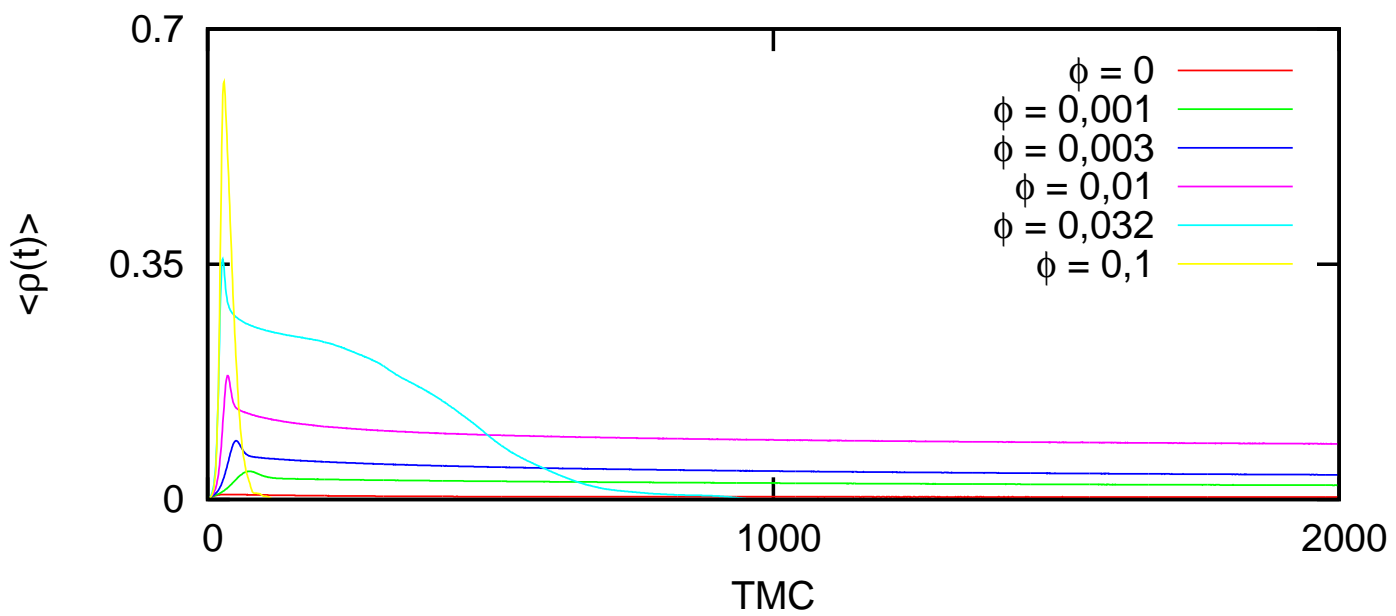

Figura 5.11: Densidade de interface média do MSC em cadeia com $\langle k\rangle=10$, para distintos valores de redirecionamento de arestas.

Resumindo, verificamos que (com exceção do MSC numa cadeia linear) a evolução segue um padrão. Inicialmente a densidade de interface média cresce, até atingir o valor máximo $\langle\rho\rangle_{\max }$, valor este que aumenta com a desordem da rede. Percebemos também que, em todos os casos (reticulados, na rede WS e na rede BA) $\langle\rho\rangle_{\max }$ aumenta com o grau médio da rede. O tempo que o sistema leva para atingir $\langle\rho\rangle_{\max }$, em todos os casos, 
aumenta conforme o grau médio e diminui com a desordem das redes. Depois de atingido o valor máximo $\langle\rho\rangle_{\max }$, dois comportamentos distintos foram encontrados: caso a desordem na rede e o grau médio sejam baixos $\langle\rho\rangle$ alcança uma configuração desordenada (em que atinge o patamar $\langle\rho\rangle=\rho_{p}$ ) e nele permanece por longos tempos; por outro lado, caso $\phi$ ou $\langle k\rangle$ sejam grandes $\langle\rho(t)\rangle \rightarrow 0$, i.e., o sistema ordena, rapidamente.

O valor inicial da densidade de interface média, $\langle\rho(0)\rangle$, verificado nas simulações é aproximadamente o mesmo $(\approx 0,002)$. Uma estimativa para tal valor pode ser obtida considerando que, de acordo com o MSC, inicialmente são escolhidos $N_{c}$ eleitores iniciais, um para cada candidato. Se o número de candidatos $N_{c}$ for bem menor que o total de eleitores $N \gg N_{c}$ podemos supor que poucos destes eleitores iniciais serão vizinhos entre si, e cada eleitor inicial teria apenas vizinhos em $\sigma=0$, indecisos. Temos então que as únicas arestas que apontam para eleitores de opinião distinta são as que ligam os eleitores iniciais e seus vizinhos, e o número total destas arestas será $\left|E_{\text {dif }}\right|=\sum_{\text {(e. inic.) }} k_{i}$, sendo que a restrição na somatória indica que a soma é apenas sobre os eleitores iniciais. Para um número razoável de candidatos podemos, lembrando que os eleitores iniciais são escolhidos de forma aleatória, fazer a seguinte aproximação: $\frac{\sum_{(\text {e. inic.) }} k_{i}}{N_{c}}=\frac{\sum_{i=1}^{N} k_{i}}{N}$. Dado que $\rho$ mede a fração de arestas que aponta para eleitores de opinião distinta temos

$$
\langle\rho(0)\rangle=\frac{\left|E_{\text {dif }}\right|}{|E|}=\frac{\sum_{(\text {e. inic. })} k_{i}}{\frac{1}{2} \sum_{i=1}^{N} k_{i}}=\frac{2 N_{c}}{N}
$$

que, para os valores $N=10^{5}$ e $N_{c}=10^{2}$ usados nas simulações teríamos $\langle\rho(0)\rangle=0,002$, compatível com os resultados observados.

Assim como a densidade de interface inicial do MSC para as redes estudadas, o MSC na cadeia linear também pode ser compreendido de maneira relativamente simples. No início, os eleitores iniciais, separados uns dos outros por (em média) $\frac{N}{N_{c}}$ eleitores indecisos, convencem seus vizinhos indecisos e os domínios de opiniões crescem de forma conexa. O eleitor em uma das duas fronteiras de um domínio convence um vizinho indeciso com probabilidade 0,5 e, portanto, após sucessivas tentativas cada fronteira avança em torno de 1 eleitor a cada 2 TMC. Cada fronteira se expandirá desta forma até encontrar outro domínio e, se antes do encontro cada "eleitor de fronteira" contribuía com uma aresta entre eleitores de opinião distinta (entre este eleitor e seu vizinho indeciso), após o encontro ambos contribuem com apenas uma (a saber, a aresta entre eles). De forma que os encontros de fronteiras de domínios acarretam numa diminuição $\langle\rho(t)\rangle$, até o momento em que não há mais eleitores indecisos e as arestas entre eleitores discordantes são simplesmente as arestas entre as $N_{c}$ fronteiras de domínio e a estimativa do patamar atingido será 


$$
\rho_{p}^{e}=\frac{\left|E_{\text {dif }}\right|}{|E|}=\frac{N_{c}}{\frac{1}{2} \sum_{i=1}^{N} k_{i}}=\frac{N_{c}}{N}
$$

de acordo com o patamar encontrado nas simulações (ver figura 5.7). A ordem de grandeza do tempo decorrido até o sistema atingir $\rho_{p}$ pode ser estimada pelo tempo que duas fronteiras levariam para se encontrar se separadas pela distância média $\frac{N}{N_{c}}$, que é o tempo que cada uma levaria para percorrer $\frac{N}{2 N_{c}}$ eleitores, a meio eleitor por TMC, ou seja, $\frac{N}{N_{c}}$ TMC (nas simulações do MSC na cadeia linear $\frac{N}{N_{c}}=10^{3}$ e o tempo para atingir $\rho_{p}$ foi em torno de $3 \cdot 10^{3}$ TMC ).

O comportamento do MSC em uma cadeia com $\langle k\rangle \neq 2$ difere da cadeia linear, pois a desordem cresce até um valor máximo $\langle\rho(t)\rangle_{\max }$ (o que é compreensível pois um domínio conexo em uma cadeia com $\langle k\rangle \neq 2$ terá mais vizinhos fora do domínio do que no caso linear). No entanto, assim como no caso da cadeia linear, $\langle\rho(t)\rangle$ também atinge patamares $\rho_{p}$ que também podem ser estimados de forma análoga ao feito para a cadeia linear: dois domínios fronteiriços são separados por pelo menos $\frac{\langle k\rangle(\langle k\rangle+2)}{8}$ arestas; se nenhum domínio foi eliminado temos $N_{c}$ fronteiras; as únicas arestas que ligam eleitores de opinião distinta são as arestas de fronteira; temos então que

$$
\rho_{p}^{e}=\frac{\left|E_{\text {dif }}\right|}{|E|}=\frac{\frac{\langle k\rangle(\langle k\rangle+2)}{8} N_{c}}{\frac{1}{2} \sum_{i=1}^{N} k_{i}}=\frac{N_{c}}{N} \frac{(\langle k\rangle+2)}{4}
$$

Na tabela 5.2 apresentamos as estimativas de $\rho_{p}$ para o MSC em cadeias (para diversos valores de $\langle k\rangle)$ bem como o resultado obtido nas simulações.

\begin{tabular}{|c|c|c|}
\hline$\langle k\rangle$ & $\rho_{p}^{e}$ & $\rho_{p}$ \\
\hline \hline 2 & 0,001 & 0,001 \\
\hline 4 & 0,0015 & 0,0017 \\
\hline 6 & 0,002 & 0,0024 \\
\hline 8 & 0,0025 & 0,0032 \\
\hline 10 & 0,0030 & 0,0039 \\
\hline 100 & 0,0255 & 0,0148 \\
\hline
\end{tabular}

Tabela 5.2: Estimativa de $\rho_{p}$ e o valor obtido nas simulações para $\langle k\rangle=2,4,6,8,10$ e 100 .

Percebemos que para valores de $\langle k\rangle$ baixos a estimativa ficou abaixo do valor obtido, provavelmente por ser $\frac{\langle k\rangle(\langle k\rangle+2)}{8}$ o número mínimo de arestas entre domínios, quando 
o número efetivo pode ser maior ${ }^{7}$. Para $\langle k\rangle=100$, o valor de $\rho_{p}$ foi superestimado e isso se deve à extinção de alguns domínios antes do sistema alcançar o platô, o que diminui o valor de $\rho_{p}$.

Quanto ao fato do tempo que o sistema leva para atingir $\langle\rho(t)\rangle_{\max }$ aumentar com $\phi$ e diminuir com $\langle k\rangle$, acreditamos que tenha relação com o mesmo fenômeno descrito na seção 3.1.2, causado pela probabilidade de convencimento da regra IIa favorecer eleitores de grau baixo. Assim, domínios em redes de grau médio baixo crescem, inicialmente, mais rapidamente que domínios em redes de grau médio alto. O efeito que a desordem na rede causa no tempo de maximização de $\langle\rho(t)\rangle$ deve se basear na mesma característica do modelo: ao redirecionar as arestas faz com que a distribuição de graus dos domínios se "alargue"; então os domínios terão eleitores com grau baixo, que aceleram o processo de convencimento inicial.

Faz-se necessário ainda compreender a distinção entre o ordenamento rápido do MSC em redes com desordem ou grau médio altos, e o ordenamento lento nos outros casos. Ressaltamos que este comportamento é essencialmente distinto dos modelos de Glauber e do votante discutidos na seção anterior: com grau médio baixo e sem desordem na rede o sistema também ordena lentamente, porém, em redes com desordem ou grau alto, o sistema não ordena, fica congelado em configurações especiais.

Acreditamos que a origem deste fenômeno está em dois fatores principais: o fato do MSC ser um modelo cuja influência flui de um eleitor para seus vizinhos (de dentro para fora) e a relação entre o número de eleitores e o tamanho da "superfície"8 dos domínios em cada rede específica. Nos modelos em que o fluxo de influência flui de fora para dentro, cada sítio pode mudar sua opinião aproximadamente uma vez por TMC. Não é o que ocorre no caso do MSC: a cada passo um eleitor é escolhido para tentar influenciar seus vizinhos; um domínio com um grande número de eleitores tentará convencer um também grande número de vizinhos; um eleitor vizinho de um grande domínio será assediado um grande número de vezes e, com maior probabilidade, acabará cedendo e mudando de opinião ${ }^{9}$. No entanto, esse processo não ocorre em qualquer rede e o caso da cadeia unidimensional é exemplar, pois dois domínios, um grande e outro pequeno, com fronteira comum, disputam seus eleitores de forma isonômica. Como conseqüência a fronteira tem a mesma probabilidade de avançar para qualquer um dos lados: um domínio não enxerga o tamanho do outro e os eleitores internos ao domínio ficam se autoconvencendo, sem alterar a configuração. Neste sentido o aumento da desordem na estrutura da rede e do

\footnotetext{
${ }^{7}$ Pode inclusive acontecer de um domínio não ser conexo, aumentando assim o valor de $\langle\rho(t)\rangle$.

${ }^{8}$ Entendemos por superfície de um domínio relativa a um candidato $\sigma$, ou de um conjunto de eleitores, o conjunto $\Gamma(\sigma)$ de eleitores que não estão em $\sigma$ e são vizinhos de um eleitor em $\sigma$.

${ }^{9}$ Não podemos deixar de fazer uma analogia entre este processo e a situação desagradável do jogo WAR quando temos um território isolado e ficamos cercado pelo inimigo que, em apenas uma rodada, nos desfere uma série de ataques provenientes de territórios vizinhos ao nosso e, ao fim, consegue tomá-lo.
} 
grau médio devem aumentar a superfície dos domínios, expondo-os.

Por fim acreditamos que, para modelos com fluxo externo (de dentro para fora) de influência, existam, para cada rede, valores críticos de desordem e grau médio abaixo dos quais o ordenamento é lento. Estes valores críticos podem, no entanto, variar conforme o poder de convencimento do modelo. Resultados de Gonzáles, Souza e Herrmann corroboram este quadro, pois, numa rede "pseudo-fractal" (ver [10]) o MSC com probabilidade de convencimento usual, $k_{i}^{-1}$, não ordena para tempos longos; mas, ao aumentar o poder de convencimento para $k_{i}^{-0,5}$, percebem o ordenamento para tempos curtos. 


\section{Capítulo 6}

\section{Conclusões}

Analisamos, nesta dissertação, o modelo de Sznajd generalizado para redes complexas (MSC), segundo versão de Bernardes, Stauffer e Kertész [1]. Aprofundamos o estudo de Bernardes e colegas para o MSC em uma rede de Barabási-Albert, introduzimos alterações na dinâmica do MSC (ainda em uma rede de Barabási-Albert), para estudar tanto o efeito de ruído como de defeitos, e verificamos o comportamento do modelo em redes de distintas características topológicas. Desenvolvemos ainda uma abordagem de campo médio para o modelo na rede BA, e estudamos a estatística de votos nas eleições de vereadores da cidade de São Paulo para 2000 e 2004. Para o cálculo do expoente, adaptamos o método da estimação via máxima verossimilhançaa para o caso em que há efeitos de tamanho finito nos dois extremos da distribuição.

É sabido [1] que o MSC na rede BA apresenta, durante o transiente, distribuição de candidatos por número de votos que se assemelha à distribuição no caso de eleições reais: leis de potência $f(v) \propto v^{-\alpha}$ com expoente $\alpha \approx 1$ [9]. Na seção 2.2 apresentamos o comportamento da distribuição de candidatos por número votos nas eleições de 2000 e 2004 para vereadores do município de SãoPaulo. O ajuste de leis de potências a dados reais deve ser feito de forma cuidadosa e utilizamos a Estimação via Máxima Verossimilhança [13] para tal tarefa. No entanto, como o EMV foi desenvolvido apenas para dados sem desvios, em eventos raros, com relação à lei de potência, generalizamos o EMV para estes casos (ver apêndice A) de forma a poder aplicá-lo a esse problema. Obtivemos os expoentes, $\alpha_{2000}=1,47(4)$ e $\alpha_{2004}=1,47(3)$, sendo que a lei de potência é seguida, nos dois casos, para um intervalo de votos de aproximadamente três ordens de grandeza.

Sobre o MSC na rede BA, constatamos (seção 3.1.2) que o grau do eleitor inicial influencia fortemente o desenvolvimento do domínio de eleitores associado ao candidato, sendo que quanto maior o grau do eleitor inicial mais difícil torna-se a vitória. Concluímos que isso se deve à probabilidade de convencimento da regra IIa (capítulo 3), que determina a probabilidade de convencimento como sendo inversa ao grau do eleitor que tenta con- 
vencer. Percebemos ainda que, após um curto tempo $t^{*}$ (aproximadamente 20 TMC e 13 TMC para redes com respectivamente $10^{5}$ e $10^{3}$ eleitores) o candidato que dominará o sistema após o transiente já está definido. Criamos uma forma de visualizar os domínios de eleitores associados aos candidatos e acompanhamos outras características topológicas destes domínios (como a superfície e o grau máximo) como meio para inferir, através de simulações, quais seriam as características principais de um domínio, no instante $t^{*}$, que levariam seu candidato à vitória. Acreditamos, após esta análise, que o fator principal é o número de votos em $t^{*}$, pois em apenas $7,3 \%$ das $10^{3}$ simulações o domínio com mais eleitores no instante $t^{*}$ não tornou-se dominante, e, nestes casos, nenhuma outra característica parecia indicar qual seria o candidato vencedor.

Ainda em uma rede BA, estudamos, no capítulo 4, as conseqüências de duas alterações na dinâmica do modelo. No primeiro caso, introduzimos defeitos à rede de eleitores, isto é, fizemos com que os eleitores iniciais de apenas um candidato não alterassem sua opinião durante o processo, constituindo o que se poderia chamar de cabos eleitorais. Comparamos a evolução do modelo em redes com e sem defeitos, através da distância de Hamming, e observamos que, como esperado, para um número crescente de cabos eleitorais, aumenta a fração de resultados finais alterados, i.e., simulações em que as redes com e sem defeitos chegaram à resultados distintos. Notamos uma sensibilidade do sistema à mudança, para um pequeno número de cabos eleitorais introduzidos, $10^{2} \mathrm{em}$ uma rede com $10^{5}$ eleitores, aproximadamente $63 \%$ dos resultados finais foi alterado. Além disso, vimos que, em várias simulações, os sistemas em comparação, sob mesmas condições, com e sem defeitos, passam por configurações completamente diferentes apesar de alcançarem a mesma configuração final, o que corrobora a idéia de que, para tempos muito curtos a configuração final do sistema já se encontra determinada (seção 3.1.4).

A segunda alteração, analisada na seção 4.2, consistiu da inserção de ruído na dinâmica do MSC em rede BA, o que foi feito através de uma probabilidade $w$ de que um eleitor não siga as regras habituais do MSC e escolha um candidato aleatório entre todos os candidatos possíveis. Esta alteração, para baixos valores de $w$, não modifica a configuração estacionária. Após o transiente o sistema converge para uma configuração em que um único candidato detém a grande maioria dos votos. Mas, para grande valores de $w$, as configurações após o transiente são tais que todos os $N_{c}$ candidatos têm aproximadamente o mesmo número de votos $\frac{N}{N_{c}}$. Analisando o processo, constatamos ser esta uma transição de primeira ordem entre os comportamentos, com $0,312<w_{t}<0,315$. A aproximação de campo médio desenvolvida foi capaz de prever corretamente a existência desta transição de fase.

Por fim, comparamos a evolução do MSC em redes distintas, com o foco na forma como o ordenamento do sistema evolui com o tempo. Medimos o ordenamento pela densidade 
de interface média $\langle\rho(t)\rangle$, a fração de arestas que aponta para eleitores com opiniões distintas. Verificamos, na maioria das redes estudada, que a evolução segue um padrão. No início, em redes com $10^{2}$ candidatos e $10^{5}$ eleitores, $\langle\rho(0)\rangle \approx 0,002$ (valor que concorda com nossa estimativa $\left.\langle\rho(0)\rangle=\frac{2 N_{c}}{N}\right)$. Então, $\langle\rho(t)\rangle$ cresce até atingir um valor máximo $\langle\rho\rangle_{\max }$, acreditamos que por conta do crescimento dos domínios e, conseqüentemente, de suas fronteiras (aumentando assim $\langle\rho(t)\rangle$ ). Após ter atingido o máximo de desordem, dois comportamentos distintos foram encontrados. Para baixos graus médios e pouca desordem na rede, as simulações indicam que o sistema se ordena até um determinado ponto, e a densidade de interface se estabiliza em um patamar $\langle\rho\rangle=\rho_{p}$ (encontramos estimativas razoáveis para $\rho_{p}$ no caso de cadeias de graus distintos). No entanto, caso a rede tenha grau médio alto ou apresente desordem, o sistema ordena rapidamente, atingindo uma configuração em que todos eleitores votam em um só candidato. Este comportamento é oposto ao que ocorre tanto no modelo de Glauber a temperatura nula como no modelo do votante, detalhados na seção 5.1. Argumentamos que provavelmente isso se deve ao fato do MSC ser um modelo em que o fluxo de influência flui de um eleitor para seus vizinhos, enquanto nos outros modelos os vizinhos influenciam o eleitor. Consideramos ainda que devem existir valores críticos para desordem e grau médio da rede, dependentes da rede e da força de convencimento do modelo, que controlam a transição entre os comportamentos, ficando o estudo detalhado desses valores para um trabalho futuro. 


\section{Apêndice A}

\section{Leis de potência}

Goldstein, Morris e Yen estudaram em [13] o ajuste de leis de potência à dados numéricos. Gerando uma série de 10000 números aleatórios segundo uma lei de potência $f(x) \propto x^{-\alpha}$, com $\alpha=2,5$, testaram distintos ajustes para resgatar o expoente original. Constataram que os ajustes lineares ao histograma log-log (tanto com intervalos de contagem constantes como com intervalos exponencialmente crescentes) dos dados levam à expoentes incompatíveis com o original. Assim, propuseram um método para estimar $\alpha$, o "Maximum Likelihood Estimation - MLE", que será por nós chamado de Estimação via Máxima Verossimilhança (EMV).

Percebemos, no entanto, que o EMV não é eficiente para dados que apresentam um desvio para eventos extremos $\left(x>x_{c}\right)$ e reformulamos o método para estes casos.

\section{A.1 Estimação via Máxima Verossimilhança}

O EMV estima o expoente $\alpha$ de uma lei de potência baseado na maximização da probabilidade $P\left(\alpha \mid\left\{x_{i}\right\}\right)$ de que $\alpha$ esteja associado a uma série de dados $\left\{x_{i}\right\}$, e leva à seguinte relação ${ }^{1}$ :

$$
\alpha=1+n\left[\sum_{i=1}^{n} \ln \left(\frac{x_{i}}{x_{\text {min }}}\right)\right]^{-1}
$$

Assim como em [13] geramos uma série aleatória que obedece uma lei de potência com $\alpha_{\text {mae }}=1,5$ e $x_{\text {min }}=100$ e utilizamos a expressão A.1 para estimar o expoente $\alpha_{\text {comp }}$ da série completa (figura A.1a) e o expoente $\alpha_{\text {trunc }}$ da mesma série, desconsideradas as ocorrências de $x<x_{c}$ (forçando um desvio para eventos raros - figura A.1b). Os valores obtidos foram $\alpha_{\text {comp }}=1,497(5)$ e $\alpha_{\text {trunc }}=1,523(5)$.

\footnotetext{
${ }^{1}$ Usualmente as séries de dados seguem leis de potência apenas para $x>x_{m i n}$, dado que a função $p(x) \propto x^{-\alpha}$ diverge com $x \rightarrow 0 . x_{\text {min }}$ é, portanto, o valor mínimo para o qual a série obedece a lei de
} 

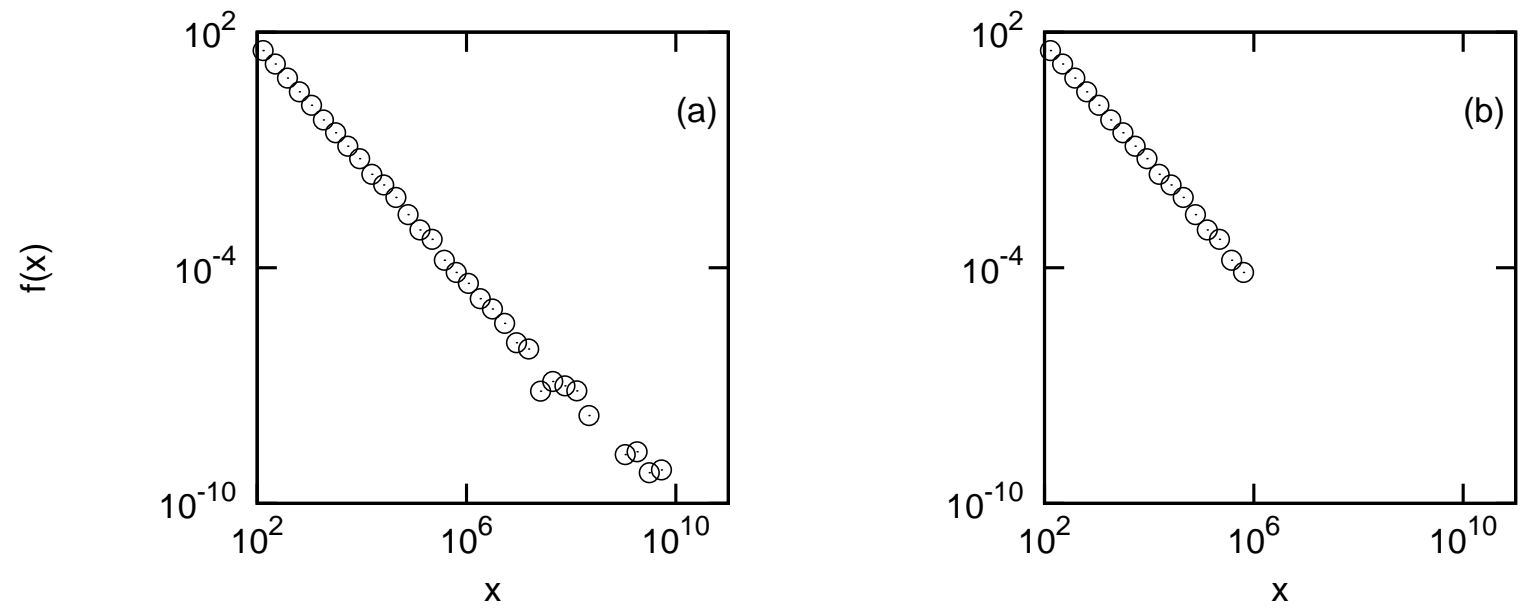

Figura A.1: Histograma de séries aleatórias que obedecem lei de potência com $\alpha=1,5$. (a) Série completa. (b) Série truncada, sendo $x_{c}=10^{6}$ o valor de corte de $x$ superior.

Claramente $\alpha_{c o m p}$ é compatível com $\alpha_{\text {mae }}$. O desacordo entre $\alpha_{\text {trunc }}$ e $\alpha_{\text {mae }}$ deve-se provavelmente à assunção implícita à expressão A.1, de que ambas as séries não têm desvios para eventos extremos. Assim, adaptamos o EMV, de forma muito similar ao desenvolvimento em [12], de forma a levar em conta este tipo de problema.

Supondo uma distribuição de probabilidades $f\left(x_{i}\right)$ tal que

$$
f\left(x_{i}\right)=\left\{\begin{array}{cc}
0 & x_{i}<x_{\text {min }} \\
C x_{i}^{-\alpha} & x_{\min }<x_{i}<x_{c} \\
0 & x_{i}>x_{c}
\end{array}\right.
$$

a normalização implica

$$
1=\int_{x_{\text {min }}}^{x_{c}} C x^{-\alpha} d x=C\left[\frac{x^{-(\alpha-1)}}{1-\alpha}\right]_{x_{\min }}^{x_{c}} \Rightarrow C=\frac{1-\alpha}{x_{c}^{(1-\alpha)}-x_{\min }^{(1-\alpha)}}
$$

Seja $L\left(\left\{x_{i}\right\} \mid \alpha\right)$ a probabilidade de que, dado $\alpha$, um conjunto $\left\{x_{i}\right\}$ de $n$ dados pertença à $f\left(x_{i}\right)$. Assumindo independência entre os $n$ elementos, podemos perceber que $L\left(\left\{x_{i}\right\} \mid\right.$ $\alpha$ ) é o produto entre as probabilidades de que cada $x_{i}$ pertença à $f\left(x_{i}\right)$, isto é,

$$
L\left(\left\{x_{i}\right\} \mid \alpha\right)=\prod_{i=1}^{n} p\left(x_{i}\right)=\prod_{i=1}^{n} \frac{(1-\alpha) x_{i}^{-\alpha}}{x_{c}^{(1-\alpha)}-x_{m i n}^{(1-\alpha)}}
$$

O $\alpha$ que procuramos pode ser entendido como o valor que maximiza $L\left(\alpha \mid\left\{x_{i}\right\}\right.$ ) (a probabilidade de $\alpha$ estar associado ao conjunto de dados $\left.\left\{x_{i}\right\}\right)$, i. e., $\alpha$ é o valor que potência. 
satisfaz $\frac{d}{d \alpha}\left\{\ln \left[L\left(\alpha \mid\left\{x_{i}\right\}\right)\right]\right\}=0$. Pela lei de Bayes temos:

$$
L\left(\alpha \mid\left\{x_{i}\right\}\right) \sim L\left(\left\{x_{i}\right\} \mid \alpha\right) \Rightarrow \frac{d}{d \alpha}\left\{\ln \left[L\left(\alpha \mid\left\{x_{i}\right\}\right)\right]\right\}=\frac{d}{d \alpha}\left\{\ln \left[L\left(\left\{x_{i}\right\} \mid \alpha\right)\right]\right\}
$$

e assim,

$$
\begin{aligned}
0 & =\frac{d}{d \alpha}\left\{\ln \left[L\left(\alpha \mid\left\{x_{i}\right\}\right)\right]\right\}= \\
& =\frac{d}{d \alpha}\left\{\ln \left[L\left(\left\{x_{i}\right\} \mid \alpha\right)\right]\right\} \\
& =\frac{d}{d \alpha}\left\{\ln \left[\prod_{i=1}^{n} \frac{(1-\alpha) x_{i}^{-\alpha}}{x_{c}^{(1-\alpha)}-x_{\text {min }}^{(1-\alpha)}}\right]\right\} \\
& =\frac{d}{d \alpha}\left\{\sum _ { i = 1 } ^ { n } \operatorname { l n } \left[\frac{(1-\alpha) x_{i}^{-\alpha}}{\left.\left.x_{c}^{(1-\alpha)}-x_{\min }^{(1-\alpha)}\right]\right\}}\right.\right. \\
& =\frac{d}{d \alpha}\left\{-\alpha \sum_{i=1}^{n} \ln \left[x_{i}\right]+n \ln \left[\frac{(1-\alpha)}{x_{c}^{(1-\alpha)}-x_{\min }^{(1-\alpha)}}\right]\right\} \\
& =-\sum_{i=1}^{n} \ln \left[x_{i}\right]+n \frac{d}{d \alpha}\left\{\ln \left[\frac{(1-\alpha)}{x_{c}^{(1-\alpha)}-x_{\min }^{(1-\alpha)}}\right]\right\} \\
& =-\sum_{i=1}^{n} \ln \left[x_{i}\right]-n\left\{\frac{1}{1-\alpha}+\left[\frac{\ln \left(x_{\min }\right) x_{\min }^{(1-\alpha)}-\ln \left(x_{c}\right) x_{c}^{(1-\alpha)}}{x_{c}^{(1-\alpha)}-x_{\min }^{(1-\alpha)}}\right]\right\}
\end{aligned}
$$

e então,

$$
\frac{\sum_{i=1}^{n} \ln \left[x_{i}\right]}{n}+\frac{1}{1-\alpha}+\left[\frac{\ln \left(x_{\min }\right) x_{\min }^{(1-\alpha)}-\ln \left(x_{c}\right) x_{c}^{(1-\alpha)}}{x_{c}^{(1-\alpha)}-x_{\text {min }}^{(1-\alpha)}}\right]=0
$$

Pode-se mostrar que no limite $x_{c} \rightarrow \infty$ a expressão A.2 se reduz à A.1. Com isso, dado uma série de dados é possível, pela equação A.2, encontrar $\alpha$ (na verdade a expressão deve ser resolvida numericamente, o que torna o procedimento mais difícil com relação à utilização de A.1). Utilizando o método generalizado para calcular $\alpha_{\text {trun }}$ mencionado anteriormente obtivemos $\alpha_{\text {trun }}=1.498(6)$, compatível com $\alpha_{m a e}$.

\section{A.2 Distribuição Cumulativa}

Outra ferramenta útil para o tratamento de séries de dados que seguem leis de potência é função de distribuição cumulativa.

Dada uma determinada distribuição $f(x)$, a distribuição cumulativa $F(x)$ é definida como 


$$
F(x)=\int_{x}^{\infty} f\left(x^{\prime}\right) d x^{\prime}
$$

Uma das principais utilidade da função de distribuição cumulativa está associada ao desenho da curva de distribuição $f(x)$. Geralmente, dados empíricos associados à ocorrência de determinada distribuição de probabilidade são representados por histogramas, através de um processo que, devido a existência de intervalos de contagem, acarreta na diminuição da informação inicial. No entanto, o gráfico da distribuição cumulativa possibilita a compreensão do fenômeno sem nenhuma perda de informação, e, além disso, seu desenho é extremamente simples ${ }^{2}$.

Considerando uma lei de potências $\left(f(x)=C x^{-\alpha}\right)$ temos que a distribuição cumulativa também obedece a lei de potência:

$$
F(x)=\int_{x}^{\infty} f\left(x^{\prime}\right) d x^{\prime}=\int_{x}^{\infty} C x^{-\alpha} d x^{\prime}=C\left[\frac{x^{\prime(1-\alpha)}}{1-\alpha}\right]_{x}^{\infty}
$$

e, como $\alpha>1$,

$$
C\left[\frac{x^{(1-\alpha)}}{1-\alpha}\right]_{x}^{\infty}=\frac{C}{\alpha-1} x^{-(\alpha-1)}
$$

ou seja, uma lei de potência com coeficiente $\alpha-1$, descrevendo uma linha reta num gráfico log-log. Nossa atenção, como anteriormente, se volta às distribuições com desvios para eventos raros. Neste sentido, é importante notar que, sendo $F(x)$ definida como uma integral de $x$ a $\infty$, um eventual desvio da distribuição $f(x)$ em relação à lei de potência em um intervalo inferior a um $x_{\min }$ não modificará a lei de potência apresentada na distribuição cumulativa para $x>x_{\text {min }}$. Mas, uma distribuição como uma lei de potência com um desvio para $x>x_{c}$ modifica, como mostraremos, o aspecto da distribuição cumulativa. Supondo $f(x)=\left\{\begin{array}{ccc}C^{\prime} x^{-\alpha} & \text { para } & x<x_{c} \\ 0 & \text { para } & x>x_{c}\end{array}\right.$ a distribuição cumulativa fica:

$$
\begin{gathered}
F(x)=\int_{x}^{\infty} f\left(x^{\prime}\right) d x^{\prime}= \\
=\left\{\begin{array}{crl}
\int_{x}^{x_{c}} C^{\prime} x^{-\alpha} d x^{\prime}=C^{\prime}\left[\frac{x^{\prime(1-\alpha)}}{1-\alpha}\right]_{x}^{x_{c}}=\frac{C^{\prime}}{\alpha-1} x^{-(\alpha-1)}+K & \text { para } & x<x_{c} \\
0 & \text { para } & x>x_{c}
\end{array}\right.
\end{gathered}
$$

\footnotetext{
${ }^{2} \mathrm{O}$ gráfico pode ser feito ordenando os dados de maneira decrescente e associando a cada dado o seu índice.
} 
onde $K=\frac{C^{\prime}}{1-\alpha} x_{c}^{-(\alpha-1)}$. Temos então que, num gráfico log-log, diferentemente do caso de uma distribuição cumulativa relativa à uma lei de potência sem desvios, que se apresenta como uma reta $\left(\log (F(x))=-(\alpha-1) \cdot \log (x)+\log \left(\frac{C}{\alpha-1}\right)\right)$, no caso da distribuição cumulativa com "cut off" superior temos:

$$
\log (F(x))=\log \left(x^{-(\alpha-1)}-x_{c}^{-(\alpha-1)}\right)+\log \left(\frac{C^{\prime}}{\alpha-1}\right)
$$

que se aproxima de uma reta com inclinação $-(\alpha-1)$, apenas para $x \ll x_{c}$.

Podemos verificar estes resultados através da construção do gráfico da distribuição cumulativa das séries estudadas na seção A.1 (ver figura A.1). Estes gráficos, tanto para a série truncada como para a série completa são apresentados na figura A.2.
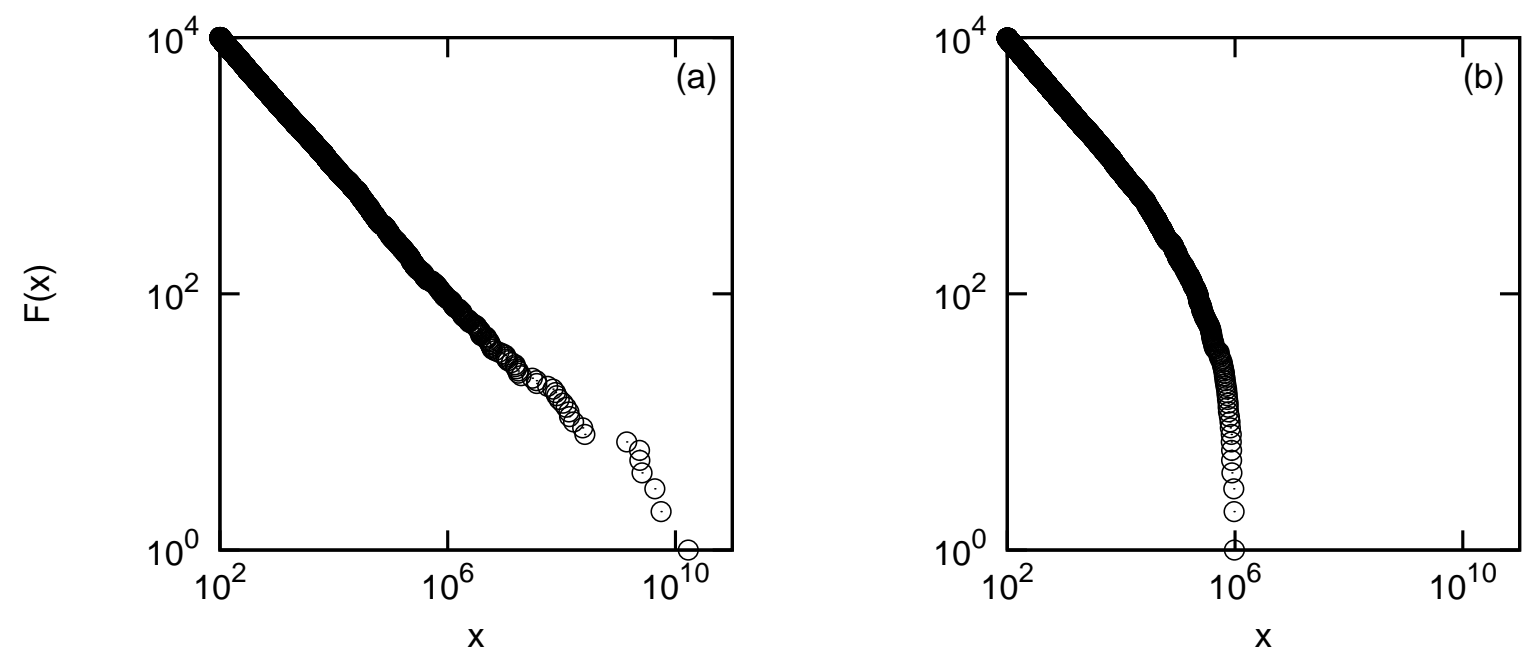

Figura A.2: Gráfico log-log das distribuições cumulativas das séries completa e truncada.

Percebe-se claramente o desvio, com relação à reta esperada, que o truncamento causa. 


\section{Referências Bibliográficas}

[1] BERNARDES, A. T.; STAUFFER, D.; KERTÉSZ, J. Election results and the sznajd model on barabasi network. Eur. Phys. J. B, v. 25, p. 123-127, 2002.

[2] NEWMAN, M. E. J. The structure and function of complex networks. SIAM Review, v. 45, p. $167-256,2003$.

[3] BOCCALETTI, S. et al. Complex networks: Structure and dynamics. Phys. Reports, v. 424, p. 175-308, 2006.

[4] WATTS, D. J.; STROGATZ, S. H. Collective dynamics of 'small-world' networks. Nature, v. 393, p. 440-442, 1998.

[5] BARABÁSI, A. L.; ALBERT, R. Emergence of scaling in random networks. Science, v. 286, p. 509-512, 1999.

[6] FEOFILOFF, P.; KOHAYAKAWA, Y.; WAKABAYASHI, Y. Uma Introdução Sucinta à Teoria dos Grafos. São Paulo: [s.n.], 2005.

[7] BOLLOBÁS, B. Random Graphs. London: Academic, 1985.

[8] ALBERT, R.; BARABÁSI, A. Statistical mechanics of complex networks. Rev. Mod. Phys., v. 74, p. 47-97, 2002.

[9] COSTA-FILHO, R. N. et al. Scaling behavior in a proporcional voting process. Phys. Rev. E, v. 60, p. 1067-1068, 1999.

[10] GONZÁLES, M. C.; SOUZA, A. O.; HERRMANN, H. J. Opinion formation on a deterministic pseudo-fractal network. Int. J. Mod. Phys., v. 15, p. 45-57, 2003.

[11] TRE-SP. Disponível em: <http://www.tre-sp.gov.br/>. Acesso em: out. 2004.: [s.n.].

[12] NEWMAN, M. E. J. Power laws, pareto distributions and zipf's law. cond-mat, p. 04122004, Dezembro 2004. 
[13] GOLdstein, M. L.; MORRIS, S. A.; YEN, G. G. Problems with fitting to the power-law distribution. Eur. Phys. J. B, v. 41, p. 255-258, 2004.

[14] EFRON, B. Computer and the theory of statistics: thinking the unthinkable. SIAM Review, v. 21, p. 460-480, 1979.

[15] SALINAS, S. R. A. Introdução à Mecânica Estatística. São Paulo: Edusp, 1997.

[16] TOMÉ, T.; OLIVEIRA, M. J. Dinâmica Estocástica e Irreversibilidade. São Paulo: Edusp, 2001.

[17] SZNAJD-WERON, K.; SZNAJD, J. Opinion evolution in closed community. Int. J. Mod. Phys., v. 11, p. 1157-1165, 2000.

[18] STAUFFER, D.; SOUSA, A. O.; OLIVEIRA, S. M. de. Generalization to square lattice of sznajd sociophysics model. Int. J. Mod. Phys., v. 11, p. 1239-1245, 2000.

[19] BERNARDES, A. T. et al. Damage spreading, coarsening dynamics and distribution of political votes in sznajd model on square lattice. Int. J. Mod. Phys., v. 12, p. 159-167, 2001.

[20] SZNAJD-WERON, K. Sznajd model and its applications. Acta Phys. Pol. B, v. 36, p. $2537-2547,2005$.

[21] MARRO, J.; DICKMANN, R. Nonequilibrium Phase Transitions on lattice models. Cambridge: Cambridge University Press, 1995.

[22] NORTH, S. C. Drawing graphs with NEATO. http://www.graphviz.org/Documentation/neatoguide, 2002.

[23] MOBILIA, M. Does a single zealot affect an infinite group of voters? Phys. Rev. Lett., v. 91(2), p. 028701(4), 2003.

[24] MOBILIA, M.; GEORGIEV, I. T. Voting and catalytic processes with inhomogeneities. Phys. Rev. E, v. 71, p. 046102(17), 2005.

[25] SPIRIN, V.; KRAPIVSKY, P. L.; REDNER, S. Fate of zero-temperature ising ferromagnets. Phys. Rev. E, v. 63, p. 036118(4), 2001.

[26] BOYER, D.; MIRAMONTES, O. Interface motion and pinnig in small-world networks. Phys. Rev. E, v. 67, p. 035102(4), 2003.

[27] CASTELlanO, C. et al. Comparision of voter and glauber ordering dynamics on networks. Phys. Rev. E, v. 71, p. 066107(8), 2005. 
[28] DORNIC, I. et al. Critical coarsening without surface tension: The universality class of the voter model. Phys. Rev. Lett., v. 87, p. 045701(4), 2001.

[29] SUCHECKI, K.; EGUÍLUZ, V. M.; MIGUEL, M. S. Voter model dynamics in complex networks: Role of dimensionality, disorder and degree distribution. Phys. Rev. E, v. 72 , p. 036132(8), 2005.

[30] CASTEllanO, C.; VIlONE, D.; VESPignani, A. Incomplete ordering of the voter model on small-world networks. Europhys. Lett., v. 63, p. 153-158, 2003. 